
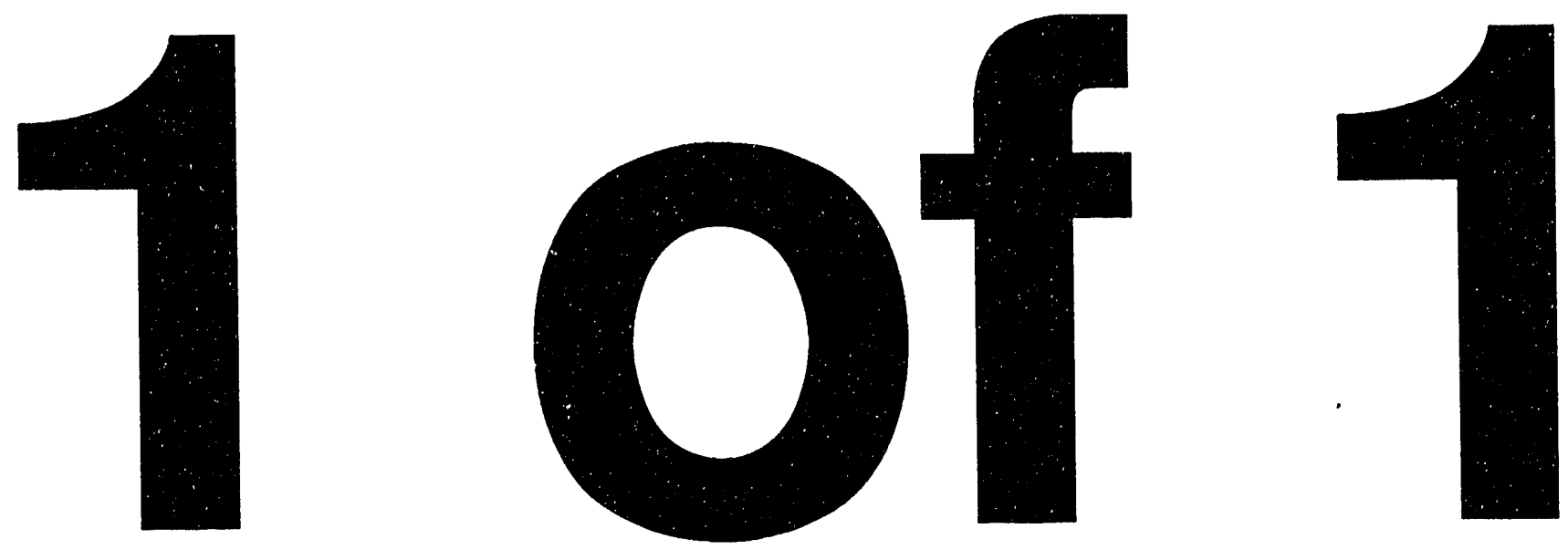


\title{
AN IMPROVEMENT IN THE VALUE OF THE ENERGY OF THE FIRST EXCITED STATE IN ${ }^{229} \mathrm{TH}$
}

\author{
R. G. Helmer and C. W. Reich
}

Published April 1993

\section{IDAHO NATIONAL ENGINEERING LABORATORY \\ EG\&G IDAHO, INC. \\ IDAHO FALLS, IDAHO 83415}




\section{ABSTRACT}

It has been known for many years that the first excited state of ${ }^{229}$ Th 1 ies close to the ground state. Originally this energy was given as $<0.1 \mathrm{keV}$; later, the authors reported a value of $-1 \pm 4 \mathrm{eV}$. Since the existence of a nuclear state at this very low energy is of considerable interest, measurements of its energy, half-life and modes of excitation and deexcitation are important. In an attempt to improve the level energy, we have measured over $175 \gamma$-ray spectra with several combinations of radionuclides. In comparison with our earlier study, we have considered more $\gamma$ rays in ${ }^{229} \mathrm{Th}$, used more well-measured reference 1 ines, used more detectors, used detectors with better low-energy resolution, more closely matched peak count rates, and specifically considered certain systematic errors. From this large set of measurements we have deduced a value of $3.5 \pm 1.0$ $\mathrm{eV}$ for the energy of this level. 


\section{ACKNOWLEDGEMENTS}

The authors wish to acknowledge the assistance of the staff of the Radiation Measurements Laboratory for the use of a counting room and for assistance in optimizing the electronics. They also wish to thank E. W. Killian for modifications of the GINA spectral analysis program, $J$. D. Baker for preparing most of the sources used, $K$. D. Watts for assisting with the measurements, and R. C. Greenwood for comments on the manuscript. 


\section{CONTENTS}

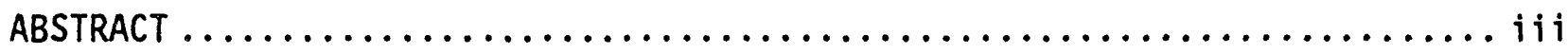

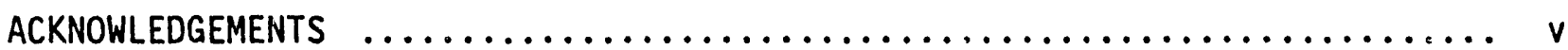

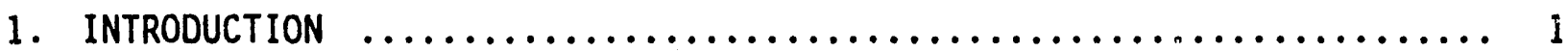

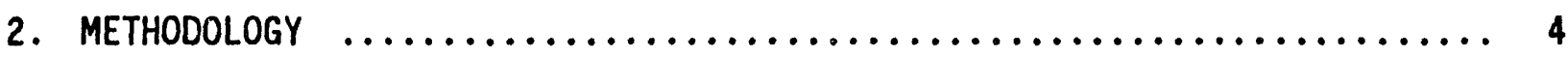

2.1 Energy Scale and Uncertainties $\ldots \ldots \ldots \ldots \ldots \ldots \ldots \ldots \ldots, 4$

2.2 Calibration Sources $\ldots \ldots \ldots \ldots \ldots \ldots \ldots \ldots \ldots \ldots \ldots \ldots \ldots, 4$

2.3 Measurement and Analysis Methods $\ldots \ldots \ldots \ldots \ldots \ldots \ldots \ldots \ldots, 5$

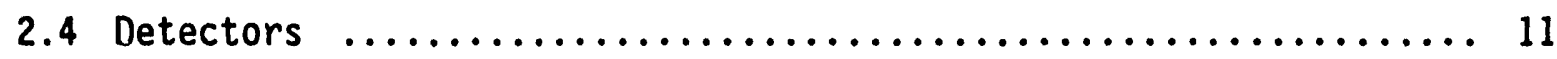

3. MEASUREMENT RESULTS AND $\gamma$-RAY ENERGIES WITHOUT ${ }^{233} \mathrm{U} \ldots \ldots \ldots \ldots \ldots, 12$

3.1 Measurement Results for ${ }^{169} \mathrm{~Tb},{ }^{172} \mathrm{Hf}_{+}{ }^{172} \mathrm{Lu}$, and ${ }^{249} \mathrm{Am} \ldots \ldots \ldots . .12$

$3.2 \gamma$-Ray Energies for ${ }^{161} \mathrm{~Tb},{ }^{172} \mathrm{Hf}_{+}{ }^{172} \mathrm{Lu}$, and ${ }^{241} \mathrm{Am} \ldots \ldots \ldots \ldots \ldots . \ldots \ldots$

4. MEASUREMENT RESULTS AND $\gamma$-RAY ENERGIES FOR ${ }^{233} \mathrm{U} \ldots \ldots \ldots \ldots \ldots \ldots . \ldots 17$

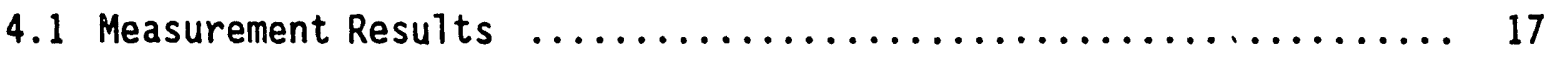

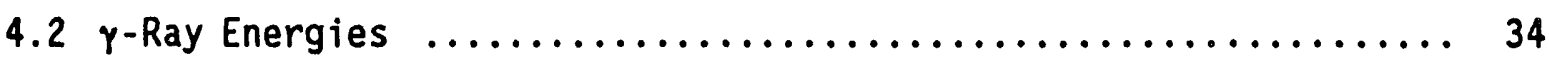

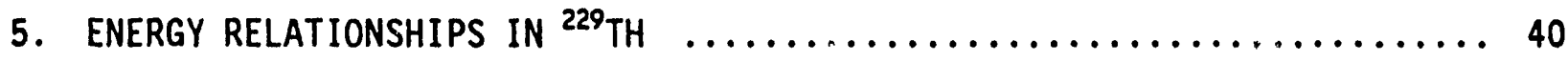

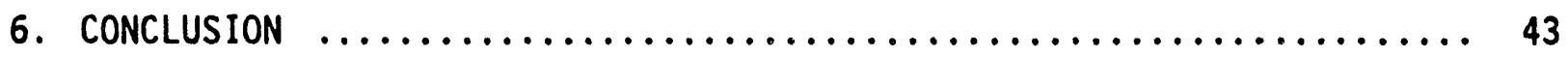

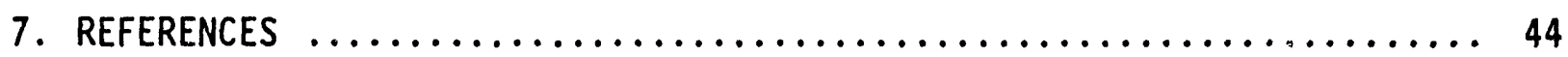

FIGURES

1. A portion of the low-energy level scheme of ${ }^{229} \mathrm{Th}$ showing the $\gamma$ rays that are used in this determination of the energy, $\Delta$, of the first excited level

2. Portion of a ${ }^{161} \mathrm{~Tb}$ and ${ }^{241} \mathrm{Am}$ spectrum from the $\mathrm{OR}-16$

detector showing the $\gamma$-ray lines at 25.65 and $26.34 \mathrm{keV}$.

The solid curves show spectral background used in the

fit to the $26.34 \mathrm{keV}$ peak and the Gaussian plus

background from the fit 


\section{CONTENTS (CONTINUED)}

3. Portion of the ${ }^{233} \mathrm{U}$ and ${ }^{172} \mathrm{Hf}+{ }^{172} \mathrm{Lu} \gamma$-ray spectrum measured with the $\mathrm{Si}(\mathrm{Li})$ detector showing the $\gamma$ rays at $23.93,25.31$,

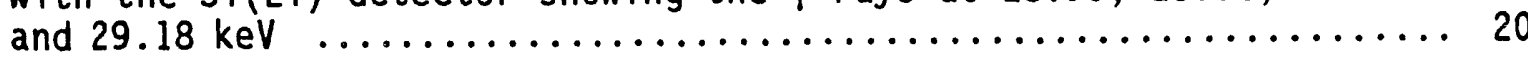

4. Portion of the ${ }^{233} U$ and ${ }^{241} A m \gamma$-ray spectrum measured with the $0 R-16$ detector showing the $\gamma$ rays at $25.31,26.34$, and $29.18 \mathrm{keV}$

5. Portion of the ${ }^{233} \mathrm{U}$ and ${ }^{161} \mathrm{~Tb}$-ray spectrum measured with the $\mathrm{Si}(\mathrm{Li})$ detector showing the $\gamma$ rays at $48.91,53.61$, and

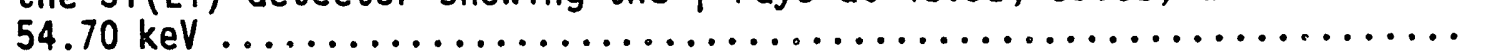

6. Portion of the ${ }^{233} U \gamma$-ray spectrum measured with the $0 R-16$ detector showing the $\gamma$ rays at 67.94 and $71.81 \mathrm{keV} \ldots \ldots \ldots \ldots \ldots 23$

7. Portion of the ${ }^{233} \mathrm{U}$ and ${ }^{161} \mathrm{~Tb} \gamma$-ray spectrum measured with from the $\mathrm{Si}(\mathrm{Li})$ detector showing the $\gamma$ rays at 71.81 and $74.56 \mathrm{keV}$

8. Portion of the ${ }^{233} \mathrm{U}$ and ${ }^{182} \mathrm{Ta} \gamma$-ray spectrum measured with from the OR-16 detector showing the $\gamma$ rays at 97.13 and $100.10 \mathrm{keV}$

9. Portion of the ${ }^{233} U \gamma$-ray spectrum measured with the $O R-16$ detector showing the $\gamma$-rays at 117.16 and $118.97 \mathrm{keV}$

10. Portion of the ${ }^{233} \mathrm{U}$ and ${ }^{169} \mathrm{Yb} \gamma$-ray spectrum measured with the $P G-16$ detector showing the $\gamma$ rays at 130.52 and $135.33 \mathrm{keV}$

11. Portion of the ${ }^{233} U \gamma$-ray spectrum measured with the $O R-16$ detector showing the $\gamma$ rays at 146.34 and $148.15 \mathrm{keV}$

12. Portion of the ${ }^{233} \mathrm{U}$ and ${ }^{169} \mathrm{Yb} \gamma$-ray spectrum measured with the PG-16 detector showing the $\gamma$ rays at $177.21,187.96$,

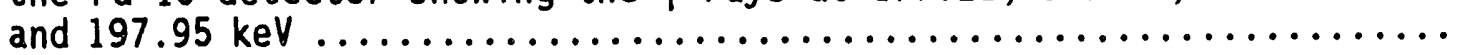

13. Portion of the ${ }^{233} \mathrm{U}$ and ${ }^{182} \mathrm{Ta} \gamma$-ray spectrum measured with the $O R-12$ detector showing the $\gamma$ rays at 217.15 and $222.10 \mathrm{keV}$, as well as the fit of a doublet to the former peak $\ldots \ldots \ldots \ldots \ldots \ldots$

14. Portion of the ${ }^{233} U$ and ${ }^{182} \mathrm{Ta} \gamma$-ray spectrum measured with the $0 R-12$ detector showing the $\gamma$ rays at 264.02 and $274.73 \mathrm{keV}$

15. Gaussian fits to peaks at $59 \mathrm{keV}$, a singlet from ${ }^{241} \mathrm{Am}$, and $42 \mathrm{keV}$, a doublet from ${ }^{233} \mathrm{U}$... 


\section{CONTENTS (CONTINUED)}

\section{TABLES}

1. Energies of reference and calibration lines $\ldots \ldots \ldots \ldots \ldots \ldots \ldots$

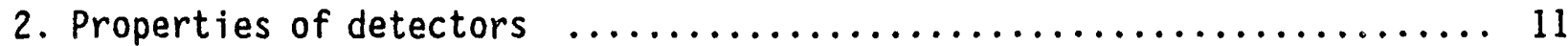

3. Measured spectra that do not include ${ }^{233} \mathrm{U} \ldots \ldots \ldots \ldots \ldots \ldots \ldots \ldots$

4. Measured $\gamma$-ray energy differences between lines of ${ }^{172} \mathrm{Hf}+{ }^{172} \mathrm{Lu}$ and ${ }^{241} \mathrm{Am}$ and $\mathrm{lines}$ of ${ }^{161} \mathrm{~Tb}$ and ${ }^{241} \mathrm{Am} \ldots \ldots \ldots \ldots \ldots$

5. Measured $\gamma$-ray energy differences between lines of ${ }^{161} \mathrm{~Tb}$ and ${ }^{172} \mathrm{Hf}$ and two 1 ines ${ }^{18 \mathrm{~Tb}} \ldots \ldots \ldots \ldots \ldots \ldots \ldots \ldots \ldots \ldots \ldots \ldots \ldots . \ldots \ldots$

6. Measured $\gamma$-ray energy differences for two lines from ${ }^{172} \mathrm{Hf}+{ }^{172} \mathrm{Lu} \quad \ldots \ldots 50$

7. Energies deduced for $\gamma$ rays from ${ }^{161} \mathrm{~Tb},{ }^{172} \mathrm{Hf}+{ }^{172} \mathrm{Lu}$, and ${ }^{241} \mathrm{Am} \ldots \ldots . .14$

8. Comparison of our results with those previously published in the evaluations of the Table of Radioactive Isotopes (TRI)

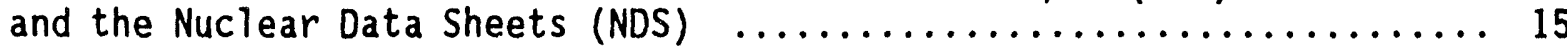

9. Spectra measured that include ${ }^{233} U \ldots \ldots \ldots \ldots \ldots \ldots \ldots \ldots \ldots \ldots$

10. Measured $\gamma$-ray energy differences for ${ }^{241} \mathrm{Am}$ reference lines of

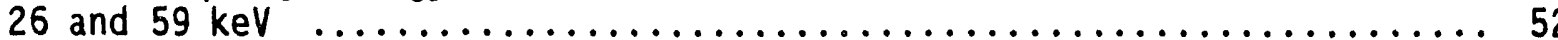

11. Measured $\gamma$-ray energy difference from the ${ }^{152} \mathrm{Eu}$ reference line of

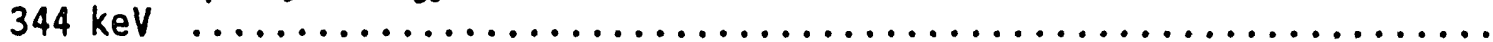

12. Measured $\gamma$-ray energy differences from the ${ }^{210} \mathrm{~Pb}$ reference line of $46 \mathrm{keV}$

13. Measured $\gamma$-ray energy differences from the ${ }^{170} \mathrm{Tm}$ reference line of $84 \mathrm{keV}$

14. Measured $\gamma$-ray energy differences from the ${ }^{161} \mathrm{~Tb}$ reference

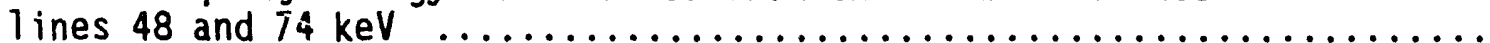

15. Measured $\gamma$-ray energy differences from the ${ }^{172} \mathrm{Hf}$ reference lines of 23 and $78 \mathrm{keV}$

16. Measured $\gamma$-ray energy differences from the ${ }^{182} \mathrm{Ta}$ reference

17. Measured $y$-ray energy differences ffrom the ${ }^{169} \mathrm{Yb}$ reference lines of 63 to $307 \mathrm{keV}$ 


\section{CONTENTS (CONTINUED)}

18. Measured $\gamma$-ray energy differences between lines from

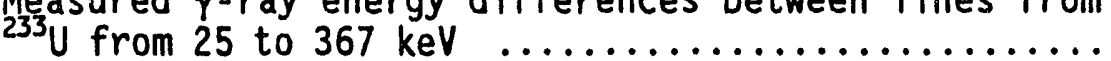

19. Shifts in calculated peak positions as fitting range is increased

20. $\gamma$-ray energies for ${ }^{233} \mathrm{U}$ lines 36

21. Difference between crossover and cascade energies

22. Energy of ${ }^{229}$ Th first excited level, $\Delta$ 43 


\section{AN IMPROVEMENT IN THE VALUE OF THE ENERGY OF THE FIRST EXCITED STATE IN ${ }^{229}$ TH}

\section{INTRODUCTION}

In $\gamma$-ray studies of the level structure of ${ }^{229} \mathrm{Th}$ from the a decay of ${ }^{233} \mathrm{U}$, Kroger and Reich concluded that the first excited state, with $\mathrm{J}^{\pi}=3 / 2^{+}$, in ${ }^{229} \mathrm{Th}$ occurs within $0.1 \mathrm{keV}$ of the $5 / 2^{+}$ground state. More recently, Reich and Helmer ${ }^{2}$ reported measurements of $\gamma$-ray energy differences from which they deduced that this level energy is $-1 \pm 4 \mathrm{eV}$. Since it is presumed ${ }^{2}$ that the $3 / 2^{+}$state 1 ies above the $5 / 2^{+}$state, this result also may be stated as indicating that this first excited level lies below $7 \mathrm{eV}$ (at the 20 level). The relationships of the $\gamma$ rays involved in these measurements are shown in Figure 1. The energy, $\Delta$, of the first excited level is given by each of the four combinations

$$
\begin{aligned}
& \Delta=97-25-71, \\
& \Delta=97-67-29 \\
& \Delta=148-118+117-146, \text { and } \\
& \Delta=148-76+74-146 .
\end{aligned}
$$

Also of interest are two cascade-crossover combinations

$$
\begin{aligned}
& 217=187+29 \text { and } \\
& 164=135+29 .
\end{aligned}
$$

The existence of an excited nuclear state at such a low energy has stimulated considerable interest; see, for example, References 3-8. The basic reason for this interest is that this nuclide may offer the chance to explore new methods of exciting nuclear states. For example, one might be able to excite the electron cloud from an external source (e.g., a laser or a particle) and then have the energy transferred to the nucleus. Such experiments would be of considerable interest in atomic and molecular, as well as nuclear, physics. Since this type of excitation is one of the steps in a basic conceptual design of a $\gamma$-ray laser, such measurements would be of interest in that field also.

Because of the interest in this particular level, we undertook a series of measurements to determine more precise energies for some of the $\gamma$ rays from the decay of ${ }^{233} \mathrm{U}$ in order to reduce the uncertainty in the deduced level energy. These measurements differ from the previous ones ${ }^{2}$ in the following ways: 


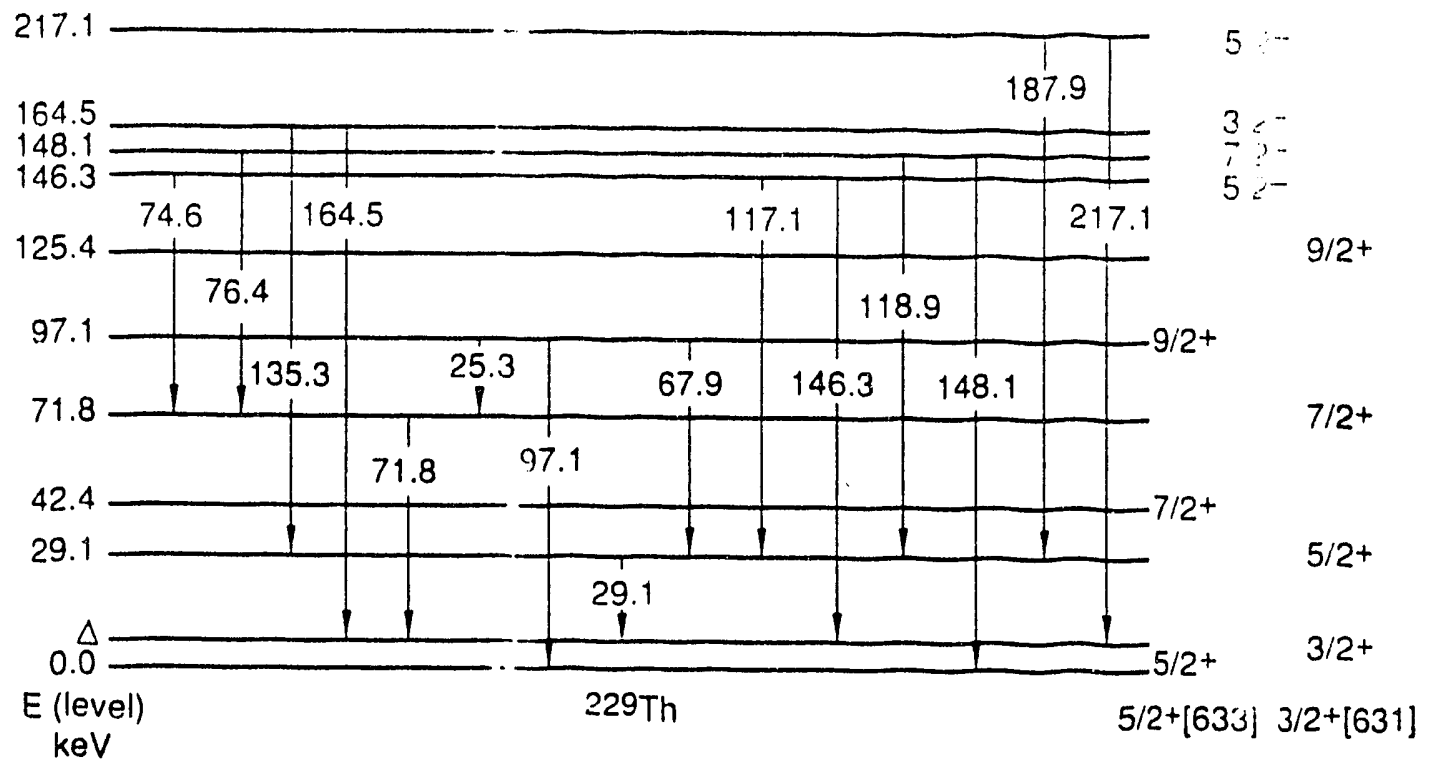

2920840

Figure 1. A portion of the low-energy level scheme of ${ }^{229} \mathrm{Th}$ showing the $\gamma$ rays that are used in this determination of the energy, $\Delta$, of the first excited level.

- more $\gamma$ rays in ${ }^{229} \mathrm{Th}$ were considered;

- measurements were made on more detectors, 5 rather than 1;

- more reference lines were used for calibration;

- more measurements were made for each energy difference;

- detectors with better energy resolution were used, especially at the lowest energies;

- the activities of the calibration and ${ }^{233} \mathrm{U}$ sources were carefully matched, so they could be mounted adjacent to each other and thereby reduce the systematic errors due to peak shifts with source position ; and

- the peak fitting was done on an interactive system. 
In this report, we describe the methods used (sect. 2); the measurement of the energies for some $\gamma$ rays from ${ }^{161} \mathrm{~Tb},{ }^{172} \mathrm{Hf}+{ }^{172} \mathrm{Lu}$, and ${ }^{241} \mathrm{Am}$ (sect. 3); the measurement of the energies for some $\gamma$ rays from ${ }^{233} U$ (sect. 4); and the application of these results to the level energy in ${ }^{229} \mathrm{Th}$ (sect. 5); and the conclusion (sect. 6). For completeness, and for possible future use, all of the energy differences obtained in this study are reported even though many of them are not applicable to the ${ }^{229}$ Th level-energy determination. 


\section{METHODOLOGY}

\subsection{Energy Scale and Uncertainties}

In this report all of the $\gamma$-ray energies are on the scale used for the IUPAP-recommended list of energies ${ }^{10}$. On this scale the primary $\gamma$ ray from the decay of ${ }^{198} \mathrm{Au}$ is 411.8044 (11) $\mathrm{keV}$. The energy of this 1 ine has been determined from very precise measurements of its wavelengt ${ }^{11}$.

There are two uncertainties that apply to this energy value. The first is the combination of all the measurement uncertainties that apply to its wavelength; this uncertainty is $0.37 \mathrm{ppm}$, or $0.16 \mathrm{eV}$. The second uncertainty is that from the conversion of the $\gamma$-ray wavelength to the electron-Volt scale; this is $2.6 \mathrm{ppm}$. The total uncertainty is obtained by combining these two contributions in quadrature. If one were to adjust the electron-Volt energy scale to correspond to the most recent values of this wavelength and the fundamental constants, the energy of this $411-\mathrm{keV}$ line would be reduced by $5.8 \mathrm{ppm}$. Most of the other calibration lines used here would consequently be reduced by a similar amount. This small change would not influence our final result and, therefore, this correction has not been made.

For the analysis in this report, we need consider only the measurement uncertainties for the calibration lines used. That is, we can do all the calculations on what is effectively the wavelength scale. In this way, the measurements relative to different reference lines are properly weighted. In principle, the uncertainty in the conversion between the wavelength and electron-Volt scales is added back in for the final result. But, since the measurement uncertainty in our final result is of the order of $15 \%$, this uncertainty is not significant.

\subsection{Calibration Sources}

In the search for radionuclides that provide $\gamma$-ray $l$ ines that would be useful as reference lines, there were two criteria. First, the $\gamma$-ray energies should be very well known. Ideally, this means that the uncertainty in the energy is $<1 \mathrm{eV}$ and that its measurement was made in the last 15 years or so. Second, the reference lines should be near to, but resolved from, each of the $\gamma$ rays from ${ }^{233} U$ of interest.

The energy-calibration sources used were ${ }^{172} \mathrm{Hf}+{ }^{172} \mathrm{Lu},{ }^{161} \mathrm{~Tb},{ }^{241} \mathrm{Am},{ }^{182} \mathrm{Ta}$, ${ }^{169} \mathrm{Yb},{ }^{152} \mathrm{Eu},{ }^{210} \mathrm{~Pb}$, and ${ }^{170} \mathrm{Tm}$. The energies of the $\gamma$ rays used are given in Table 1. Among these lines, those for ${ }^{172} \mathrm{Hf}_{+}{ }^{172} \mathrm{Lu}$ and ${ }^{241} \mathrm{Am}$ were measured ${ }^{12}$ specifically for this study. The ${ }^{241} \mathrm{Am}$ lines were remeasured because the 
previous values did not meet the above criteria: these values ${ }^{17.18}$ had uncertainties of $1 \mathrm{eV}$; and the measurements are old (i.e., 1968 and 1970). The values for ${ }^{172} \mathrm{Hf}(1.87 \mathrm{y})+{ }^{172}$ Lu were measured to allow the use of the 23.9Hf line as an intermediate reference line between the $25.6 \mathrm{~Tb}$ line and the 25.3U line. (The notation $25 \mathrm{~Tb}$ means the $25 \mathrm{-keV}$ line from the decay of ${ }^{161} \mathrm{~Tb}$. The notation for the radionuclides is: ${ }^{152} \mathrm{Eu}, \mathrm{Eu} ;{ }^{161} \mathrm{~Tb}, \mathrm{~Tb}:{ }^{169} \mathrm{Yb}, \mathrm{Yb} ;{ }^{170} \mathrm{Tm}$, $\mathrm{Tm} ;{ }^{172} \mathrm{Hf}+{ }^{172} \mathrm{Lu}, \mathrm{Hf} ;{ }^{182} \mathrm{Ta}, \mathrm{Ta} ;{ }^{210} \mathrm{~Pb}, \mathrm{~Pb},{ }^{233} \mathrm{U}, \mathrm{U}$; and ${ }^{249} \mathrm{Am}, \mathrm{Am}$.) The only remaining line that does not meet the above criteria is that for ${ }^{210} \mathrm{~Pb}$, which is from Helmer et al.$^{13}$ and is known only to $1 \mathrm{eV}$. The radionuclides 1 isted in Table 1 have many other $\gamma$ rays with well-measured energies, but these lines were either not in an energy range of interest, or there were ${ }^{233} \mathrm{U}$ lines which interfered with their use.

The use of the 25.6Tb 1 ine as a reference line is somewhat complicated, since this line is not resolved from the $25.3 \mathrm{U}$ line, whose energy we wish to determine. Therefore, we have had to make use of two-step processes to determine this $25.6 \mathrm{~Tb}-25.3 \mathrm{U}$ energy difference. ${ }^{172} \mathrm{Hf}$ has a strong 1 ine at $23.9 \mathrm{keV}$, so we measured the $23.9 \mathrm{Hf}-25.3 \mathrm{U}$ and $23.9 \mathrm{Hf}-25.6 \mathrm{~Tb}$ differences. Similarly, the ${ }^{249} \mathrm{Am}$ line at $26.3 \mathrm{keV}$ was used to obtain the $25.3 \mathrm{U}-26.3 \mathrm{Am}$ and 25.6Tb - 26.3Am differences.

The reference- 1 ine energies in Table 1 were used in the determination of the energies of $50 \gamma$ rays from 25.3 to $367.7 \mathrm{keV}$ in ${ }^{229} \mathrm{Th}$.

The calibration sources were prepared by depositing a solution containing the radionuclide on a backing of Kaptan film, drying the solution, and covering it with tape and Kaptan film. In most cases, sources were made with a range of activities. The ${ }^{233} U$ sources were also made with a range of activities. This variety of source strengths was necessary so the ${ }^{233} U$ and calibration sources could be paired in such a way as to have similar peak count rates for the lines to be compared, and still have the sources be adjacent to each other. In all cases the source holders were in contact, so the sources were separated by distances of $\sim 0.3 \mathrm{~cm}$.

\subsection{Measurement and Analysis Methods}

The typical measurement procedure can be illustrated for the case of comparing the $42 \mathrm{U}$ line with the $46 \mathrm{~Pb}$ line. Particular sources of ${ }^{233} \mathrm{U}$ and ${ }^{210} \mathrm{~Pb}$ were chosen so that the count rates in these two peaks were comparable when the sources were placed adjacent to each other. A source-to-detector distance of $10 \mathrm{~cm}$ was typically chosen so that the sources were ' $\mathrm{far}$ ' from the detector compared to the difference in the source position $(\sim 0.3 \mathrm{~cm})$, but still gave a sufficient count rate. Half of the measured spectra were obtained with the ${ }^{233} U$ source nearer the detector and the other 
Table 1. Energies of reference and calibration lines. Uncertainties include only those from the measurement and not that from the conversion between the wavelength and electron-Volt energy scales (see text).

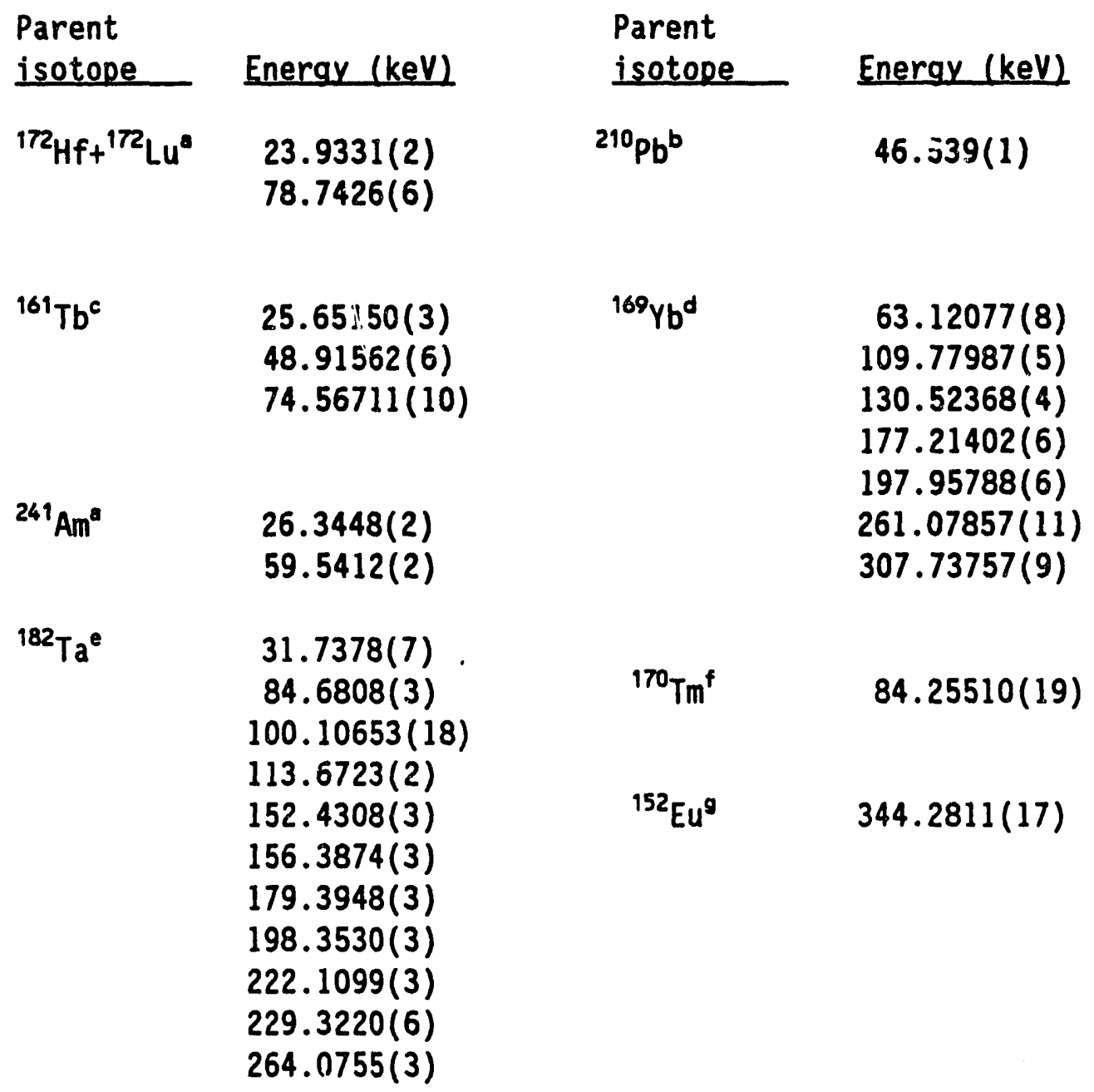

anergies from Reference 12 and were measured for this study.

b Energy from Reference 13.

c Energy from Reference 14.

d Energies from Reference 15.

- Energies from Reference 10, except for the 31-keV $\gamma$ ray, which is computed from the $116.4186(6)-84.68-8(3)$ difference.

f Energy from Reference 10.

9 Energy from Reference 10. See also Reference 16. 
haif with the ${ }^{210} \mathrm{~Pb}$ source nearer the detector; this would cancel out any bias in the energy difference due to differences in the source-detector distances. Since ${ }^{210} \mathrm{~Pb}$ has only one $\gamma$ ray, most of the calibration lines used were from ${ }^{233} \mathrm{U}$.

A crude estimate was made of the magnitude of the shift in the apparent line energy with source distance for a typical counting arrangement. For the planar Ge detector discussed in Reference 9, we can deduce from the figures therein

- for a 1489-keV $\gamma$ ray, the change in the apparent energy of a peak as a function of the source-detector distance is $-1.2 \mathrm{eV} / \mathrm{cm}$ at a distance of $10 \mathrm{~cm}$ (Figure 4 of Reference 9);

- the shift at $500 \mathrm{keV}$ is abou: 0.2 times the shift at $1489 \mathrm{keV}$ (Figure 3 of Reference 9); and

- the shift at energies below $500 \mathrm{keV}$ is approximately proportional to the $\gamma$-ray energy.

For a typical measurement made in this study, we have

- a source-detector distance of $10 \mathrm{~cm}$;

- a difference in source distance between sources of $0.3 \mathrm{~cm}$;

- a voltage gradient in the detector of about twice that of the detector in Reference 9; and

- a typical $\gamma$-ray energy of $100 \mathrm{keV}$.

For this case, the estimated peak shift between the sources is the above $\sim 1.2 \mathrm{eV} / \mathrm{cm}$, times 2.0 for the larger voltage gradient, times 0.3 for the distance difference of $0.3 \mathrm{~cm}$, times 0.2 to go from 1489 to $500 \mathrm{keV}$, and times 0.2 to go from 500 to $100 \mathrm{keV}$. This amounts to $0.03 \mathrm{eV}$, and thus can be neglected.

In the analysis of these spectra, the energy-channel relationship is taken to be

$$
E(x)=a+b \cdot(x-\delta)+c \cdot(x-\delta)^{2}
$$

and the peak widths, FWHM, are 


$$
W(x)=(\alpha+\beta \cdot x)^{1 / 2},
$$

where $x$ is the channel and $E$ is the energy. The user identifies the $\gamma$-ray peaks to be used in these calibrations and provides the $\gamma$-ray energies. The parameters a, b, and $c$ are determined by a least-squares fit to the energies and positions of these peaks; and the parameters $\alpha$ and $\beta$ are from a similar fit to the peak widths and positions. The $\delta$ is an estimated zero offset that is computed separately before the parameters $a, b$, and $c$ are computed. In this step the routine automatically defines the peak fitting region for each peak; that is, the fitting is not interactive.

An interactive routine is then used to fit the peaks of interest in determining $y$-ray energy differences. In this peak-fitting routine the user identifies, on a video screen, the channels below and above the peak to be used to determine the linear or step background function, the channel range included in the fit of the peak parameters, and the initial centroid of the peak. The initial peak width is taken from the width-calibration function. The peak parameters are then calculated by a nonlinear least-squares routine.

The peak positions, $X_{1}$ and $x_{2}$, from these fits are then used to determine the difference in energy between nearby peaks, namely,

$$
\Delta E=E_{2}-E_{1}=b \cdot\left(X_{2}-X_{1}\right)+c \cdot\left(X_{2}^{2}-X_{1}^{2}\right) .
$$

The calculation of the uncertainty in this difference includes the variances in $b, c, X_{1}$, and $x_{2}$ and the covariance between $b$ and $c$. This uncertainty is dominated by the two terms involving $\operatorname{var}\left(X_{1}\right)$ and $\operatorname{var}\left(X_{2}\right)$.

For each energy difference where data were taken on different detectors, several weighted averages are computed. These weighted averages are computed with the weights taken as $1 / \sigma^{2}$, where $\sigma$ is the uncertainty. Averages are computed for each detector separately, and for all of the data together. The reduced $-\chi^{2}$ value, $\chi_{R}{ }^{2}$, is determined for each average. If the $\chi_{R}{ }^{2}$ values are larger than expected, or the averages from different detectors are inconsistent, the data are reviewed to determine if there is an identifiable problem. In some cases a sir.gle value, which was an extreme outlier, was removed and the averages recalculated.

The uncertainties given throughout this work, except as influenced by the $\chi_{R}{ }^{2}$ values, are statistical. In fitting a set of calibration lines, we use a quadratic relationship, $E_{q}(X)$, between the energy and the channel number which will differ from the true relationship, $E_{t}(X)$, by an amount $\delta E(E \gamma)$. There are several contributions to this difference: (i) the statistical variations in the peak locations; (ii) any errors (not uncertainties, but 
actual errors) in the calibration energies; and (iii) the fact that the true relationship may not be adequately represented by any quadratic function (i.e., the true relationship has higher order terms). In addition to these general contributions, for an individual $\gamma$-ray peak a fourth factor would be any shift in its position due to other peaks in the spectrum. In our computation of an energy difference, $\Delta E$, between two lines from one spectrum, all of these factors are ignored.

Before discussing our method of addressing these four factors, let us note the precision we are implying in our results. The smallest uncertainty that we have quoted for an average $\Delta E$ is $0.1 \mathrm{eV}$. Since this is from more than 16 measurements, this corresponds to an uncertainty of about $0.4 \mathrm{eV}$ for an individual measurement, if each measured value has the same uncertainty. Many measurements were made with a gain scale corresponding to $20 \mathrm{eV}$ per channal. An uncertainty in a peak position of $0.4 \mathrm{eV}$ then corresponds to 0.02 channels. It is questionable if $\delta E(E \gamma)$ is this small. However, since we are always determining an energy difference, it is actually only the change in $\delta E(E y)$ between the two peak positions that needs to be this small.

Our decision to quote only the statistical uncertainty is based on the following. It is assumed that, since the first factor is statistical, in an average over many spectra, it will be averaged out. It is assumed that the second contribution will be identified, or at least partially averaged out, by using different calibration lines whenever possible.

We chose to treat the third factor by making our measurements in the following manner. Each measurement was made on a different gain scale, and measurements were made on different detectors, each with its own ADC and amplifier. Both of these variations in the experimental setup are expected to result in different functions $\delta E(E \gamma)$. It is assumed that by averaging the results from all of the measurements the average $\delta E$ will approach zero.

The fourth factor must be dealt with individually for each peak for which it is a concern. A case of particular interest is the 25Tb - 26Am difference. Since these peaks are not completely resolved, as shown in Figure 2 , in fitting one of these peaks, the second peak will tend to move the apparent peak location of the first peak closer to that of the second one. Therefore, the measured difference is expected to be less than the actual difference. If this effect is significant, the observed difference should increase as the detector resolution improves. In fact, the values from the $\mathrm{Si}(L i)$ and OR-16 detectors agree very we11, so this effect is negligible and all of these measurements have been used. 


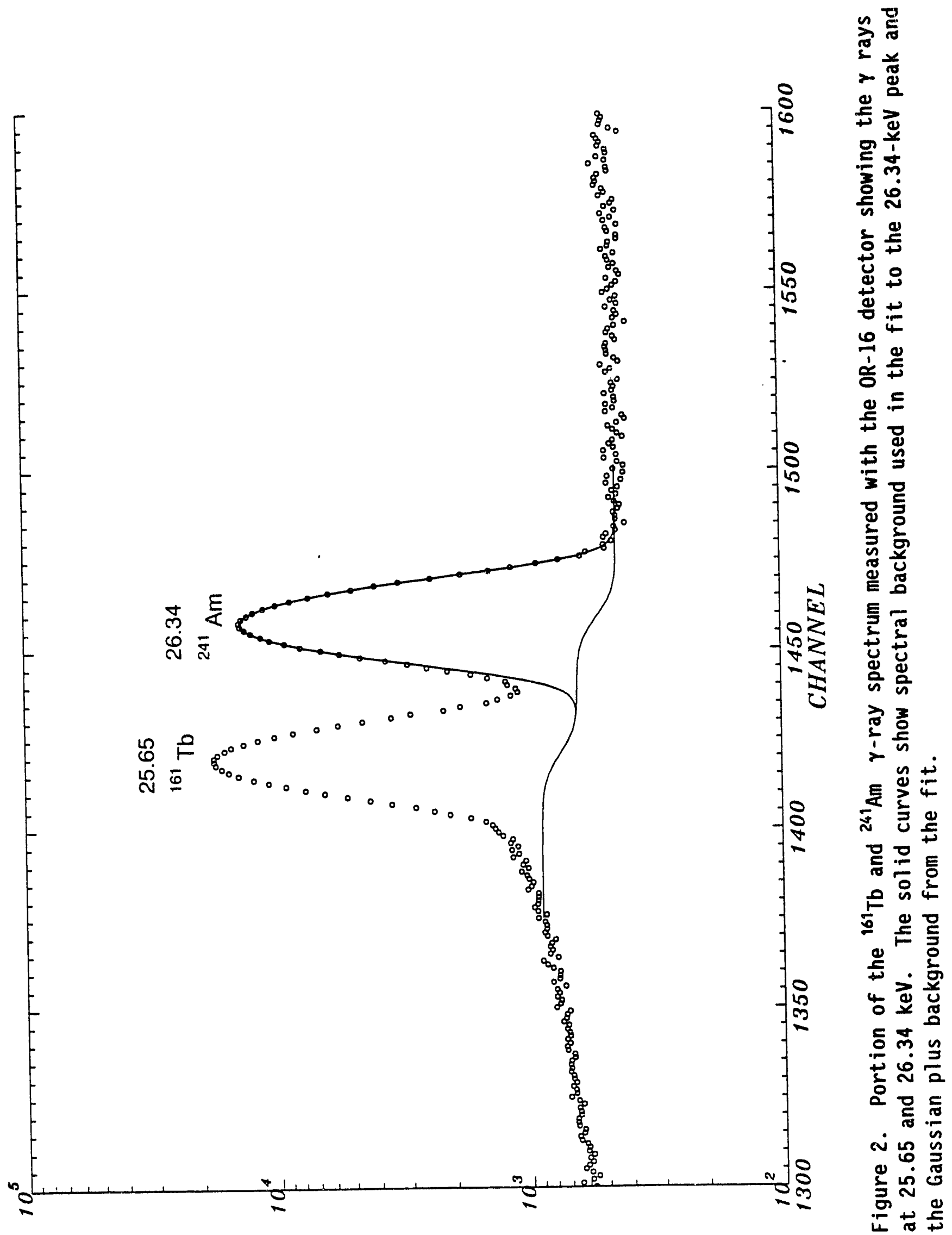

施 


\subsection{Detectors}

Some properties of the five detectors used in this study are given in Table 2. The detectors include two high-purity Ge coaxial detectors, two Ge planar detectors, and a $\mathrm{Si}(\mathrm{L} i)$ detector. The resolutions given in the table are not the optimum values for these detectors; rather, they are observed values for actual spectra, where the counting times are typically 72 hours.

Table 2. Properties of detectors.

\begin{tabular}{|c|c|c|c|c|c|c|c|}
\hline Detector & Material & Shape & $\begin{array}{l}\text { Volume } \\
\left(\mathrm{cm}^{3}\right)\end{array}$ & $\begin{array}{l}\text { Diam. } \\
(\mathrm{mm})\end{array}$ & $\begin{array}{l}\text { Depth } \\
\text { (mm) }\end{array}$ & $\frac{\text { FWHM }}{29 \mathrm{keV}}$ & $\frac{(\mathrm{eV}) \mathrm{at}}{1 ? 2 \mathrm{keV}}$ \\
\hline OR-12 & $\mathrm{Ge}$ & coaxial & 114 & & & & 950 \\
\hline$P G-21$ & $\mathrm{Ge}$ & coaxial & 63 & & & & 900 \\
\hline$P F-16$ & $\mathrm{Ge}$ & planar & & 16 & 10 & 390 & \\
\hline$O R-16$ & $\mathrm{Ge}$ & planar & & 10 & 7 & 270 & \\
\hline $\mathrm{Si}$ & $S i(L i)$ & planar & & 6 & 4 & 345 & \\
\hline
\end{tabular}




\section{MEASUREMENT RESULTS AND $\gamma$-RAY ENERGIES WITHOUT ${ }^{23} U$}

To simplify the discussion of the results, we have divided the spectral measurements into two groups: those spectra that do not include ${ }^{233} \mathrm{U}$; and those that do. The 66 spectra that do not include ${ }^{233} \mathrm{U}$ were measured to obtain improved $\gamma$-ray energies for ${ }^{172} \mathrm{Hf}+{ }^{172} \mathrm{Lu}$ and ${ }^{241} \mathrm{Am}$; these spectra are listed in Table 3.

In Tables 4-6 the spectra used will be identified by the spectral codes given in Table 3. (To make it easier to follow the text, all tables of the measured energy differences are placed after the references.) In these spectral codes the letters $A-E$ identify the detector, the $N$ indicates that ${ }^{233} \mathrm{U}$ was not present, and the numbers indicate the order in which the spectra were obtained on the particular detector.

\subsection{Measurement Results for ${ }^{161} \mathrm{~Tb},{ }^{172} \mathrm{Hf}_{+}{ }^{172} \mathrm{Lu}$, and ${ }^{261} \mathrm{Am}$}

Tables 4, 5, and 6 give the individual values for all of the energy differences determined from spectra not containing ${ }^{233} \mathrm{U}$. Where they are not obvious, the radionuclides present in the source can be deduced from the entry in Table 3 for the specific spectral code. In each of these three tables, the weighted average of the energy difference is given for each detector and then for all of the values together. Any individual value that has been excluded from the averages is identified and the reason is given.

The value adopted for our use is the last value given in each column.

\section{$3.2 \gamma$-Ray Energies for ${ }^{161} \mathrm{~Tb},{ }^{172} \mathrm{Hf}+{ }^{172} \mathrm{Lu}$, and ${ }^{241} \mathrm{Am}$}

The $\gamma$-ray energies deduced from these data are given in Table 7 . These values are compared in Table 8 with values from two published evaluations, namely the Table of Radioactive Isotopes ${ }^{19}$ and the Nuclear Data Sheets ${ }^{20-22}$. It is clear that the uncertainties quoted here are significantly smaller than the previous ones. It is also interesting that the energy of the 59-keV line from the decay of ${ }^{241} \mathrm{Am}$ has changed by $\sim 4 \mathrm{eV}$. A paper on the results of the analysis of these data has been accepted for publication ${ }^{12}$.

There is some statistical objection to including in Table 7 entries which involve the use a line measured in this study as a reference line for a second line. For example, the $78-\mathrm{keV}$ line was measured relative to the $74-\mathrm{keV}$ line from ${ }^{161} \mathrm{~Tb}$. Then the $81-\mathrm{keV}$ line is shown as being measured with respect to both the 74- and 78-keV lines. In spite of this objection, we have included both values in Table 7 , and have averaged both values to get the final $81-\mathrm{keV}$ 
Table 3. Measured spectra that do not include ${ }^{233} \mathrm{U}$.

Dates are given in the form month and day, all dates are in 1992.

\begin{tabular}{|c|c|c|c|c|c|c|c|}
\hline Detector & Date & Nuclides & $\begin{array}{l}\text { Spectral } \\
\text { code } \\
\end{array}$ & Detector & Date & Nuclides & $\begin{array}{l}\text { Spectral } \\
\text { code }\end{array}$ \\
\hline \multirow[t]{26}{*}{$P G-16$} & 0220 & $\mathrm{~Tb} \& \mathrm{Hf}$ & CNI & $S i(L i)$ & 0210 & Hf \& Am & EN1 \\
\hline & 0221 & $\mathrm{~Tb} \& \mathrm{Hf}$ & CN2 & & 0213 & Hf \& Am & EN2 \\
\hline & 0221 & $\mathrm{~Tb} \& \mathrm{Hf}$ & CN3 & & 0218 & Hf \& Am & EN3 \\
\hline & 0224 & $\mathrm{~Tb} \& \mathrm{Hf}$ & CN4 & & 0220 & $\mathrm{~Tb} \& \mathrm{Am}$ & EN4 \\
\hline & 0225 & $T b \& H f$ & CN5 & & 0221 & $\mathrm{~Tb} \& \mathrm{Am}$ & EN5 \\
\hline & 0226 & $\mathrm{~Tb} \& \mathrm{Hf}$ & CN6 & & 0224 & Tb \& Am & EN6 \\
\hline & 0316 & Tb \& Hf & CN7 & & 0225 & Tb \& Am & EN7 \\
\hline & 0318 & $\mathrm{~Tb} \& \mathrm{Hf}$ & CN8 & & 0226 & Tb \& Am & EN8 \\
\hline & 0326 & $\mathrm{~Tb} \& \mathrm{Hf}$ & CN9 & & 0227 & $\mathrm{~Tb} \& \mathrm{Hf}$ & EN9 \\
\hline & 0330 & $\mathrm{~Tb} \& \mathrm{Am}$ & CN10 & & 0229 & $\mathrm{~Tb} \& \mathrm{Hf}$ & EN10 \\
\hline & 0401 & Tb \& Am & CN11 & & 0302 & $\mathrm{~Tb} \& \mathrm{Hf}$ & EN11 \\
\hline & 0409 & $\mathrm{~Tb} \& \mathrm{Am}$ & $\mathrm{CN} 12$ & & 0303 & $\mathrm{~Tb} \& \mathrm{Hf}$ & EN12 \\
\hline & 0415 & $\mathrm{~Tb} \& A m$ & CN13 & & 0305 & $\mathrm{~Tb} \& \mathrm{Hf}$ & EN13 \\
\hline & 0415 & Tb \& Am & CN14 & & 0307 & $\mathrm{~Tb} \& \mathrm{Hf}$ & EN14 \\
\hline & 0416 & Tb \& Am & CN15 & & 0310 & Tb \& Hf & EN15 \\
\hline & 0417 & Tb \& Am & $\mathrm{CN} 16$ & & 0312 & $\mathrm{~Tb} \& \mathrm{Hf}$ & EN16 \\
\hline & 0427 & Hf \& Am & CN17 & & 0314 & $\mathrm{~Tb} \& \mathrm{Hf}$ & EN17 \\
\hline & 0429 & Hf \& Am & CN18 & & 0316 & $T b \& A m$ & EN18 \\
\hline & 0430 & $\mathrm{Hf} \& \mathrm{Am}$ & CN19 & & 0318 & Tb \& Am & EN19 \\
\hline & 0504 & Hf \& Am & CN2O & & 0319 & $\mathrm{~Tb} \& \mathrm{Am}$ & EN20 \\
\hline & 0506 & Hf \& Am & CN21 & & 0321 & $T b \& A m$ & EN21 \\
\hline & 0507 & $\mathrm{Hf} \& \mathrm{Am}$ & CN22 & & 0401 & Tb \& Am & EN22 \\
\hline & 0511 & $H f \& A m$ & CN23 & & 0409 & $\mathrm{~Tb} \& \mathrm{Am}$ & EN23 \\
\hline & 0514 & $H f \& A m$ & CN24 & & 0415 & $\mathrm{~Tb} \& \mathrm{Am}$ & EN24 \\
\hline & 0518 & Hf \& Am & $\mathrm{CN} 25$ & & 0416 & Tb \& Am & EN25 \\
\hline & & & & & 0417 & $\mathrm{~Tb} \& \mathrm{Am}$ & EN26 \\
\hline \multirow[t]{10}{*}{$0 R-16$} & 0423 & $T b \& A m$ & DN1 & & 0521 & Hf \& Am & EN27 \\
\hline & 0424 & Tb \& Am & DN2 & & 0526 & Hf \& Am & EN28 \\
\hline & 0428 & $T b \& A m$ & DN3 & & 0528 & $\mathrm{Hf} \& \mathrm{Am}$ & EN29 \\
\hline & 0429 & Tb \& Am & DN4 & & 0601 & Hf \& Am & EN30 \\
\hline & 0501 & $T b \& A m$ & DN5 & & 0605 & Hf \& Am & EN31 \\
\hline & 0504 & $\mathrm{~Tb} \& \mathrm{Am}$ & DN6 & & & & \\
\hline & 0507 & $\mathrm{~Tb} \& \mathrm{Am}$ & DN7 & & & & \\
\hline & 0511 & $\mathrm{~Tb} \& \mathrm{Am}$ & DN8 & & & & \\
\hline & 0514 & $\mathrm{~Tb} \& A m$ & DN9 & & & & \\
\hline & 0518 & $\mathrm{~Tb} \& \mathrm{Am}$ & DN10 & & & & \\
\hline
\end{tabular}


Table 7. Energies deduced for y rays from ${ }^{161} \mathrm{~Tb},{ }^{172} \mathrm{Hf}+{ }^{172} \mathrm{Lu}$, and ${ }^{241} \mathrm{Am}$.

\begin{tabular}{|c|c|c|c|c|c|}
\hline $\begin{array}{l}\text { Parent } \\
\text { isotope }\end{array}$ & $\begin{array}{l}\text { Line } \\
(\mathrm{keV})\end{array}$ & $\begin{array}{l}\text { Reference } \\
\text { line }\end{array}$ & $\begin{array}{c}\text { Difference } \\
(\mathrm{keV})\end{array}$ & $\frac{y-\text { ray }}{\text { Individual }}$ & $\begin{array}{c}\text { energy (keV) } \\
\text { Average }\end{array}$ \\
\hline${ }^{161} \mathrm{~Tb}$ & 57.1 & $48 T \mathrm{~Tb}$ & $8.2764(3)$ & $57.1920(3)$ & \\
\hline \multirow[t]{8}{*}{${ }^{172} H f{ }^{172} L u$} & 23.9 & $25 \mathrm{~Tb}$ & $1.7184(2)$ & $23.9331(2)$ & \\
\hline & 78.7 & $74 \mathrm{~Tb}$ & $4.1755(6)$ & $78.7426(6)$ & \\
\hline & 81.7 & $\begin{array}{l}74 T a \\
781 \mathrm{u}\end{array}$ & $\begin{array}{l}7.1841(6) \\
3.0088(4)\end{array}$ & $\begin{array}{l}81.7512(6) \\
81.7514(7)\end{array}$ & $81.7513(5)$ \\
\hline & 90.6 & $\begin{array}{l}74 T b \\
81 H f\end{array}$ & $\begin{array}{r}16.0787(8) \\
8.8907(8)\end{array}$ & $\begin{array}{l}90.6458(8) \\
90.6420(9)\end{array}$ & $90.6440(19)$ \\
\hline & 112.7 & 90Lu & $22.1340(19)$ & $112.7780(27)$ & \\
\hline & 114.0 & $112 \mathrm{Lu}$ & $1.2827(7)$ & $114.0607(28)$ & \\
\hline & 122.9 & $114 \mathrm{Hf}$ & $8.8549(12)$ & $122.9156(30)$ & \\
\hline & 125.8 & $122 \mathrm{Hf}$ & $2.8966(8)$ & $125.8122(31)$ & \\
\hline \multirow[t]{2}{*}{${ }^{241} \mathrm{Am}$} & 26.3 & $\begin{array}{l}25 \mathrm{~Tb} \\
23 \mathrm{Hf}\end{array}$ & $\begin{array}{l}0.6933(2) \\
2.4118(9)\end{array}$ & $\begin{array}{l}26.3448(2) \\
26.3449(9)\end{array}$ & $26.3448(2)$ \\
\hline & 59.5 & $\begin{array}{l}48 \mathrm{~Tb} \\
74 \mathrm{~Tb}\end{array}$ & $\begin{array}{l}10.6257(1)^{\mathrm{a}} \\
15.0261(2)\end{array}$ & $\begin{array}{c}59.5413(1) \\
59.5410(2)\end{array}$ & $59.5412(2)$ \\
\hline
\end{tabular}

a ${ }^{161} \mathrm{~Tb}$ has a $\gamma$ ray at 59.239 (13) keV with an intensity 0.012 times that of the $57-\mathrm{keV} \gamma$; this $59.2 \gamma$ is not expected to interfere significantly with the 59Am line. 
Table 8. Comparison of our results with the evaluated data published in the Table of Radioactive I sotopes ${ }^{19}$ (TRI) and the Nuclear Data Sheets (NDS).

\begin{tabular}{|c|c|c|c|c|}
\hline Parent & Line & Present measurement & & tion \\
\hline isotope & $(\mathrm{keV})$ & $(\mathrm{keV})$ & Ref. & Value \\
\hline${ }^{241} \mathrm{Am}$ & 26.3 & $26.3448(2)$ & $\begin{array}{l}\text { TRI } \\
\text { NDS }^{20}\end{array}$ & $\begin{array}{l}26.3445(10) \\
26.345(1)\end{array}$ \\
\hline & 59.5 & $59.5412(2)$ & $\begin{array}{l}\text { TRI } \\
\text { NDS }^{20}\end{array}$ & $\begin{array}{c}59.5364(10) \\
59.537(1)\end{array}$ \\
\hline${ }^{172} \mathrm{Hf}$ & 23.9 & $23.3331(2)$ & TRI & $23.99(5)$ \\
\hline & 81.7 & $81.7515(5)$ & TRI & $81.75(5)$ \\
\hline & 114.0 & $114.0607(25)$ & TRI & $114.06(10)$ \\
\hline & 122.9 & $122.9156(28)$ & TRI & $122.92(10)$ \\
\hline & 125.8 & $125.8122(29)$ & TRI & $125.82(5)$ \\
\hline${ }^{172} \mathrm{Lu}$ & 78.7 & $78.7426(6)$ & $\begin{array}{l}\text { TRI } \\
\text { NDS }^{21}\end{array}$ & $\begin{array}{l}78.792(7) \\
78.738(5)\end{array}$ \\
\hline & 90.6 & $90.6449(13)$ & $\begin{array}{l}\text { TRI } \\
\text { NOS }^{21}\end{array}$ & $\begin{array}{c}90.665(17) \\
90.647(3)\end{array}$ \\
\hline & 112.7 & $112.7780(24)$ & $\begin{array}{l}\text { TRI } \\
\text { NDS }^{21}\end{array}$ & $\begin{array}{c}112.757(20) \\
112.793(5)\end{array}$ \\
\hline${ }^{161} \mathrm{~Tb}$ & 57.1 & $57.1920(3)$ & $\begin{array}{l}\text { TRI } \\
\text { NDS }^{22}\end{array}$ & $\begin{array}{l}57.212(5) \\
57.196(2)\end{array}$ \\
\hline
\end{tabular}


energy value. This objection also applies to the values for the 81 - and 90 $\mathrm{keV}$ lines from ${ }^{172} \mathrm{Hf}+{ }^{172} \mathrm{Lu}$ and the $26-\mathrm{keV} 1$ ine from ${ }^{241} \mathrm{Am}$. in the latter case, the $23-\mathrm{keV}$ line from ${ }^{172} \mathrm{Hf}$ is based on the $25-\mathrm{keV}$ line from ${ }^{161} \mathrm{~Tb}$. However, in this case we set out explicitly to provide an alternate path to the 26-keV value because of the small separation, $0.69 \mathrm{keV}$, between the 25- and 26-keV lines. A proper treatment of the averaging of these values would involve taking into account the correlation between them; this has not been done. But, it should be noted that in all three of these cases the uncertainty for the individual energy value is smaller for the value directly tied to the ${ }^{161} \mathrm{~Tb}$ reference line. Therefore, a more complete uncertainty analysis would not change the result significantly. 


\section{MEASUREMENT RESULTS AND $\gamma$-RAY ENERGIES FOR ${ }^{233} U$}

\subsection{Measurement Results}

A total of 111 spectra containing ${ }^{233} \mathrm{U}$ were measured for this study; these spectra are listed in Table 9. Tables 10-18 give the individual values for all of the energy differences deduced from these spectra. Table 10 gives the energy differences for the reference lines from ${ }^{249} \mathrm{Am}$, Table 11 for the reference line from ${ }^{152} \mathrm{Eu}$, Table 12 from ${ }^{210} \mathrm{~Pb}$, Table 13 from ${ }^{170} \mathrm{Tm}$, Table 14 from ${ }^{161} \mathrm{~Tb}$, Table 15 from ${ }^{172} \mathrm{Hf}+{ }^{172} \mathrm{Lu}$, Table 16 from ${ }^{182} \mathrm{Ta}$, Table 17 from ${ }^{169} \mathrm{Yb}$, and Table 18 for 38 pairs of lines from ${ }^{233} \mathrm{U}$. (In these tables the lines are from ${ }^{233} U$ if they are not labeled otherwise.) Although only a few of these energy differences are of interest in the determination of the energy of the first excited state in ${ }^{229} \mathrm{Th}$, the others are given for completeness and for possible future use. For these tables, the information in Table 9 can be used to identify the nuclides present in any particular spectrum.

For each energy difference in Tables 10-18, the weighted average of the values is given for each detector and for all of the data combined. In many cases a weighted average is also given for the values from the two higher resolution Ge detectors, PG-16 and OR-16. The value adopted for subsequent use is the last value given in the column.

As illustrations of the quality of the spectra obtained, Figures 3-14 show portions of the $\gamma$-ray spectra from four of the detectors and for most of the $\gamma$ rays used in the determination of the energy of the first excited state of ${ }^{229} \mathrm{Th}$. Some of these examples are from spectra of ${ }^{233} \mathrm{U}$ only, but most of them include calibration sources. These figures show the quality of the data obtained - the typical counting statistics and the resolution obtained for many of the pairs of peaks used.

Figure 5 shows that the peaks at 52 and $53 \mathrm{keV}$ may influence the peak position of the $54-\mathrm{keV}$ peak by influencing the definition of the background below this peak, even though the 53 - and $54-\mathrm{keV}$ peaks are almost completely resolved.

From Figure 8 it is clear that the $97-\mathrm{keV}$ peak from ${ }^{233} \mathrm{U}$ has several interfering lines, both at lower and higher energies, under it. These lines, whose influence was not specifically taken into account in the analysis, may introduce a significant systematic error into the determination of the peak position of the $97-\mathrm{keV}$ peak and hence into the measurement of the 97U-100Ta energy difference, especially since the statistical uncertainty in this difference is only $0.3 \mathrm{eV}$, one of the smallest reported in this study. In order to investigate the possible magnitude of such an effect, four fits were 
Table 9. Spectra measured that include ${ }^{233} \mathrm{U}$.

Dates are given in the form of month, day, and year.

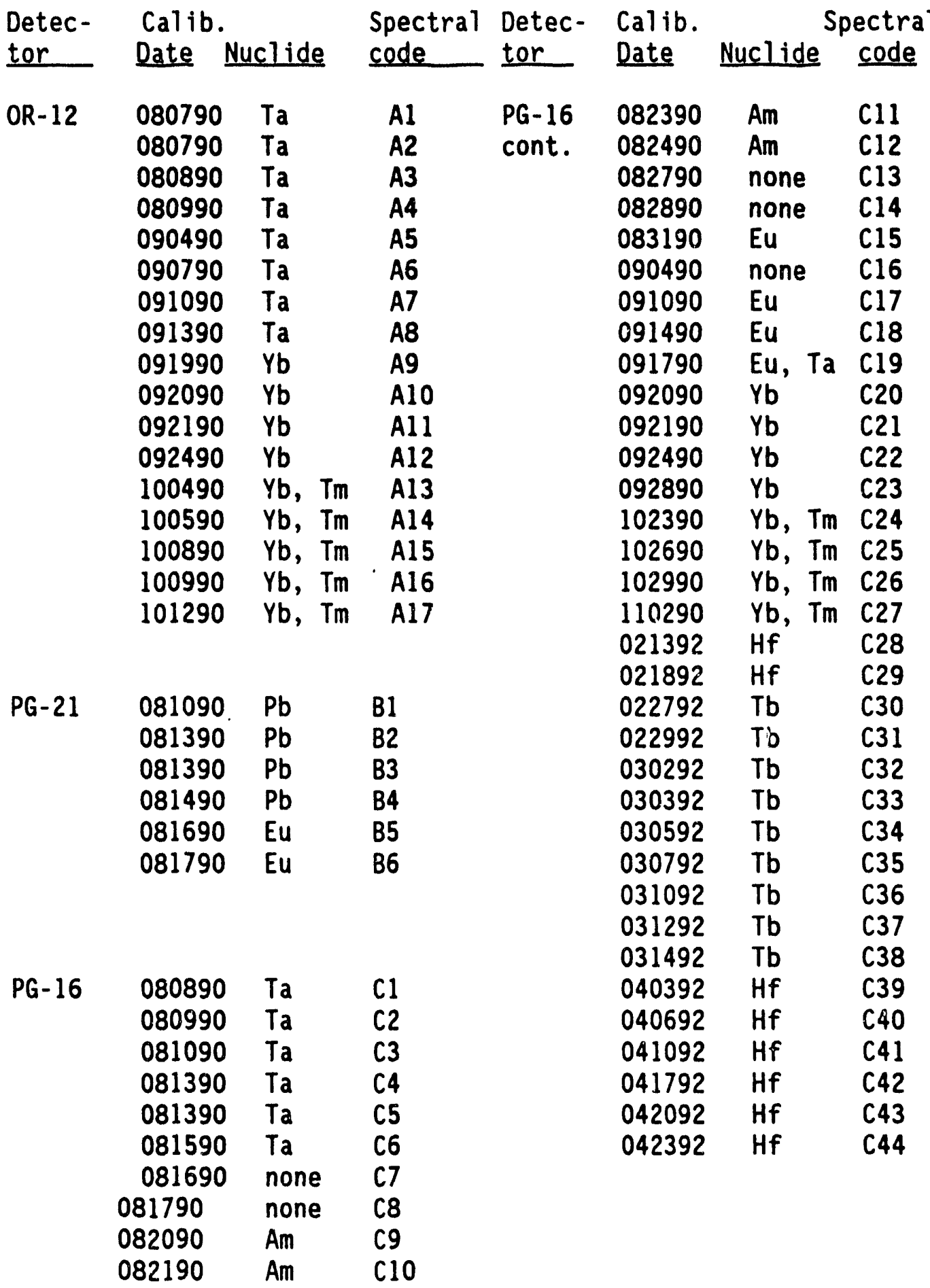


Table 9. (Continued)

Detec- Calib. tor Date Nuclide

Spectral Detec- Calib. Spectral

OR-16

\begin{tabular}{|c|c|c|c|c|c|c|}
\hline $\begin{array}{l}111390 \\
111490 \\
111690 \\
111990 \\
112190 \\
112690 \\
112890 \\
113090 \\
125390 \\
120590 \\
120790 \\
121090 \\
121290 \\
121490 \\
121990 \\
010291 \\
010791 \\
011191 \\
011691 \\
012191 \\
012391 \\
012591 \\
120391 \\
120591 \\
120991 \\
121291 \\
121691 \\
122091 \\
010392 \\
010692 \\
012792 \\
013192 \\
020392\end{array}$ & $\begin{array}{l}\text { Ta, Am } \\
\mathrm{Ta}, \mathrm{Am} \\
\mathrm{Ta}, \mathrm{Am} \\
\mathrm{Ta}, \mathrm{Am} \\
\mathrm{Ta} \\
\mathrm{Ta} \\
\mathrm{Ta} \\
\mathrm{Am} \\
\mathrm{Am} \\
\mathrm{Am} \\
\mathrm{Am} \\
\mathrm{Yb}, \mathrm{Tm} \\
\mathrm{Yb}, \mathrm{Tm} \\
\mathrm{Yb}, \mathrm{Tm} \\
\text { none } \\
\text { none } \\
\text { none } \\
\text { rone } \\
\mathrm{Pb} \\
\mathrm{Pb} \\
\mathrm{Pb} \\
\mathrm{Pb} \\
\mathrm{Am} \\
\mathrm{Am} \\
\mathrm{Am} \\
\mathrm{Am} \\
\text { nore } \\
\text { none } \\
\text { none } \\
\text { none } \\
\mathrm{Hf} \\
\mathrm{Hi} \\
\mathrm{Hf}\end{array}$ & $\begin{array}{l}D 1 \\
D \\
D 3 \\
D 4 \\
D 5 \\
D 6 \\
D 7 \\
D 8 \\
D 9 \\
D 10 \\
D 11 \\
D 12 \\
D 13 \\
D 14 \\
D 15 \\
D 16 \\
D 17 \\
D 18 \\
D 19 \\
D 20 \\
D 21 \\
D 22 \\
D 23 \\
D 24 \\
D 25 \\
D 26 \\
D 27 \\
D 28 \\
D 29 \\
D 30 \\
D 31 \\
D 32 \\
D 33\end{array}$ & $S i(L i)$ & $\begin{array}{l}121691 \\
122091 \\
122391 \\
010392 \\
011092 \\
011392 \\
012092 \\
012392 \\
012392 \\
020392 \\
020792 \\
022192 \\
032392 \\
032592 \\
032692 \\
033092 \\
040292 \\
040692 \\
041092 \\
041792 \\
042092 \\
060892 \\
061192 \\
061992 \\
062292 \\
062592 \\
062992 \\
070292\end{array}$ & $\begin{array}{l}\text { Am } \\
A m \\
A m \\
A m \\
A m \\
\text { none } \\
\text { none } \\
\text { none } \\
\text { none } \\
H f \\
H f \\
H f \\
T b \\
T b \\
T b \\
T b \\
T b \\
T b \\
T b \\
T b \\
T b \\
T b \\
H f \\
H f \\
H f \\
H f \\
H f \\
H f \\
H f \\
H f \\
H f\end{array}$ & $\begin{array}{l}\text { E1 } \\
\text { E2 } \\
\text { E3 } \\
\text { E4 } \\
\text { E5 } \\
\text { E6 } \\
\text { E7 } \\
\text { E8 } \\
\text { E9 } \\
\text { E10 } \\
\text { E11 } \\
\text { E12 } \\
\text { E13 } \\
\text { E14 } \\
\text { E15 } \\
\text { E16 } \\
\text { E17 } \\
\text { E18 } \\
\text { E19 } \\
\text { E20 } \\
\text { E21 } \\
\text { E22 } \\
\text { E23 } \\
\text { E24 } \\
\text { E25 } \\
\text { E26 } \\
\text { E27 } \\
\text { E28 }\end{array}$ \\
\hline
\end{tabular}




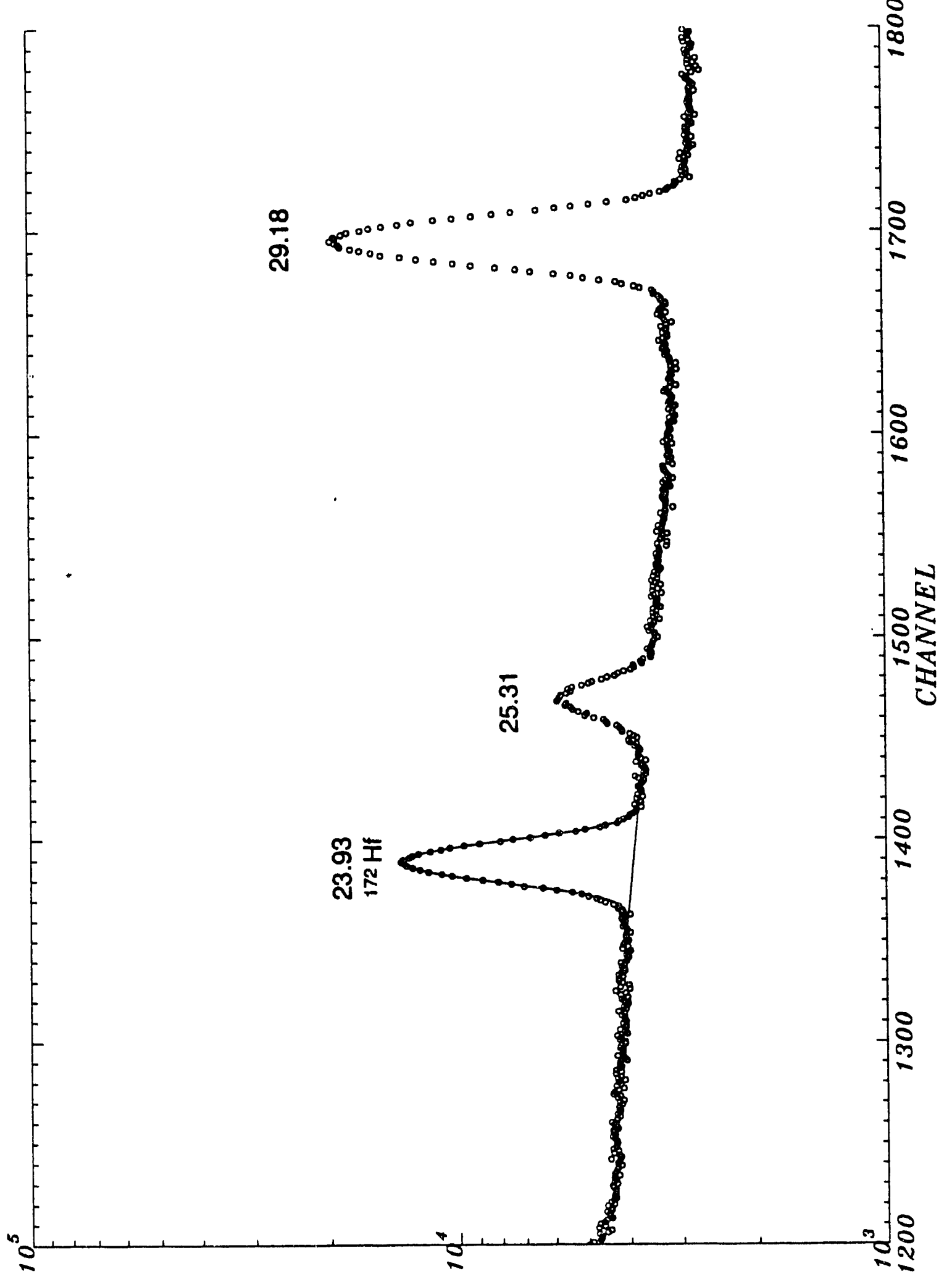

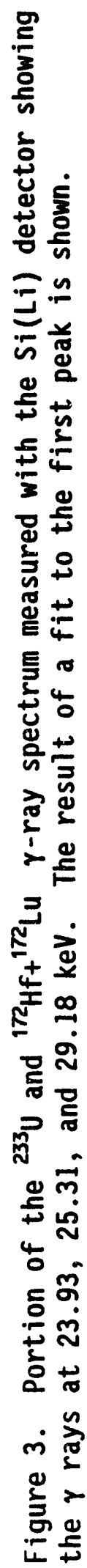




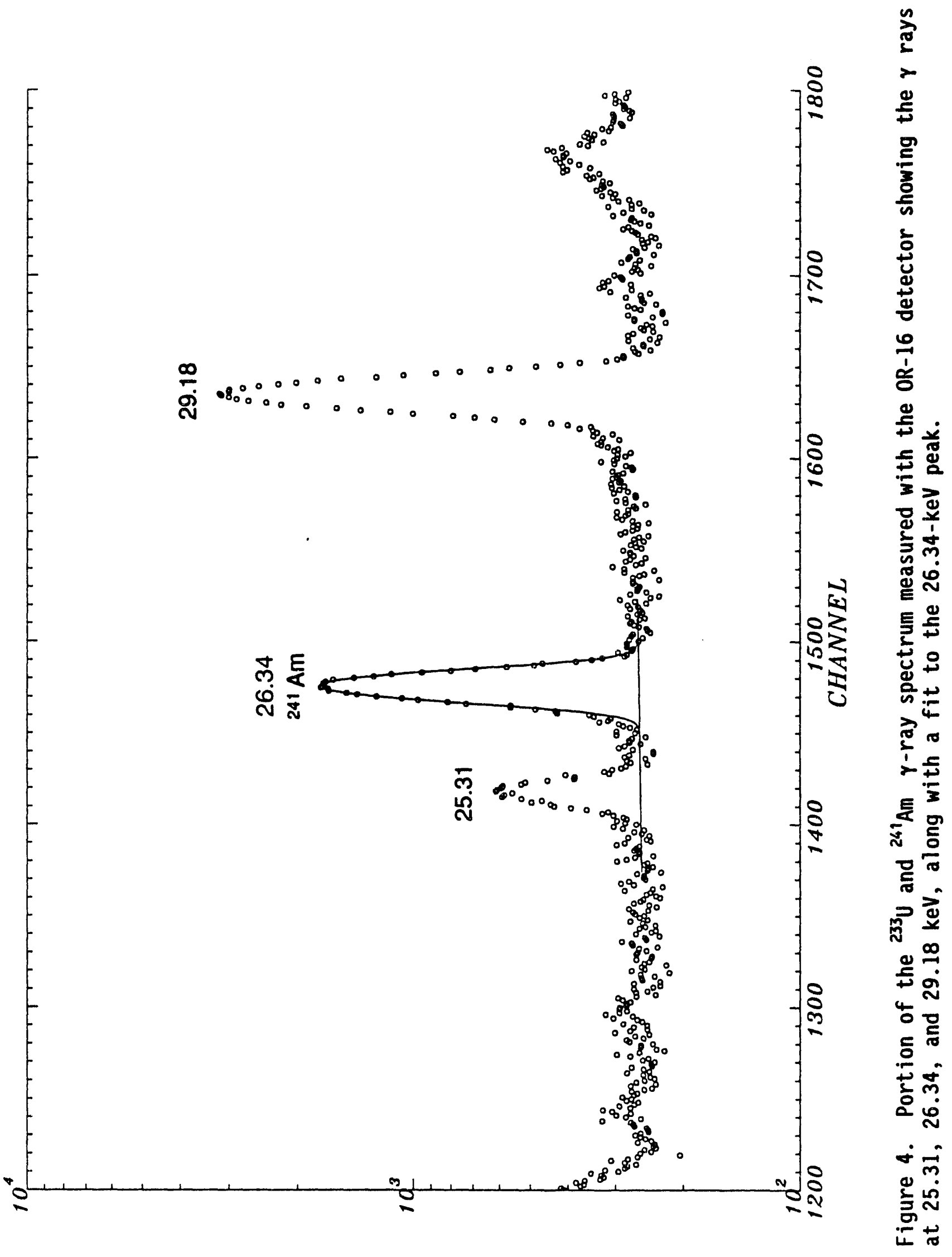




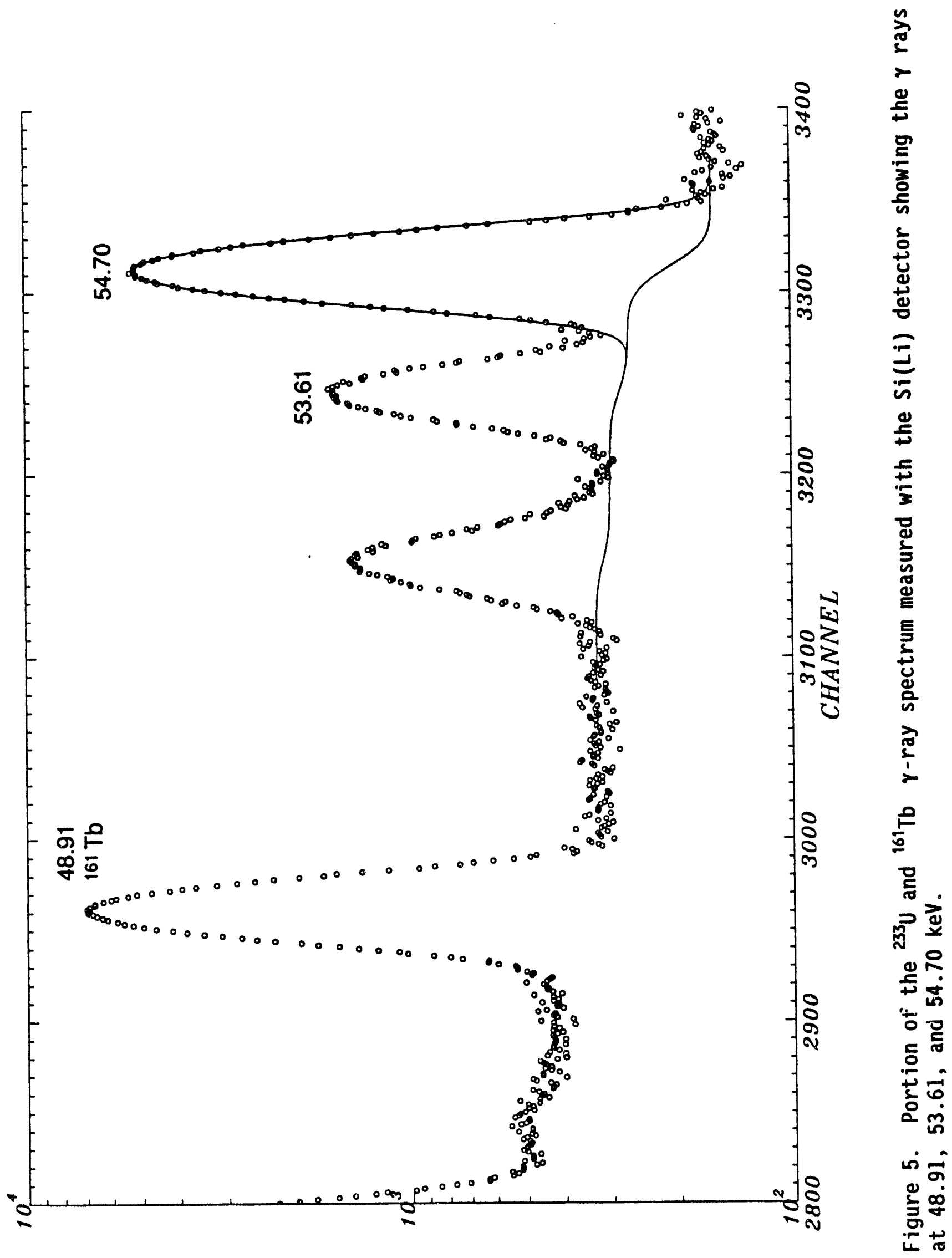




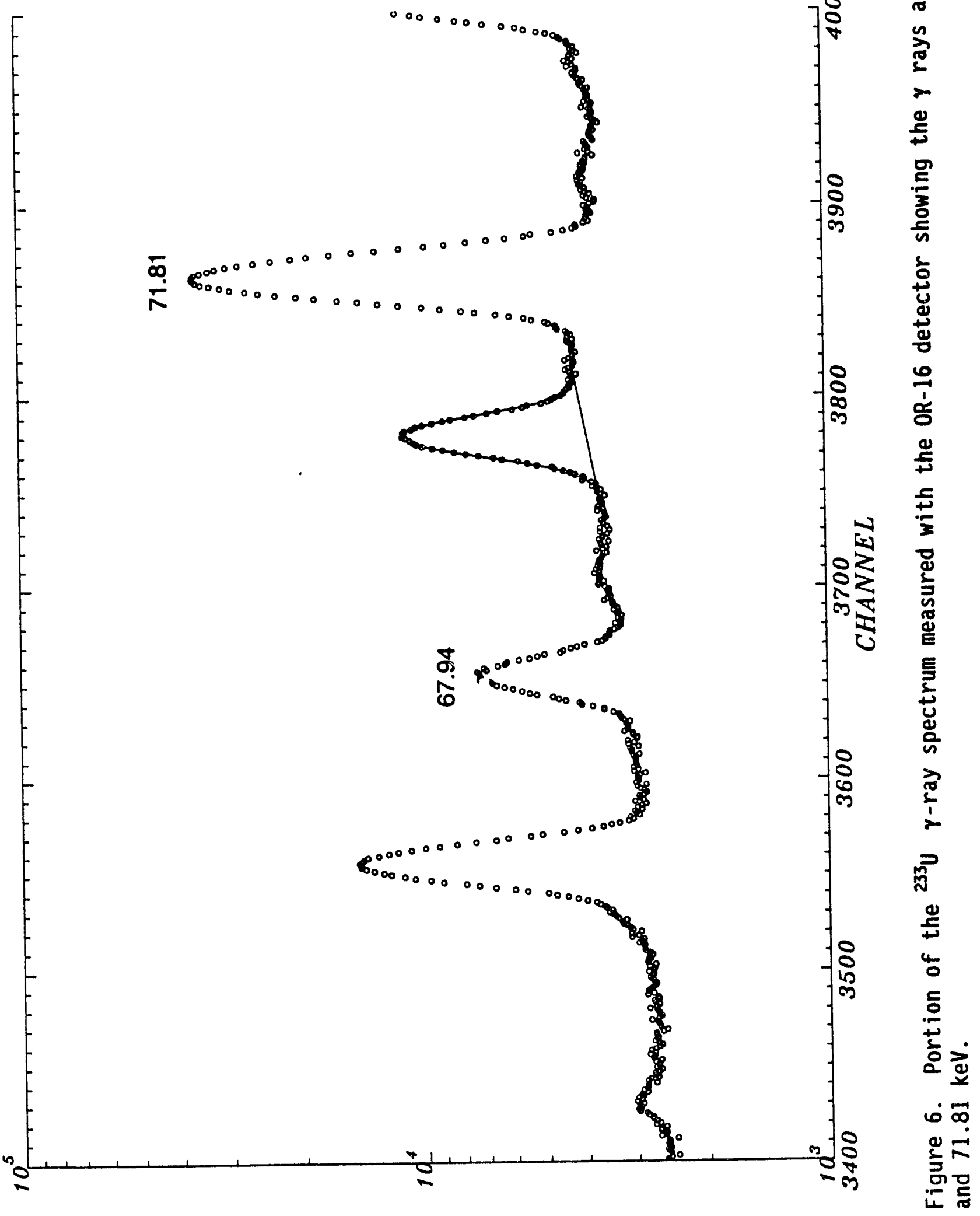




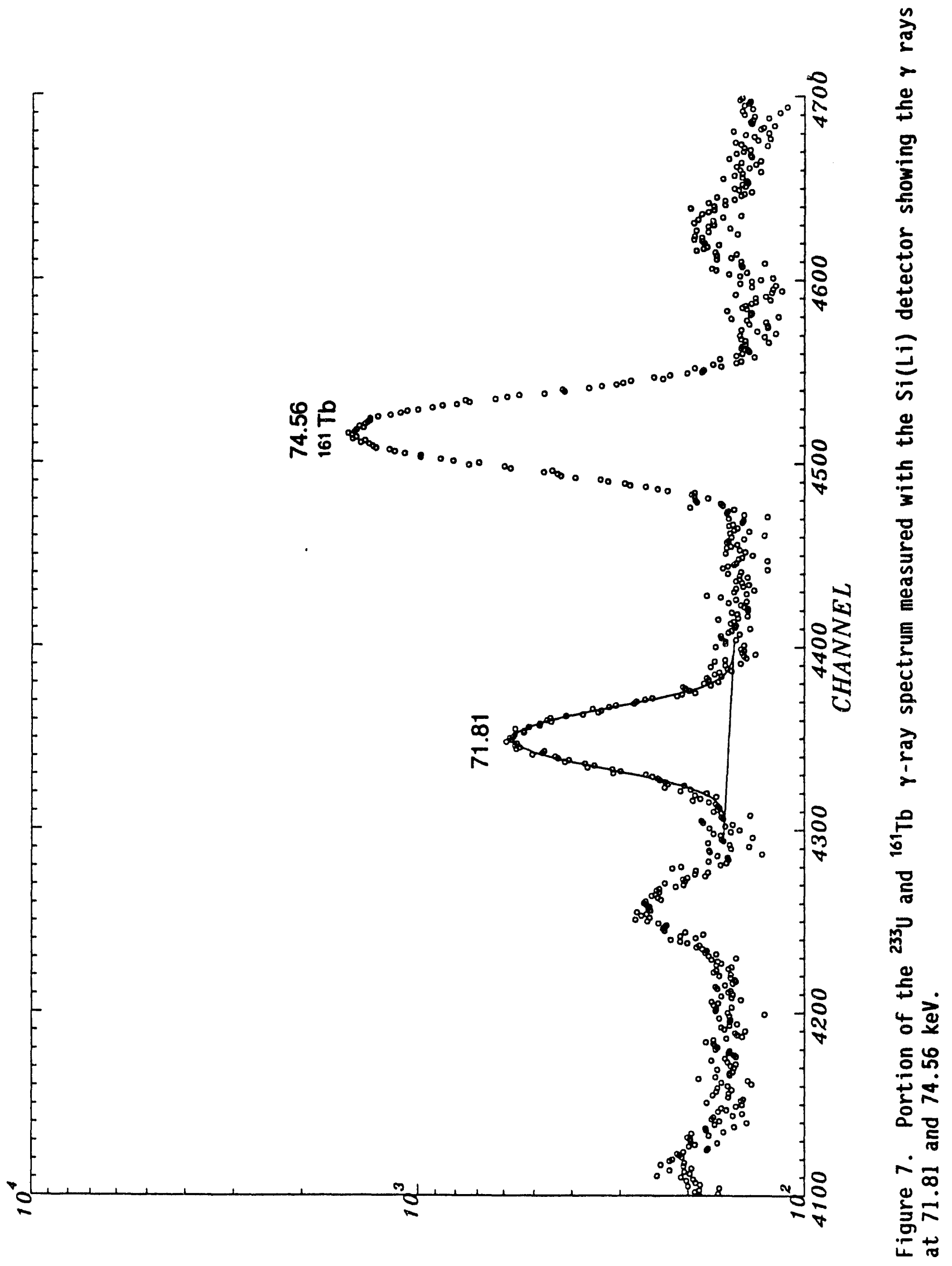




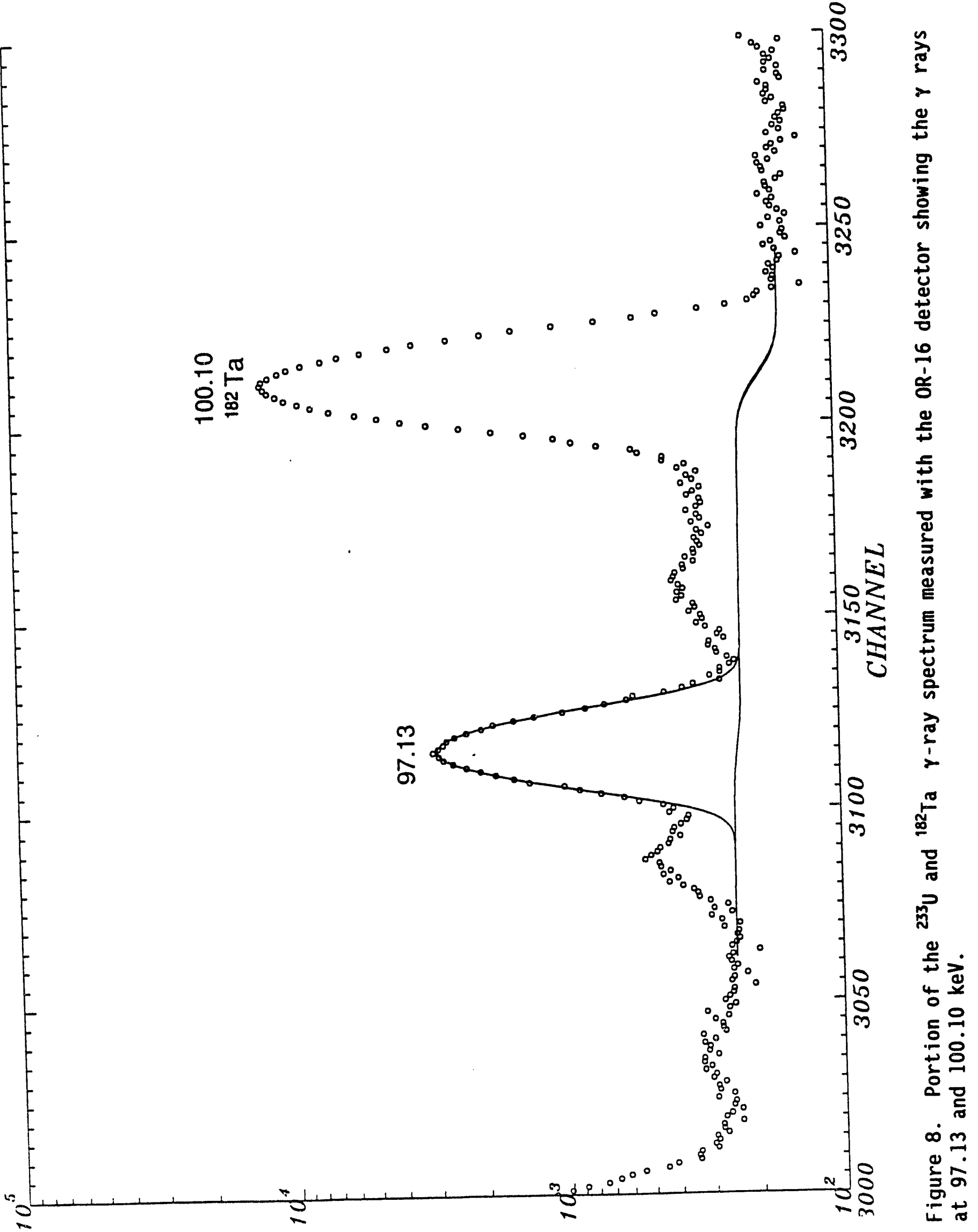




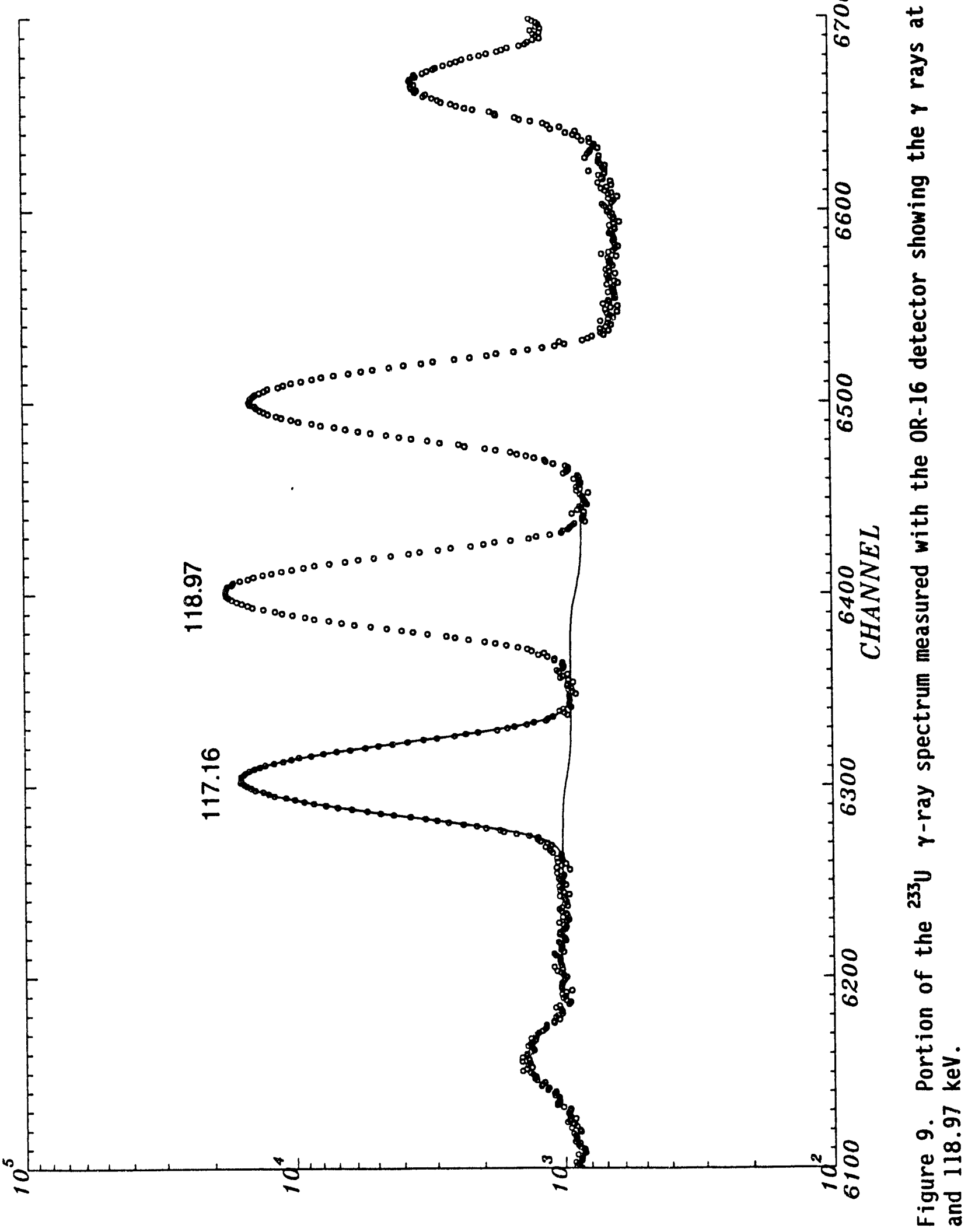




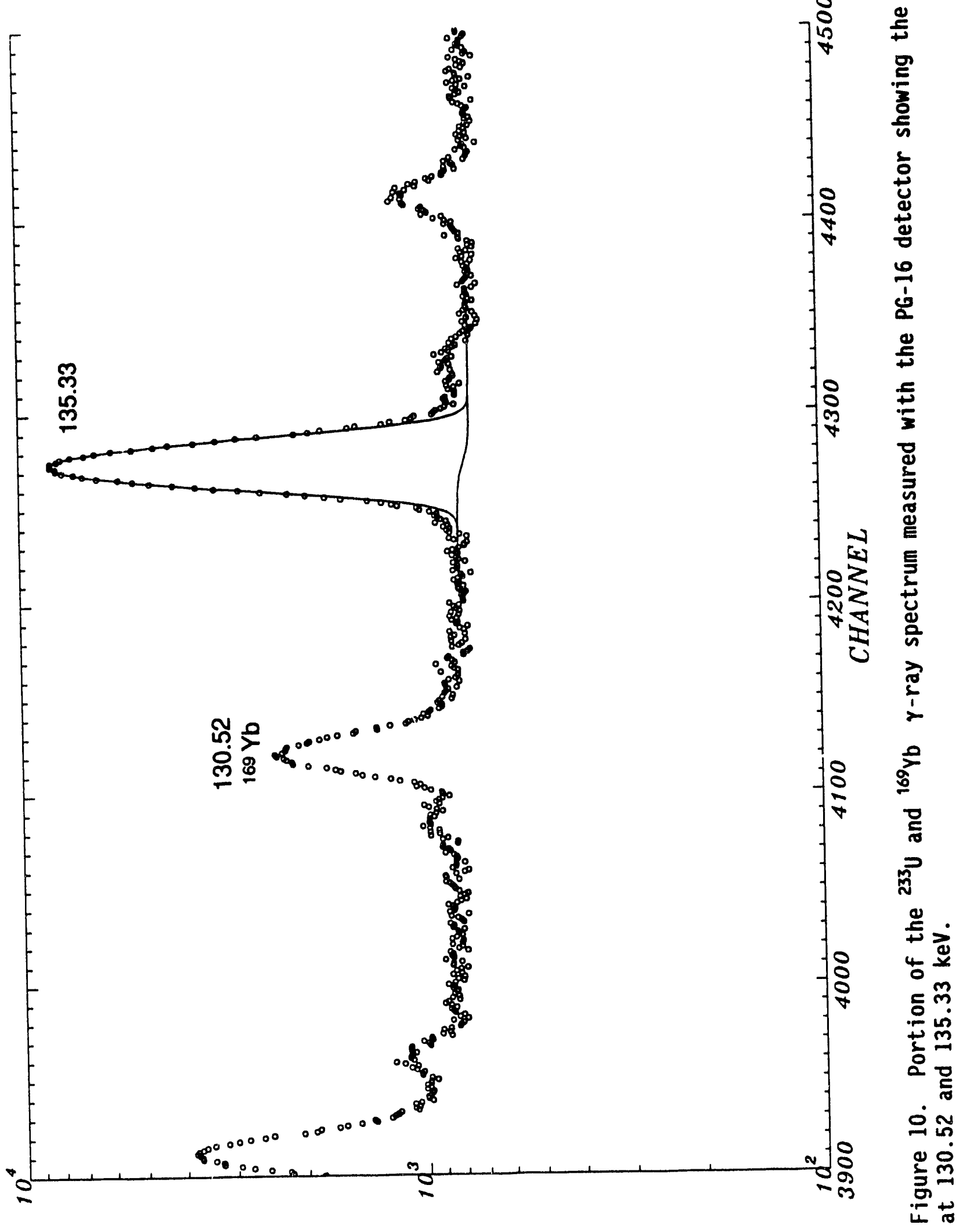




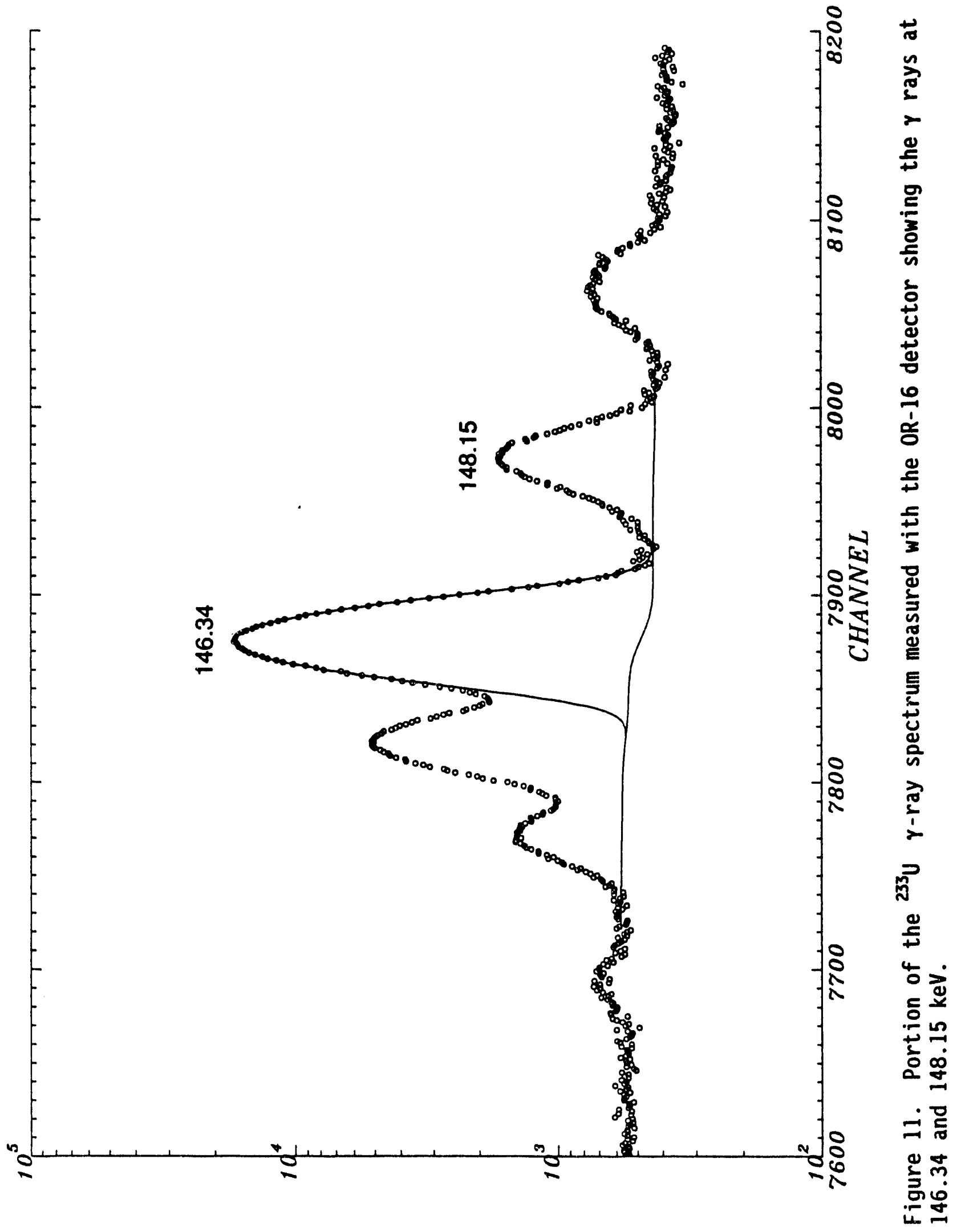




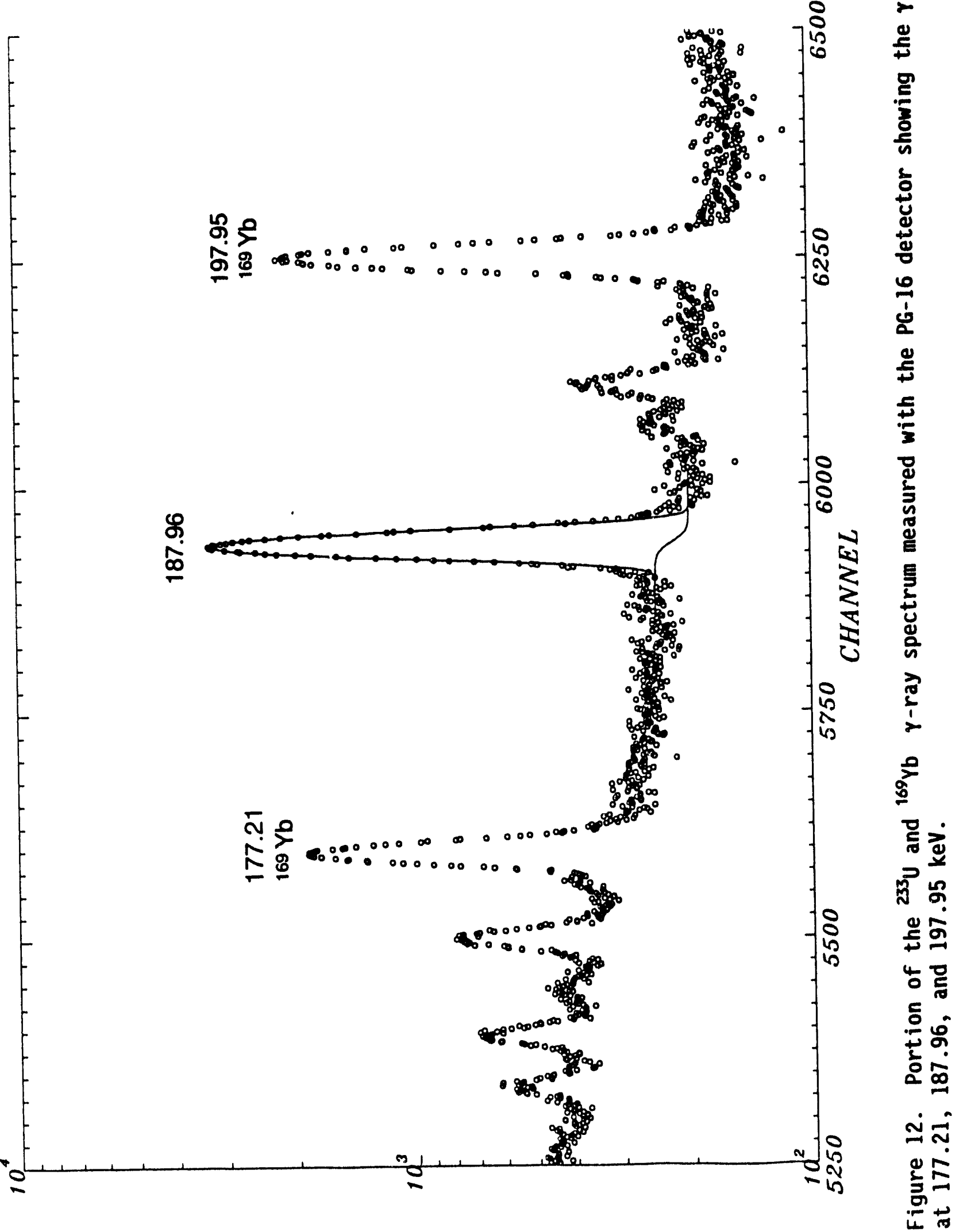




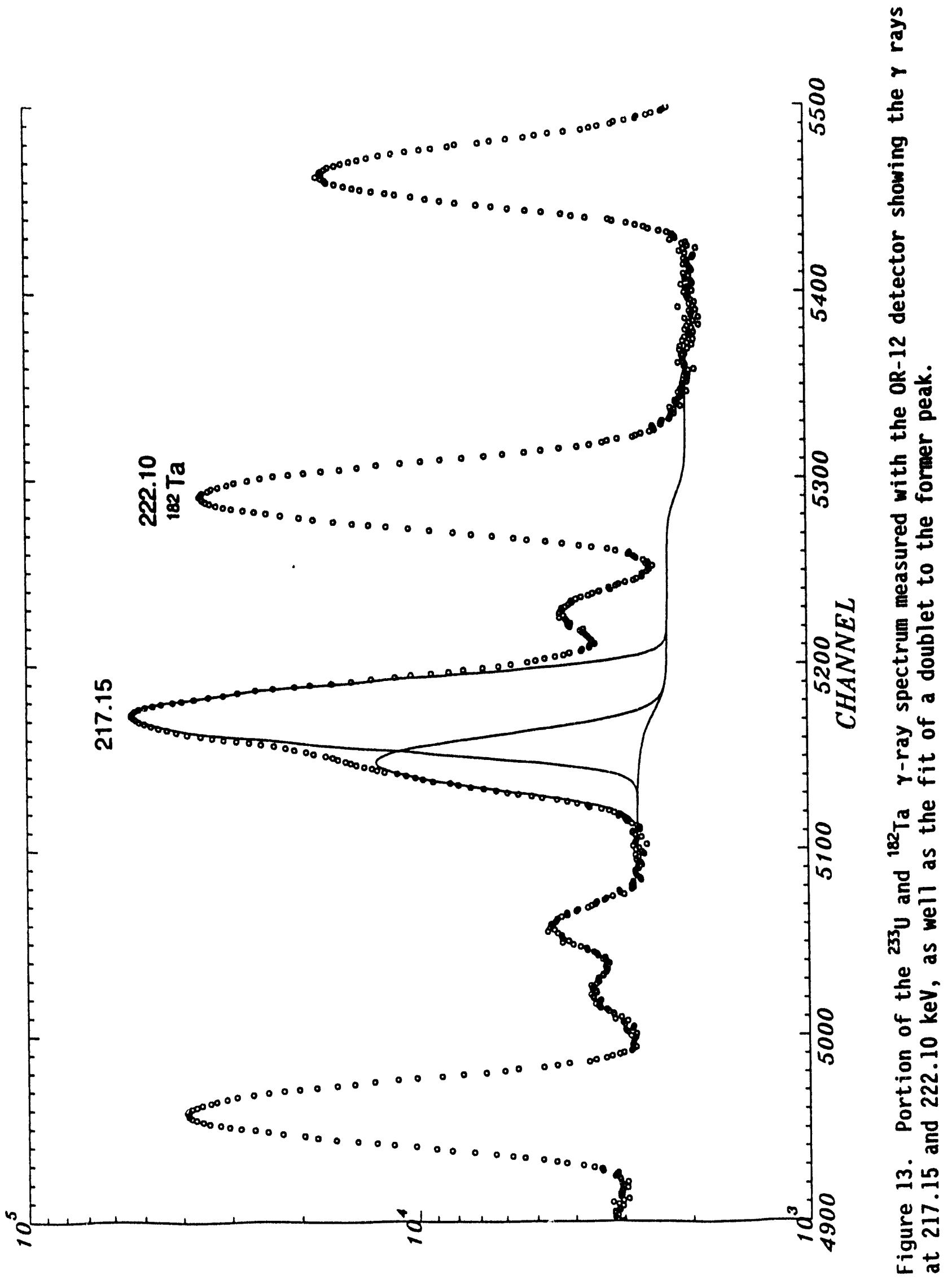




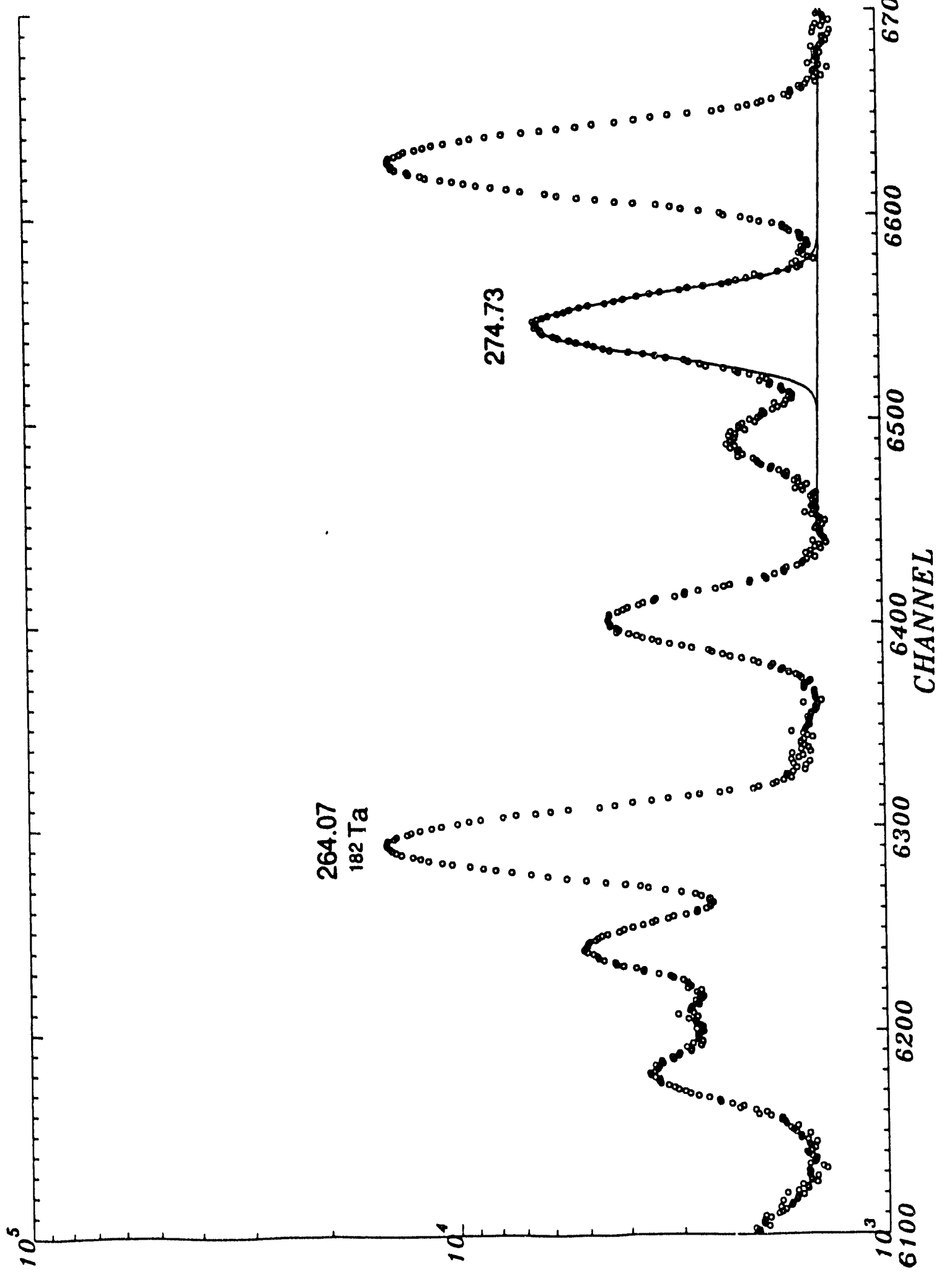

8

งิ

๘

E

वे

$\frac{1}{2}$

$\stackrel{\leftarrow}{\varpi}$

음

ले

完

4.

동

푼

융음

$\dot{-}$

눔

㞼茫 
made to this peak successively adding two channels (one on each side of the peak) to the fitting range, as shown in Table 19. The smallest fitting range, 9 channels, corresponds to the FWHM. In the analyses of the $\gamma$-ray peaks in this work, the fits are generally similar to the first two fitting ranges in this table. Similarly, four fits were made to the $100-\mathrm{keV}$ peak from ${ }^{182} \mathrm{Ta}$ in the same spectrum.

Since we fit the peaks with a symmetric Gaussian function, we expect the calculated peak position to shift to lower values as more channels are included on the low-energy side of any singlet peak. If the secondary peak on the low-energy side of the 97-keV line has any significant additional influence on the position of the main peak, we expect the shift of the calculated position of the $97-\mathrm{keV}$ peak to be larger than that of the more nearly singlet peak at $100 \mathrm{keV}$. The data in Table 19 show that there is no significant difference in the shifts observed between these two peaks as the fitting range is increased. From this, we conclude that any influence on the calculated position of the $97-\mathrm{keV}$ peak due to the presence of the peaks underlying it is less than about $0.5 \mathrm{eV}$.

In Figure 11, a pair of important peaks is shown; these are at 146 and 148 $\mathrm{keV}$. The 148-keV peak has the difficulty that it is relatively weak so it is hard to got good statistics and there is a small distortion on the low-energy side. In this case, the contribution of this peak to the uncertainty in any $\Delta E_{y}$ should be dominated by this statistical component. The 146-keV peak has the problem of the presence of the $145-\mathrm{keV}$ line. Only the top portion of the peaks are used in the fit to a singlet, and a Gaussian function without any tailing is used in the fit. If one were to fit the 145-146 pair as a doublet, one would include portions of each peak all the way down to the spectral background; and this would produce an unacceptable bias between the fits to $146-$ and 148-keV peaks. Therefore, a singlet fit to the $146-\mathrm{keV}$ peak is preferred. The difficulty in fitting the 146-keV peak is important since the energy difference between the 146- and 148-keV lines appears in two of the four energy combinations that are used to deduce $\Delta$.

As discussed above in regard to the $97-\mathrm{keV}$ peak, we have explored the change in the computed positions of the 146- and 152-keV peaks in spectrum of ${ }^{233} \mathrm{U}$ and ${ }^{152} \mathrm{Eu}$ in order to investigate the presence of possible systematic errors in the calculated position of the $146-\mathrm{keV}$ peak due to the presence of the near-lying 145-keV $\gamma$ peak (which was not specifically included in the analysis). We assume that any influence of the 145-keV peak would cause the shift in the calculated 146-keV peak position to be larger than that for the $152-\mathrm{keV}$ peak, which is a singlet. As shown in Table 19, no such effect is seen. Therefore, we conclude that any such influence is less than about 0.5 eV. 


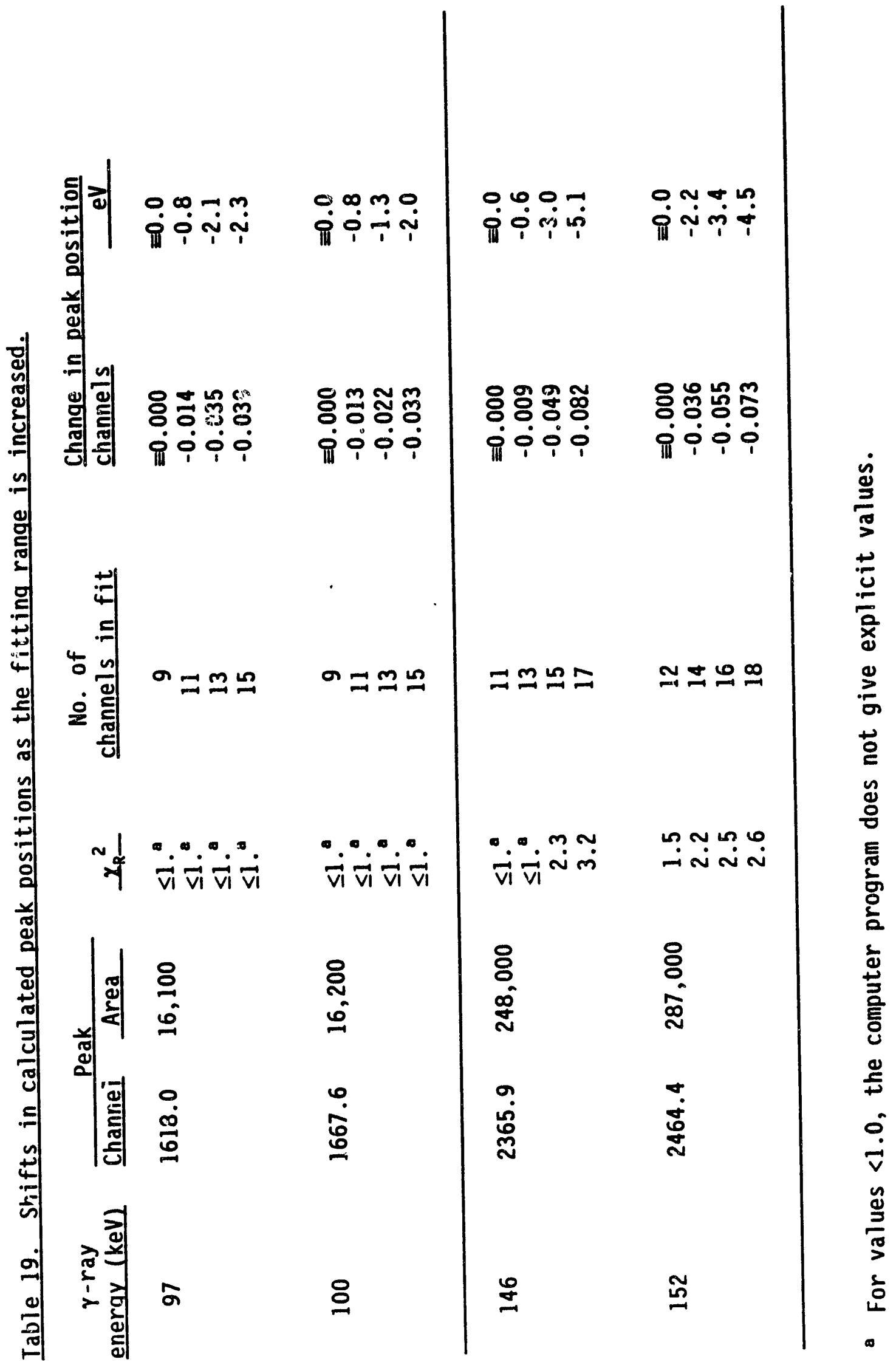


Since all four values of $\Delta$ to be discussed in Section 5 depend on either the 97-keV $\gamma$-ray energy or the 146-148 energy difference, our results depend critically on the fits to the lines in Figures 8 and 11 .

Figure 13 shows the difficulty of determining the energy of the 217-keV peak, which is part of a multiplet that is less well resolved than the others.

\section{$4.2 \gamma$-Ray Energies}

From the results in the previous section, the energies for many of the $\gamma$ rays from ${ }^{233} \mathrm{U}$ have been deduced. These results are given in Table 20.

In considering these results, the reader should understand that these energies have been determined by doing the calculations in a particular order. In some cases, the calculations could have been done in a different order, in which case some of the $\gamma$-ray energies would have been slightly different. To illustrate, assume we have the following set of data:

$$
\begin{aligned}
& \text { calibration line energies: } C_{1} \text { and } C_{2} \text { with } C_{1}<C_{2} \\
& \gamma \text { energies to be determined: } E_{1} \text { and } E_{2} \\
& \text { with } C_{1}<E_{1}<E_{2}<C_{2} \\
& \text { measurement results: } \Delta_{1}\left(E_{1}-C_{9}\right), \Delta_{2}\left(E_{2}-E_{1}\right) \text {, and } \Delta_{3}\left(C_{2}-E_{2}\right) \text {. }
\end{aligned}
$$

Then one can determine $E_{1}$ and $E_{2}$ from either of the following two sets of relationships.

$$
\begin{aligned}
& \text { (1) } E_{1}=C_{1}+\Delta_{1} \text { and } \\
& E_{2} \text { is the average of } C_{1}+\Delta_{1}+\Delta_{2} \text { and } C_{2}-\Delta_{3} \text {, }
\end{aligned}
$$

or

$$
\begin{aligned}
& E_{2}=C_{2}-\Delta_{3} \text { and } \\
& E_{1} \text { is the average of } C_{1}+\Delta_{1} \text { and } C_{2}-\Delta_{3}-\Delta_{2} .
\end{aligned}
$$

It would, of course, be possible to remove this bias of choosing a particular order for the calculations by doing a least-squares fit to each of the over-determined sets of data. To do such a fit correctly one would need to develop a covariance matrix for the measured $\Delta_{i}$ values because generally they will be highly correlated. For example, the same spectra might be used to determine $\Delta_{2}$ and, say, $\Delta_{3}$, Therefore, $\Delta_{2}$ and $\Delta_{3}$ would be correlated since the peak at $E_{2}$ is common to both. Such least-squares fits have not been done, in part, because it is felt that the improvement in the $\gamma$-ray energies would not be significant. 
In several cases in Table 20 , several values are averaged, with $1 / \sigma^{2}$ weighting, to obtain the final value. In most cases this weighting is not strictly correct since the individual values are often correlated, and this correlation has not been taken into account. For example, the average for the 187-keV $\gamma$ ray involves energy differences with respect to the 177- and 197-keV lines from ${ }^{169} \mathrm{Yb}$. These two values make use of the same $\gamma$-ray spectra and therefore the same 187-keV peaks. Thus, the two energy differences are not independent; and this is not taken into account in the calculation of the average. The effect of neglecting these correlations is that the computed uncertainty is smaller than it would be if the correlations were taken into account. 
Table 20. $\quad y$-ray energies for ${ }^{233} U$ lines

\begin{tabular}{|c|c|c|c|c|c|c|}
\hline \multirow{2}{*}{$\begin{array}{l}{ }^{233} \mathrm{U} \\
\text { Line } \\
\end{array}$} & \multicolumn{2}{|c|}{ Reference } & \multirow{2}{*}{$\begin{array}{c}\text { Adopted } \\
\Delta E_{\gamma}\end{array}$} & \multicolumn{3}{|c|}{$y$-ray energy } \\
\hline & Nuclide & Energy & & Value & Average & $x_{R}^{2}$ \\
\hline 25 & $\begin{array}{l}{ }^{249} \mathrm{Am} \\
{ }^{172} \mathrm{Hf}\end{array}$ & $\begin{array}{l}26.3448(2) \\
23.9331(2)\end{array}$ & $\begin{array}{l}1.0340(9) \\
1.3771(16)\end{array}$ & $\begin{array}{l}25.3108(9) \\
25.3101(16)\end{array}$ & $25.3106(8)$ & 0.15 \\
\hline 29 & $\begin{array}{l}{ }^{182} \mathrm{Ta} \\
{ }^{172} \mathrm{Hf} \\
{ }^{241} \mathrm{Am}\end{array}$ & $\begin{array}{l}31.7378(7) \\
23.9331(2) \\
26.3448(2)\end{array}$ & $\begin{array}{l}2.5482(10) \\
5.2489(9) \\
2.8397(4)\end{array}$ & $\begin{array}{l}29.1896(12) \\
29.1820(9) \\
29.1845(5)\end{array}$ & $29.1846(30)^{\mathrm{a}}$ & 12.9 \\
\hline 42 & $\begin{array}{l}{ }^{210} \mathrm{~Pb} \\
{ }^{182} \mathrm{Ta} \\
{ }^{161} \mathrm{~Tb} \\
{ }^{233} \mathrm{U}\end{array}$ & $\begin{array}{l}46.539(1) \\
31.7378(7) \\
48.91562(6) \\
54.7038(7)\end{array}$ & $\begin{array}{r}4.0862(6) \\
10.7181(9) \\
6.4642(4) \\
12.2510(4)\end{array}$ & $\begin{array}{l}42.453(1) \\
42.4559(11) \\
42.4518(4) \\
42.4528(15)\end{array}$ & $42.4524(7)^{b}$ & 4.27 \\
\hline 53 & $\begin{array}{l}210 \mathrm{pb} \\
{ }^{233} \mathrm{U}\end{array}$ & $\begin{array}{l}46.539(1) \\
54.7038(7)\end{array}$ & $\begin{array}{l}7.0708(12) \\
1.0927(3)\end{array}$ & $\begin{array}{l}53.610(2) \\
53.6111(14)\end{array}$ & $53.6107(11)$ & 0.20 \\
\hline 54 & $\begin{array}{l}{ }^{210} \mathrm{~Pb} \\
241 \mathrm{Am} \\
{ }^{169} \mathrm{Yb} \\
{ }^{161} \mathrm{~Tb}\end{array}$ & $\begin{array}{l}46.539(1) \\
59.5412(2) \\
63.1208(1) \\
48.91562(6)\end{array}$ & $\begin{array}{l}8.1640(5) \\
4.8374(2) \\
8.4202(7) \\
5.7890(3)\end{array}$ & $\begin{array}{l}54.703(1) \\
54.7036(4) \\
54.7006(7) \\
54.7046(3)\end{array}$ & $54.7038(14)^{a}$ & 9.63 \\
\hline 66 & $\begin{array}{l}{ }^{241} \mathrm{Am} \\
{ }^{169} \mathrm{Yb}\end{array}$ & $\begin{array}{l}59.5412(2) \\
63.1208(1)\end{array}$ & $\begin{array}{l}6.5777(6) \\
2.9968(8)\end{array}$ & $\begin{array}{l}66.1189(6) \\
66.1176(8)\end{array}$ & $66.1184(6)$ & 1.69 \\
\hline 67 & $\begin{array}{l}241 \mathrm{Am} \\
{ }^{269} \mathrm{Yb} \\
233 \mathrm{U}\end{array}$ & $\begin{array}{l}59.5412(2) \\
63.1208(1) \\
66.1184(6)\end{array}$ & $\begin{array}{l}8.4048(12) \\
4.8252(10) \\
1.8276(4)\end{array}$ & $\begin{array}{l}67.9460(12) \\
67.9460(10) \\
67.9460(7)\end{array}$ & $67.9460(5)$ & 0.00 \\
\hline 70 & $\begin{array}{l}{ }^{169} \mathrm{Yb} \\
{ }^{233} \mathrm{U}\end{array}$ & $\begin{array}{l}63.1208(1) \\
71.8159(20)\end{array}$ & $\begin{array}{l}7.1614(16) \\
1.5362(6)\end{array}$ & $\begin{array}{l}70.2822(16) \\
70.2797(21)\end{array}$ & $70.2813(13)$ & 0.90 \\
\hline 71 & $\begin{array}{l}241 \mathrm{Am} \\
{ }^{169} \mathrm{Yb} \\
{ }^{161} \mathrm{~Tb}\end{array}$ & $\begin{array}{l}59.5412(2) \\
63.1208(1) \\
74.56711(10)\end{array}$ & $\begin{array}{l}12.2719(10) \mathrm{N} \\
8.6947(4) \\
2.7492(6)\end{array}$ & $\begin{array}{c}A m^{7} 1.8131(10) \\
71.8155(4) \\
71.8179(6)\end{array}$ & $71.8159(20)^{\mathrm{a}}$ & 9.97 \\
\hline 74 & $\begin{array}{l}{ }^{182} \mathrm{Ta} \\
{ }^{170} \mathrm{Tm} \\
233 \mathrm{U} \\
233 \mathrm{U}\end{array}$ & $\begin{array}{l}84.6808(3) \\
84.2551(2) \\
71.8159(20) \\
76.3507(27)\end{array}$ & $\begin{array}{c}10.1273(24) \\
9.7172(6) \\
2.7242(3) \\
1.8099(8)\end{array}$ & $\begin{array}{l}74.5535(24) \\
74.5379(6) \\
74.5401(20) \\
74.5408(28)\end{array}$ & $74.5390(40)^{\mathrm{a}}$ & 13.5 \\
\hline 76 & $\begin{array}{l}{ }^{182} \mathrm{Ta} \\
{ }^{170} \mathrm{Tm}\end{array}$ & $\begin{array}{l}84.6808(3) \\
84.2551(2)\end{array}$ & $\begin{array}{l}8.3218(49) \\
7.9053(16)\end{array}$ & $\begin{array}{l}76.359(5) \\
76.3498(16)\end{array}$ & $76.3507(27)$ & 3.07 \\
\hline 83 & ${ }^{170} \mathrm{Tm}$ & $84.2551(2)$ & $1.2423(20)$ & $83.0128(20)$ & & \\
\hline
\end{tabular}


Table 20. (Continued)

\begin{tabular}{|c|c|c|c|c|c|c|}
\hline \multirow{2}{*}{$\begin{array}{l}233 \mathrm{U} \\
\text { Line }\end{array}$} & \multicolumn{2}{|c|}{ Reference } & \multirow{2}{*}{$\begin{array}{c}\text { Adopted } \\
\mathrm{AE}_{\gamma}-\end{array}$} & \multicolumn{3}{|c|}{$y$-ray energy } \\
\hline & Nuclide & Energy & & Value & Average & $x_{R}^{2}$ \\
\hline 85 & ${ }^{170} \mathrm{Tm}$ & $84.2551(2)$ & $1.1673(17)$ & $85.4224(17)$ & & \\
\hline 88 & ${ }^{170} \mathrm{Tm}$ & $84.2551(2)$ & $4.2195(14)$ & $88.4746(14)$ & & \\
\hline 89 & $\begin{array}{l}{ }^{170} \mathrm{Tm} \\
{ }^{182} \mathrm{Ta} \\
{ }^{233} \mathrm{U}\end{array}$ & $\begin{array}{l}84.2551(2) \\
84.6808(3) \\
93.3502(3)\end{array}$ & $\begin{array}{l}5.6995(5) \\
5.2785(10) \\
3.3924(3)\end{array}$ & $\begin{array}{l}89.9546(5) \\
89.9593(10) \\
89.9578(4)\end{array}$ & $89.9568(24)^{a}$ & 15.9 \\
\hline 93 & ${ }^{233} \mathrm{U}$ & $97.1344(3)$ & $3.7842(1)$ & $93.3502(3)$ & & \\
\hline 97 & ${ }^{182} \mathrm{Ta}$ & $100.1065(2)$ & $2.9721(2)$ & $97.1344(3)$ & & \\
\hline 117 & ${ }^{182} \mathrm{Ta}$ & $\begin{array}{l}113.6723(2) \\
118.9721(15)\end{array}$ & $\begin{array}{l}3.4905(12) b \\
1.8092(2)\end{array}$ & $\begin{array}{r}\text { d } 17.1628(12) \\
117.1629(15)\end{array}$ & $117.1628(9)$ & 0.00 \\
\hline 118 & $\begin{array}{l}182 \mathrm{Ta} \\
233 \mathrm{U}\end{array}$ & $\begin{array}{l}113.6723(2) \\
120.8194(7)\end{array}$ & $\begin{array}{l}5.2973(12) \\
1.8464(2)\end{array}$ & $\begin{array}{l}118.9696(12) \\
118.9730(7)\end{array}$ & $118.9721(15)$ & 5.99 \\
\hline 120 & $\begin{array}{l}169 \mathrm{Yb} \\
233 \mathrm{U}\end{array}$ & $\begin{array}{l}130.5237(0) \\
135.3393(5)\end{array}$ & $\begin{array}{c}9.7036(13) \\
14.5202(6)\end{array}$ & $\begin{array}{l}120.8201(13) \\
120.8191(8)\end{array}$ & $120.8194(7)$ & 0.43 \\
\hline 123 & $\begin{array}{l}{ }^{169} \mathrm{Yb} \\
{ }^{233} \mathrm{U}\end{array}$ & $\begin{array}{l}130.5237(0) \\
120.8194(7)\end{array}$ & $\begin{array}{l}6.6370(13) \\
3.0663(4)\end{array}$ & $\begin{array}{l}123.8867(13) \\
123.8857(8)\end{array}$ & $123.8860(7)$ & 0.43 \\
\hline 135 & ${ }^{169} \mathrm{Yb}$ & $130.5237(0)$ & $4.8156(5)$ & $135.3393(5)$ & & \\
\hline 139 & $\begin{array}{l}{ }^{169} \mathrm{Yb} \\
233 \mathrm{U}\end{array}$ & $\begin{array}{l}130.5237(0) \\
135.3393(5)\end{array}$ & $\begin{array}{l}9.2135(50) \\
4.3863(23)\end{array}$ & $\begin{array}{l}139.7372(50) \\
139.7256(24)\end{array}$ & $139.7278(45)$ & 4.37 \\
\hline 146 & $\begin{array}{l}{ }^{169} \mathrm{Yb} \\
{ }^{182} \mathrm{Ta} \\
{ }^{182} \mathrm{Ta}\end{array}$ & $\begin{array}{l}130.5237(0) \\
152.4308(3) \\
156.3874(3)\end{array}$ & $\begin{array}{c}15.8228(25) \\
6.0848(7) \\
10.0410(8)\end{array}$ & $\begin{array}{l}146.3465(25) \\
146.3460(8) \\
146.3464(9)\end{array}$ & $146.3462(6)$ & 0.06 \\
\hline 164 & $\begin{array}{l}{ }^{169} \mathrm{Yb} \\
{ }^{182} \mathrm{Ta} \\
{ }^{182} \mathrm{Ta} \\
{ }^{182} \mathrm{Ta}\end{array}$ & $\begin{array}{l}177.2140(1) \\
152.4308(3) \\
156.3874(3) \\
179.3948(3)\end{array}$ & $\begin{array}{c}12.6905(10) \\
12.0932(8) \\
8.1372(9) \\
14.8711(9)\end{array}$ & $\begin{array}{l}164.5235(10) \\
164.5240(9) \\
164.5246(9) \\
164.5237(9)\end{array}$ & $164.5240(5)$ & 0.27 \\
\hline 169 & ${ }^{169} \mathrm{Yb}$ & $177.2140(1)$ & $8.2123(54)$ & $169.002(5)$ & & \\
\hline 170 & ${ }^{169} \mathrm{Yb}$ & $177.2140(1)$ & $6.4049(24)$ & $170.8091(24)$ & & \\
\hline 174 & ${ }^{169} \mathrm{Yb}$ & $177.2140(1)$ & $3.0221(20)$ & $174.1919(20)$ & & \\
\hline & & & & 37 & & \\
\hline
\end{tabular}


Table 20. (Continued)

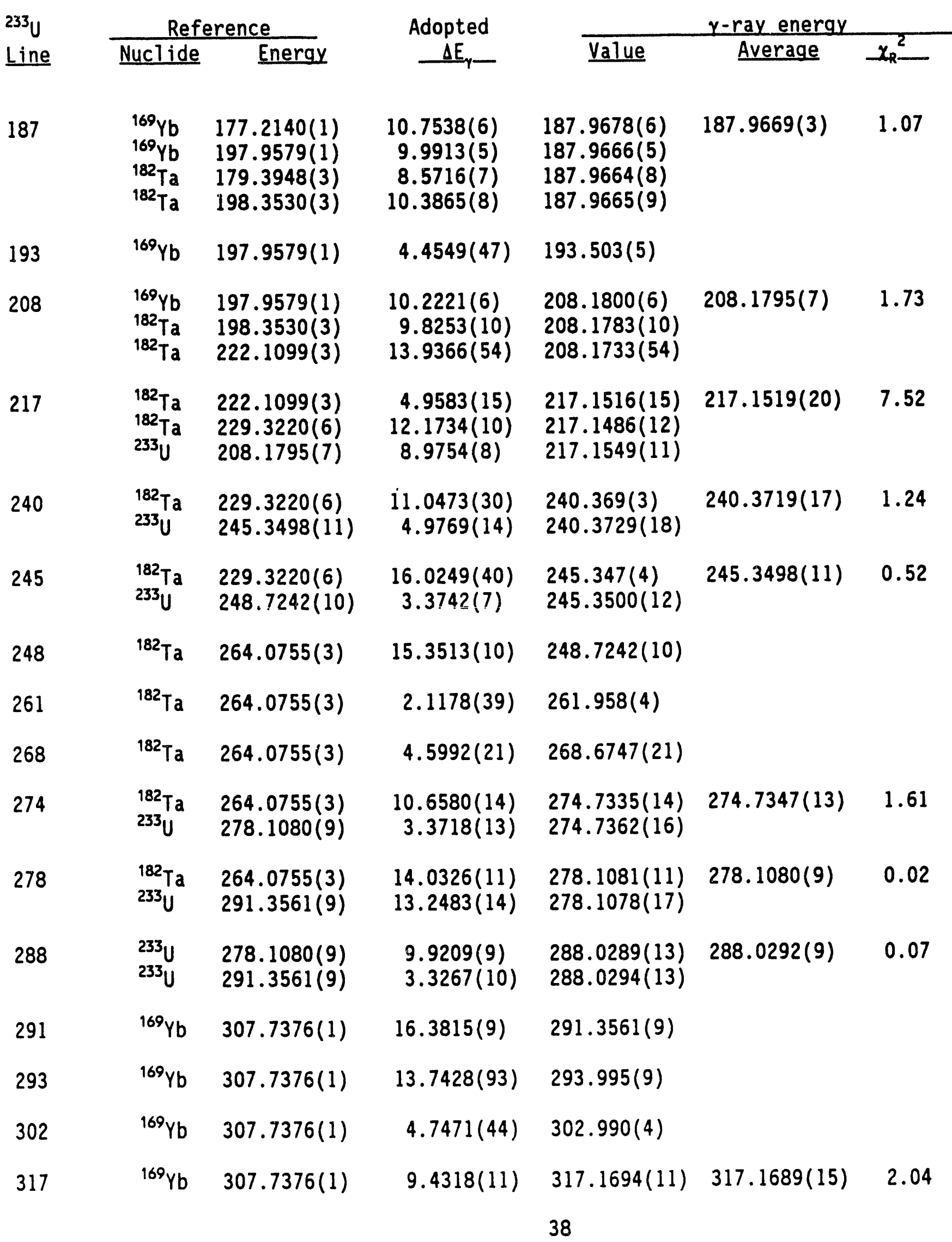


Table 20. (Continued)

\begin{tabular}{|c|c|c|c|c|c|c|}
\hline \multirow{2}{*}{$\begin{array}{l}{ }^{233} \mathrm{U} \\
\text { Line }\end{array}$} & \multicolumn{2}{|c|}{ Reference } & \multirow{2}{*}{$\begin{array}{c}\text { Adopted } \\
\Delta E_{\gamma}\end{array}$} & \multicolumn{3}{|c|}{$y$-ray energy } \\
\hline & $\begin{array}{l}\text { Rete } \\
\text { Nuclide }\end{array}$ & $\frac{\text { rence }}{\text { Energy }}$ & & Value & Average & $\underline{x}_{R}^{2}$ \\
\hline & ${ }^{152} \mathrm{Eu}$ & $344.2811(19)$ & $27.1168(28)$ & $317.1643(34)$ & & \\
\hline 320 & $\begin{array}{l}{ }^{169} \mathrm{Yb} \\
152 \mathrm{Eu} \\
233 \mathrm{U}\end{array}$ & $\begin{array}{l}307.7376(1) \\
344.2811(19) \\
317.1689(15)\end{array}$ & $\begin{array}{c}12.8102(11) \\
23.7410(28) \\
3.3782(4)\end{array}$ & $\begin{array}{l}320.5478(11) \\
320.5401(34) \\
320.5471(16)\end{array}$ & $320.5471(13)$ & 2.32 \\
\hline 323 & $\begin{array}{l}{ }^{152} \mathrm{Eu} \\
{ }^{233} \mathrm{U}\end{array}$ & $\begin{array}{l}344.2811(19) \\
320.5471(13)\end{array}$ & $\begin{array}{c}20.9013(27) \\
2.8337(9)\end{array}$ & $\begin{array}{l}323.3798(33) \\
323.3808(16)\end{array}$ & $323.3806(14)$ & 0.07 \\
\hline 328 & ${ }^{233} \mathrm{U}$ & $323.3806(14)$ & $5.3779(44)$ & $328.758(5)$ & & \\
\hline 336 & $\begin{array}{l}152 \mathrm{Eu} \\
233 \mathrm{U}\end{array}$ & $\begin{array}{l}344.2811(19) \\
323.3806(14)\end{array}$ & $\begin{array}{r}7.6639(19) \\
13.2400(13)\end{array}$ & $\begin{array}{l}336.6172(27) \\
336.6206(19)\end{array}$ & $336.6195(16)$ & 1.06 \\
\hline 365 & ${ }^{152} \mathrm{Eu}$ & $344.2811(19)$ & $21.5394(29)$ & $365.8205(35)$ & & \\
\hline & $\begin{array}{l}{ }^{152} \mathrm{Eu} \\
{ }^{233} \mathrm{U}\end{array}$ & $\begin{array}{l}344.2811(19) \\
365.8205(35)\end{array}$ & $\begin{array}{c}23.5095(95) \\
1.9809(117)\end{array}$ & $\begin{array}{l}367.791(10) \\
367.801(12)\end{array}$ & $367.795(8)$ & 0.41 \\
\hline
\end{tabular}

Calculated uncertainty has been increased by a factor of 2.0 due to the large $x_{R}^{2}$ value. b Known doublet (see text), so the measured peak energy may vary with detector resolution. 


\section{ENERGY RELATIONSHIPS IN ${ }^{229} \mathrm{TH}$}

There are several interesting relationships among the energies of the $\gamma$ rays in ${ }^{229}$ Th to be discussed before the energy of first excited state is determined. First, we should comment on the cascade-crossover relationship involving the first three levels in the ground-state rotational band. As shown in Figure 1 , this includes the 42- and 54-keV $\gamma$-ray cascade and the $97-$ $\mathrm{keV}$ crossover involving the levels at 0,42 , and $97 \mathrm{keV}$. In our previous article $e^{2}$ we did not use this relationship because there was reasonable evidence that the observed $42-\mathrm{keV}$ peak had two components. $\gamma-\gamma$ coincidence data ${ }^{1}$ imply the existence a weaker $42-\mathrm{keV} \gamma \mathrm{ra}$. between the levels at 71.8 and $29.1 \mathrm{keV}$, although this $\gamma$ ray was not directly observed. From the level energies deduced without use of the $42-\mathrm{keV}$ lines, the energy of the weaker $\gamma$ ray is $200 \mathrm{eV}$ higher than that of the ground-state $\gamma$ ray. Previous attempts to observe the doublet nature of the $42-\mathrm{keV}$ peak were unsuccessful. However, with improved resolution of the $0 R-16$ detector, we have been able to observe a difference between the shape of the $42-\mathrm{keV}$ peak and those of the neighboring strong peaks. This is illustrated in Figure 15, where 15A shows that the 59$\mathrm{keV}$ peak from ${ }^{241} \mathrm{Am}$ is well fit by a Gaussian function and $15 \mathrm{~B}$ shows that the 42-keV peak deviates from a Gaussian function in a manner which implies the existence of a second component on the high-energy side of the main peak. Since both of these peaks. are in the same spectrum and have similar peak-tocontinuum ratios, we are satisfied that the $42-\mathrm{keV}$ peak is a doublet, and that the weaker component has the higher energy, as expected.

The remaining analysis depends critically on deductions related to the relative intensities of certain possible $\gamma$ rays in the ${ }^{229} \mathrm{Th}$ level scheme. In order to be able to deduce the value of $\Delta$, the energy of the first excited state, the $\gamma$ rays that populate the levels at 0 or $\Delta$ keV must populate only one of them with significant intensity. In Reference 23, this question has been discussed in some detail, and it has been deduced that these lines are sufficiently pure (possible "contaminants" weaker by factors of the order of 10) for the purposes of this analysis. These arguments are not repeated here.

As shown in Figure 1 , there are a few relationships among the $\gamma$-ray energies reported in Table 20 that can be used to provide checks on the quality or consistency of these results. In the relationships (see Section 1) that we will use to determine the energy of the ${ }^{229}$ Th first excited state, the first two require that

$$
E(71)-E(67)=E(29)-E(25) \text {. }
$$




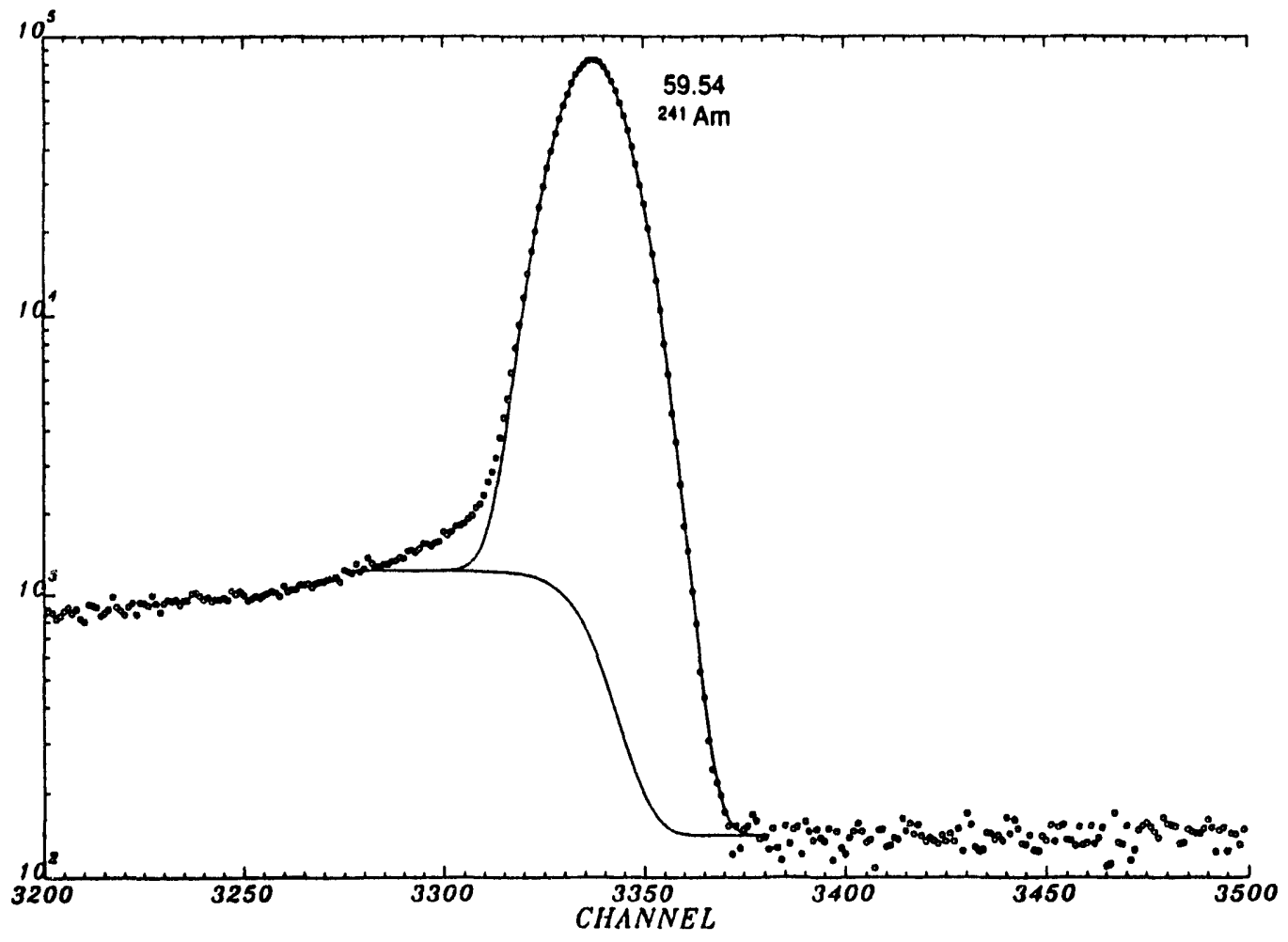

- (a)

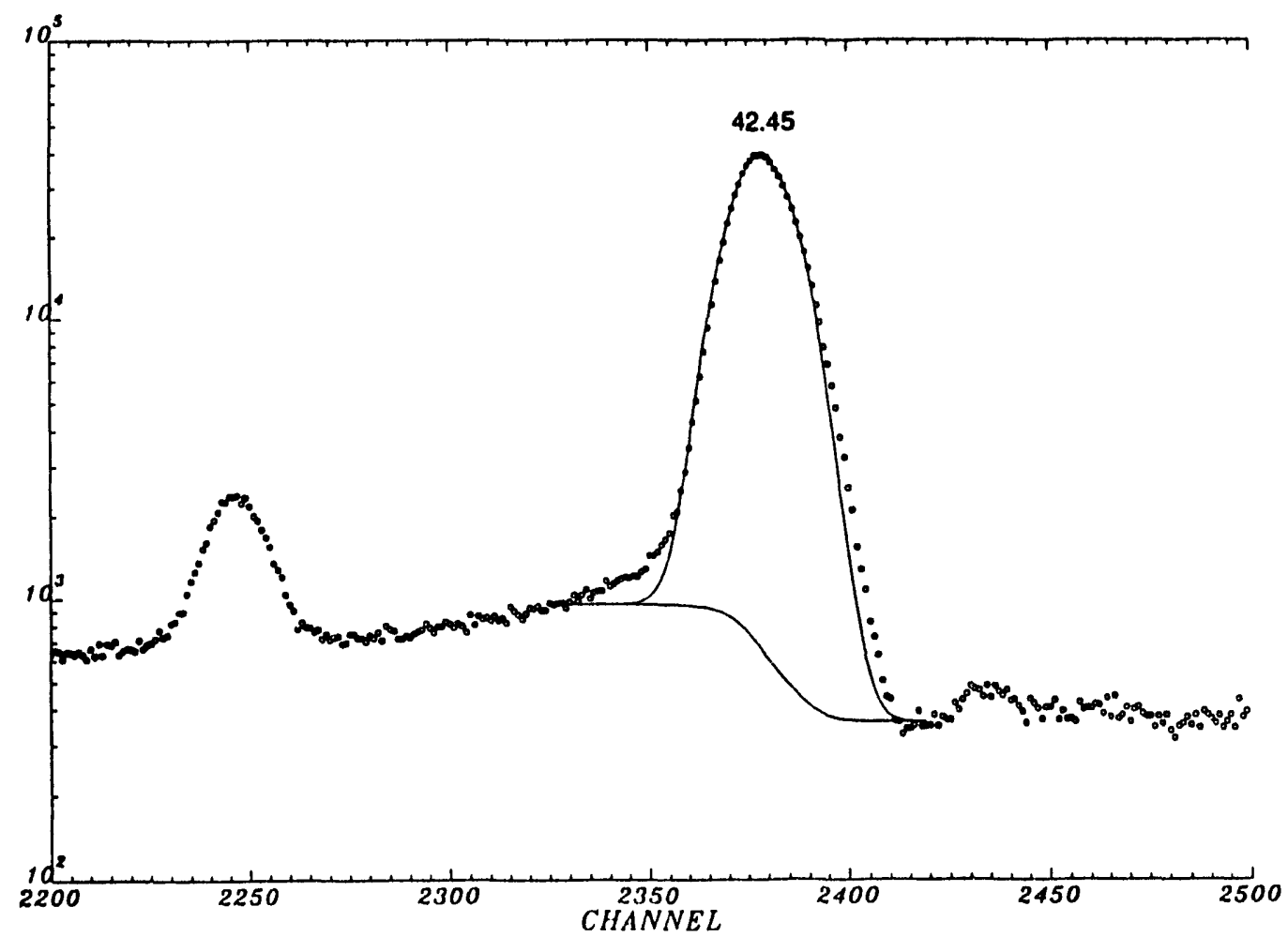

(b)

Figure 15. Gaussian fits to peaks at $59 \mathrm{keV}$, a singlet from ${ }^{241} \mathrm{Am}$, and 42 $\mathrm{keV}$, a doublet from ${ }^{233} \mathrm{U}$. 
From Table 18a and $18 \mathrm{~b}$, these two differences, as directly determined, are 3.8685(4) and $3.8701(4) \mathrm{keV}$, respectively. Although these two values differ by $0.0016(6) \mathrm{keV}$, more than the associated uncertainty, this is not unreasonable considering the weakness of the 25- and 67-keV peaks as shown in Figures 3, 4, and 6. (The 29- and 71-keV lines are the ones that, from spin-parity considerations, potentially could be doublets feeding the 0 - and $\Delta$-kev levels.)

There are two cascade-crossover combinations that can also be used to test the consistency of the ${ }^{233} U \gamma$-ray energies. These combinations are shown in Figure 1. The corresponding differences between the cascade and crossover energies are shown in Table 21. Both of these values are consistent with zero, and their uncertainties are dominated by that of the 29-keV 1 ine, which is $0.0030 \mathrm{keV}$. If one assumes that these relations are actually zero, one can use th $m$ to deduce the energy of this $y$ ray. The two resulting values are $29.1850(20)$ and $29.1847(7) \mathrm{keV}$, and their average is $29.1847(7) \mathrm{keV}$. Then, from the $25 \mathrm{U}$ - $29 \mathrm{U}$ difference in Table 18a, one can deduce an energy of $25.3146(8) \mathrm{keV}$ for the $25-\mathrm{keV}$ line.

From the $\gamma$-ray energies that we have determined, there are four energy combinations that can be used to obtain the energy of the first-excited level in ${ }^{229} \mathrm{Th}$. These relationships are shown in Figure 1 . The energies from these combinations are shown in Table 22. All four values show a positive energy for this level, in contrast to the result of Reference 2 where two of the three combinations gave negative values. For the first two relations, two values are given - one from the values in Table 20 for $E_{y}(25)$ and $E_{y}(29)$ and the other from the values deduced in the previous paragraph for these two lines.

Several average values are given in Table 22. The unweighted averages are given to show the influence of the weight resulting from the smaller uncertainty for the value of $0.0036(6)$ from the third relation. The next line gives the weighted averages based on the uncertainties given.

Table 21. Difference between crossover and cascade energies.

1 rays (keV) $\quad$ Difference $(\mathrm{keV})$

$217-187-29+0.0004(36)$

$164-135-29+0.0001(31)$ 
Table 22. Energy of ${ }^{229} \mathrm{Th}$ first excited level. A.

$y$ rays $(\mathrm{keV})$

97-71-25

97-67-29

[148-146] - [118-117]

[148-146] - [76-74]

Unweighted average

Weighted average

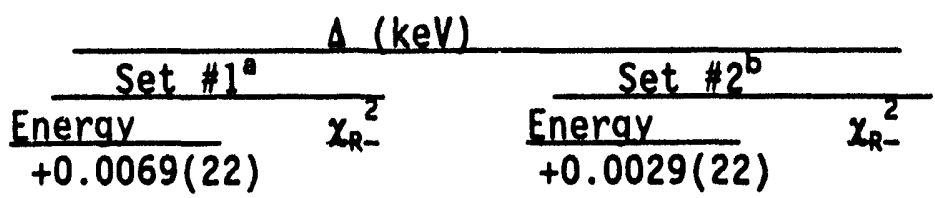

$+0.0028(31)$

$+0.0027(9)$

$+0.0036(6)$

$+0.0029(10)$

$+0.0040(10)$

$+0.0030(2)$

$+0.0036(5)$

0.93

$+0.0032(4) \quad 0.29$

- The energies for $E_{y}(25)$ and $E_{y}(29)$ are from Table 20.

b The energies for $E_{y}(25)$ and $E_{y}(29)$ are derived in the text from the computed 217-187 and 164-135 differences for the 29 line and from the measured $29-25$ (Table 18a) difference for the 25 line.

\section{CONCLUSION}

From the results in Table 22, we have adopted an energy of $0.0035(10) \mathrm{keV}$ for the first excited state of ${ }^{229} \mathrm{Th}$. This value has been taken from the two averages in the last line of the table, with the uncertainty increased by a factor of 2.0 to allow for any unidentified systematic errors. 


\section{REFERENCES}

1. L. A. Kroger and C. W. Reich, Nucl. Phys. A259, 29 (1976); L. A. Kroger, $\mathrm{Ph}$. D. thesis, University of Wyoming, 1971 (unpublished).

2. C. W. Reich and R. G. Helmer, Phys. Rev. Lett. 64, 271 (1990).

3. V. F. Strizhov and E. V. Tkalya, Sov. Phys. JETP 72, No. 3, 387 (1991).

4. E. V. Tkalya, Sov. Phys. JETP Lett. 55, 211 (1992).

5. F. F. Karpeshin, I. M. Band, M. B. Trzhaskowskaya and B. A. Zon, Phys. Lett. B282, 267 (1992).

6. E. V. Tkalya, contribution to Proc. III Int. Symposium on Weak and Electromagnetic Interactions, WEIN-92 (Dubna, 1992).

7. E. V. Tkalya, Yad. Fiz. 56, 2881 (1992).

8. S. Wycech and J. Zylicz, Erontier Topics in Nuclear and Astrophysics (IOP Publishing Ltd., Bristol 1992) p. 365

9. R. G. Helmer, R. J. Gehrke and R. C. Greenwood, Nucl. Instr. and Meth. 123, 51 (1975).

10. R. G. Helmer, P. H. M. Van Assche, and C. van der Leun, Atomic Data and Nucl. Data Tables 24, 39 (1979).

11. E. G. Kessler, R. D. Deslattes, A. Henins, and W. C. Sauder, Phys. Rev. Lett. 40, 171 (1978).

12. R. G. Helmer, accepted for publication in Nucl. Instr. and Meth.

13. R. G. Helmer, A. J. Caffrey, R. J. Gehrke and R. C. Greenwood, Nucl. Instr. and Meth. 188, 671 (1981).

14. B. Jeckelmann, W. Beer, G. De Chambrier, O. Elsenhans, K. L. Giovanetti, P. F. A. Goudsmit, H. J. Leisi, and A. Rüetschi, Nucl. Instr. and Meth. A241, 191 (1985).

15. R. D. Deslattes, E. G. Kessler, W. C. Sauder, and A. Henins, Ann. Phys. 129,378 (1980).

16. E. K. Warburton and D. E. Alburger, Nucl. Instr. and Meth. A253, 38 (1986).

17. G. C. Nelson and B. G. Saunders, Nucl. Instr. and Meth. 84, 90 (1970). 
18. R. W. Jewe11, W. John, R. Massey and B. G. Saunders, Nucl. Instr. and Meth. 62, 68 (1968).

19. E. Browne and R. B. Firestone, Table of Radioactive Isotopes (John Wiley \& Sons, New York, 1986).

20. Y. A. Ellis-Akovali, Nucl. Data Sheets 44, 407 (1985).

21. W. Gongqing, Nucl. Data Sheets 51, 577 (1987).

22. R. G. Helmer, Nucl. Data Sheets 59, 1, (1990).

23. C. W. Reich, Izv. Akad. Nauk SSSR, Ser. Fiz. 55, 878 (1991). 
Table 4. Measured $\gamma$-ray energy differences between lines of ${ }^{172} \mathrm{Hf}+{ }^{172} \mathrm{Lu}$ and ${ }^{249} \mathrm{Am}$ and lines of ${ }^{161} \mathrm{~Tb}$ and ${ }^{249} \mathrm{Am}$.

\begin{tabular}{|c|c|c|c|c|c|}
\hline $\begin{array}{l}\text { Detec- } \\
\text { tor } \\
\end{array}$ & $\begin{array}{l}\text { Spectral } \\
\text { code } \\
\end{array}$ & $23 \mathrm{Hf}-26 \mathrm{Am}$ & $25 \mathrm{~Tb}-26 \mathrm{Am}$ & $48 \mathrm{~Tb}-59 \mathrm{Am}$ & 59Am-74Tb \\
\hline$P G-16$ & $\begin{array}{l}\text { CN10 } \\
\text { CN11 } \\
\text { CN12 } \\
\text { CN13 } \\
\text { CN14 } \\
\text { CN15 } \\
\text { CN16 } \\
\text { CN17 } \\
\text { CN19 } \\
\text { CN20 } \\
\text { CN21 } \\
\text { CN23 } \\
\text { CN24 } \\
\text { CN25 }\end{array}$ & $\begin{array}{l}2.4103(5) \\
2.4119(5) \\
2.4104(6) \\
2.4111(5) \\
2.4108(4) \\
2.4112(5) \\
2.4101(4)\end{array}$ & & $\begin{array}{l}10.6254(2) \\
10.6256(2) \\
10.6256(2) \\
10.6260(3) \\
10.6256(3) \\
10.6258(2) \\
10.6259(4)\end{array}$ & $\begin{array}{l}15.0259(3) \\
15.0266(4) \\
15.0261(3) \\
15.0267(5) \\
15.0266(4) \\
15.0275(4) \\
15.0274(4)\end{array}$ \\
\hline OR-16 & $\begin{array}{l}\text { DN1 } \\
\text { DN2 } \\
\text { DN3 } \\
\text { DN4 } \\
\text { DN5 } \\
\text { DN6 } \\
\text { DN7 } \\
\text { DN8 } \\
\text { DN9 } \\
\text { DN10 }\end{array}$ & & $\begin{array}{l}0.6927(15) \\
0.6939(8) \\
0.6923(14) \\
0.6915(11) \\
0.6927(7) \\
0.6927(5) \\
0.6927(7) \\
0.6928(5) \\
0.6950(5) \\
0.6926(6)\end{array}$ & $\begin{array}{l}10.6268(9) \\
10.6269(7) \\
10.6266(14) \\
10.6266(7) \\
10.6280(6)^{a} \\
10.6290(8)^{a} \\
10.6275(5)^{a} \\
10.6315(6)^{a} \\
10.6300(7)^{a}\end{array}$ & $\begin{array}{l}15.0258(15) \\
15.0253(11) \\
15.0236(21) \\
15.0221(17) \\
15.0245(9) \\
15.0245(9) \\
15.0236(13) \\
15.0229(7) \\
15.0237(7) \\
15.0294(11)\end{array}$ \\
\hline
\end{tabular}

$\begin{array}{lllll}\text { Si(Li) } & \text { EN1 } & 2.4126(8) & & \\ & \text { EN2 } & & & \\ \text { EN3 } & 2.4114(10) & & & \\ \text { EN4 } & & 0.6925(7) & 10.6274(10) & 15.0237(24) \\ \text { EN5 } & & 0.6935(10) & 10.6249(15) & 15.0230(35) \\ \text { EN6 } & & 0.6926(6) & 10.6259(10) & 15.0276(28) \\ \text { EN7 } & & 0.6938(6) & 10.6269(11) & 15.0253(27) \\ \text { EN8 } & & 0.6935(4) & 10.6265(7) & 15.0264(15) \\ \text { EN18 } & & 0.6928(3) & 10.6265(6) & 15.0268(15)\end{array}$


Table 4. (Continued)

\begin{tabular}{|c|c|c|c|c|c|}
\hline $\begin{array}{l}\text { Detec- } \\
\text { - tor }\end{array}$ & $\begin{array}{l}\text { Spectral } \\
\text { code } \\
\end{array}$ & $23 \mathrm{Hf}-26 \mathrm{Am}$ & $25 \mathrm{~Tb}-26 \mathrm{Am}$ & 48Tb-59Am & 59Am-74Tb \\
\hline & $\begin{array}{l}\text { EN19 } \\
\text { EN20 } \\
\text { EN21 } \\
\text { EN22 } \\
\text { EN23 } \\
\text { EN24 }\end{array}$ & & $\begin{array}{l}0.6938(4) \\
0.6539(4)\end{array}$ & $\begin{array}{l}10.6266(8) \\
10.6254(6) \\
10.6254(3) \\
10.6260(9) \\
10.6242(8) \\
10.6247(10)\end{array}$ & $\begin{array}{l}15.0258(23) \\
15.0276(17) \\
15.0250(6) \\
15.0260(23) \\
15.0262(15) \\
15.0222(17)\end{array}$ \\
\hline & $\begin{array}{l}\text { EN25 } \\
\text { EN26 } \\
\text { EN27 } \\
\text { EN28 } \\
\text { EN29 } \\
\text { EN30 } \\
\text { EN31 }\end{array}$ & $\begin{array}{l}2.4135(6) \\
2.4150(8) \\
2.4141(6) \\
2.4141(7) \\
2.4150(6)\end{array}$ & & $\begin{array}{l}10.6257(7) \\
10.6244(12)\end{array}$ & $\begin{array}{l}15.0242(11) \\
15.0264(16)\end{array}$ \\
\hline
\end{tabular}

The following are weighted averages and the associated $\chi_{R}^{2}$.

$\begin{array}{lrrrr}\text { PG-16 } & 2.4108(2) & & 10.6256(1) & 15.0266(2) \\ & 1.72 & & 0.67 & 2.87 \\ \text { OR-16 } & & 0.6932(3) & 10.6267(4) & 15.0244(6) \\ & & 2.25 & 0.04 & 3.35 \\ \text { Si(Li) } & 2.4139(4) & 0.6933(2) & 10.6257(2) & 15.0253(4) \\ & 2.46 & 1.46 & 1.15 & 0.81 \\ \text { All data } & 2.4118(9)^{b} & 0.6933(2) & 10.6257(1) & 15.0261(2) \\ & 9.33 & 1.82 & 1.08 & 3.40\end{array}$

- Not used in average due to grow-in of an interfering peak in the ${ }^{161} \mathrm{~Tb}$ source.

b The weighted average of these 14 differences gives an internal uncertainty of $0.00015 \mathrm{keV}$ and an external uncertainty of 0.00045 $\mathrm{keV}$. The value given here is the latter value increased by an additional arbitrary factor of 2.0 due to the discrepancy between the averages from the individual detectors. 
Table 5. Measured $\gamma$-ray energy differences between 1 ines from ${ }^{161} \mathrm{~Tb}$ and ${ }^{172} \mathrm{Hf}$ and between two lines from ${ }^{161} \mathrm{~Tb}$.

\begin{tabular}{|c|c|c|c|c|c|c|}
\hline $\begin{array}{l}\text { Detec- } \\
\text { tor } \\
\end{array}$ & $\begin{array}{l}\text { Spectral } \\
\text { code }\end{array}$ & $23 \mathrm{Hf}-25 \mathrm{~Tb}$ & $48 \mathrm{~Tb}-57 \mathrm{~Tb}$ & 74Tb-78Hf & 74Tb-8IHf & 74Tb-90Hf \\
\hline$P G-16$ & $\begin{array}{l}\text { CN1 } \\
\text { CN2 } \\
\text { CN3 } \\
\text { CN1 } \\
\text { CN5 } \\
\text { CN6 } \\
\text { CN7 } \\
\text { CN1 } \\
\text { CN9 } \\
\text { CN11 } \\
\text { CN12 } \\
\text { CN13 } \\
\text { CN14 } \\
\text { CN15 } \\
\text { CN16 }\end{array}$ & $\begin{array}{l}1.7197(6) \\
1.7177(7) \\
1.7186(3) \\
1.7180(4) \\
1.7183(6) \\
1.7176(9) \\
1.7172(4) \\
1.7182(6) \\
1.7134(9)^{\circ}\end{array}$ & $\begin{array}{l}8.2692(22) \\
8.2787(41) \\
8.2757(7) \\
8.2764(4) \\
8.2765(9) \\
8.2754(9) \\
8.2774(7) \\
8.2777(7)\end{array}$ & $\begin{array}{c}4.1757(11) \\
4.1767(11) \\
4.1760(6) \\
4.1770(10) \\
4.1717(14) \\
4.1826(9)^{a} \\
4.1721(11) \\
4.1722(16)\end{array}$ & $\begin{array}{l}7.1871(16) \\
7.1854(15) \\
7.1841(7) \\
7.1868(9) \\
7.1844(14) \\
7.1793(17) \\
7.1826(9) \\
7.1995(13)^{a} \\
7.1806(16)\end{array}$ & $\begin{array}{c}16.0805(17) \\
16.0792(16) \\
16.0799(9) \\
16.0791(10) \\
16.0813(16) \\
16.0713(19) \\
16.0755(10) \\
16.0688(15)^{a}\end{array}$ \\
\hline$S i(L i)$ & $\begin{array}{l}\text { EN9 } \\
\text { EN10 } \\
\text { EN11 } \\
\text { EN12 } \\
\text { EN13 } \\
\text { EN14 } \\
\text { EN15 } \\
\text { EN16 } \\
\text { EN17 } \\
\text { EN22 } \\
\text { EN23 } \\
\text { EN24 } \\
\text { EN25 } \\
\text { EN26 } \\
\text { EN27 }\end{array}$ & $\begin{array}{l}1.7180(3) \\
1.7178(3) \\
1.7187(4) \\
1.7188(4) \\
1.7189(3) \\
1.7192(3) \\
1.7189(4) \\
1.7192(4) \\
1.7179(4)\end{array}$ & $\begin{array}{l}8.2757(7) \\
8.2764(4) \\
8.2765(9) \\
8.2754(9) \\
8.2774(7) \\
8.2777(7)\end{array}$ & $\begin{array}{l}4.1755(20) \\
4.1777(27) \\
4.1817(42) \\
4.1796(20) \\
4.1808(21) \\
4.1737(23) \\
4.1706(34) \\
4.1721(36) \\
4.1802(38)\end{array}$ & $\begin{array}{l}7.1819(29) \\
7.1868(40) \\
7.1909(50) \\
7.1884(35) \\
7.1867(32) \\
7.1788(29) \\
7.1812(40) \\
7.1827(42) \\
7.1835(44)\end{array}$ & $\begin{array}{l}16.0816(45) \\
16.0839(40) \\
16.0864(58) \\
16.0801(35) \\
16.0877(37) \\
16.0715(36) \\
16.0837(44) \\
16.0768(46) \\
16.0896(49)\end{array}$ \\
\hline
\end{tabular}


Table 5. (Continued)

The following are weighted averages and the associated $\chi_{R}{ }^{2}$.

$\begin{array}{lrrrrr}\text { PG-16 } & 1.7182(3) & 8.2765(4) & 4.1752(8) & 7.1842(8) & 16.0784(11) \\ & 2.22 & 3.02 & 4.13 & 4.12 & 5.12 \\ \text { Si(Li) } & 1.7186(2) & 8.2758(6) & 4.1771(12) & 7.1839(13) & 16.0817(14) \\ & 2.78 & 0.58 & 1.87 & 1.13 & 1.97 \\ \text { Al1 data } & & & & & \\ & 1.7184(2) & 8.2764(3) & 4.1755(6) & 7.1841(6) & 16.0787(8) \\ & 2.57 & 2.05 & 2.92 & 2.37 & 3.44\end{array}$

- Value is an outlier, more than 50 from the average, and was not used in the averages. 


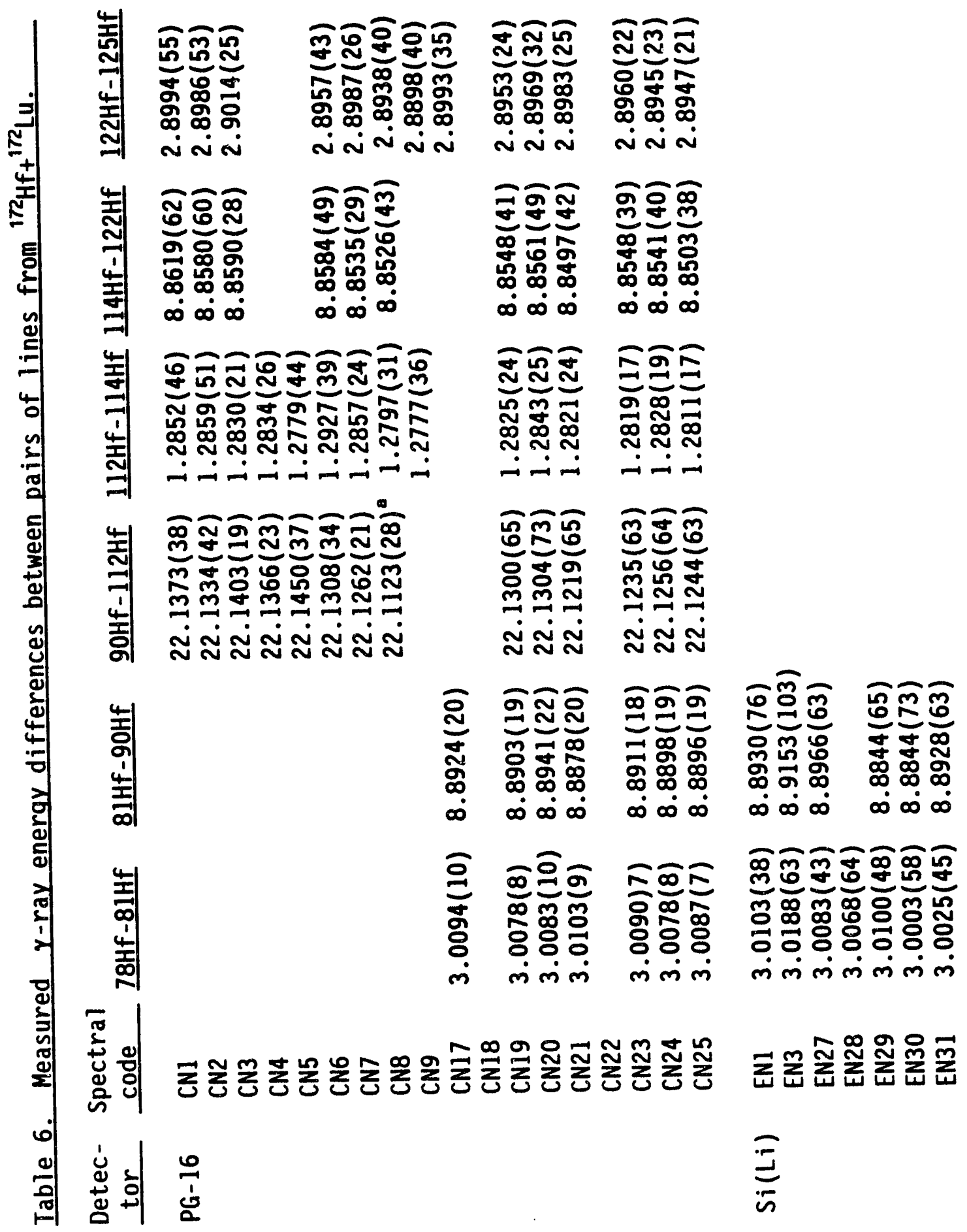




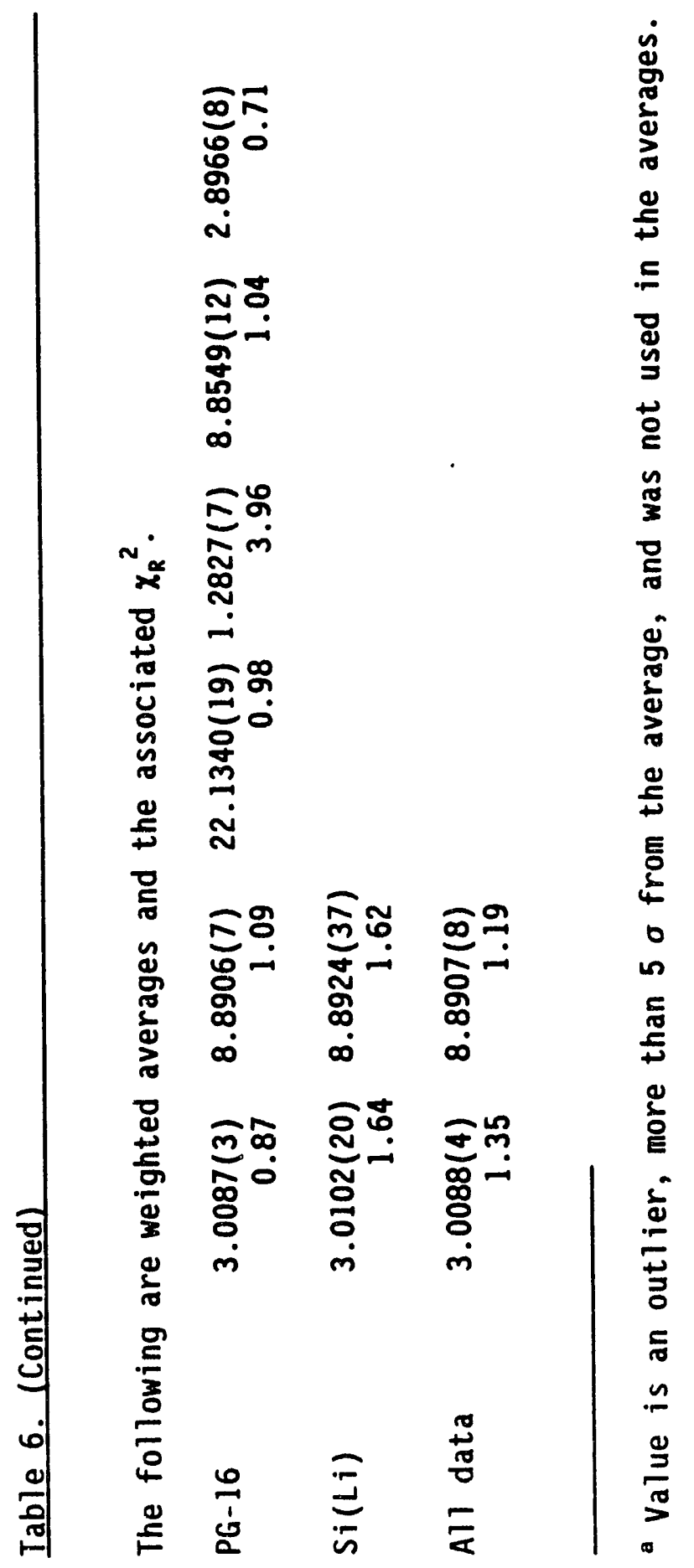




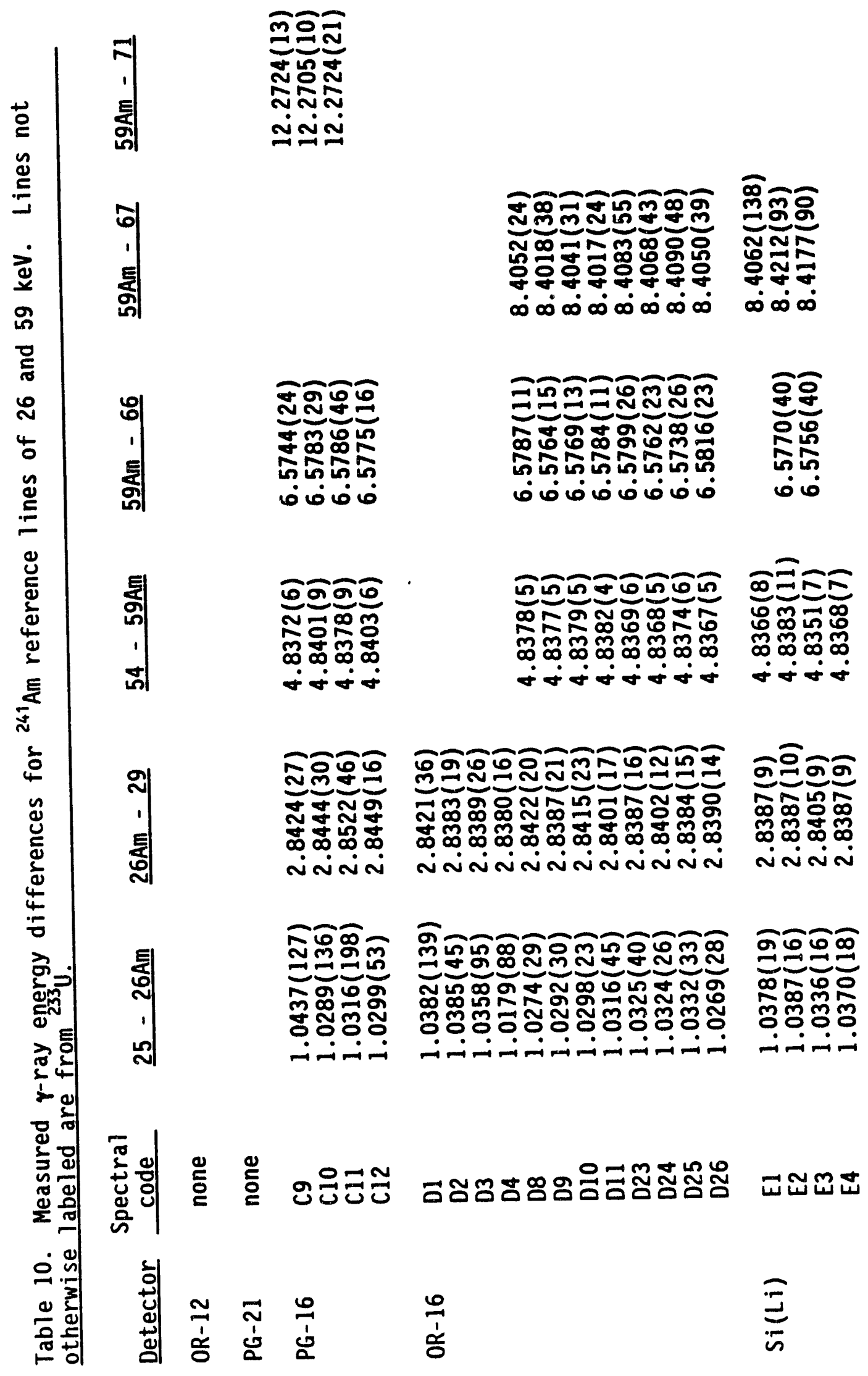




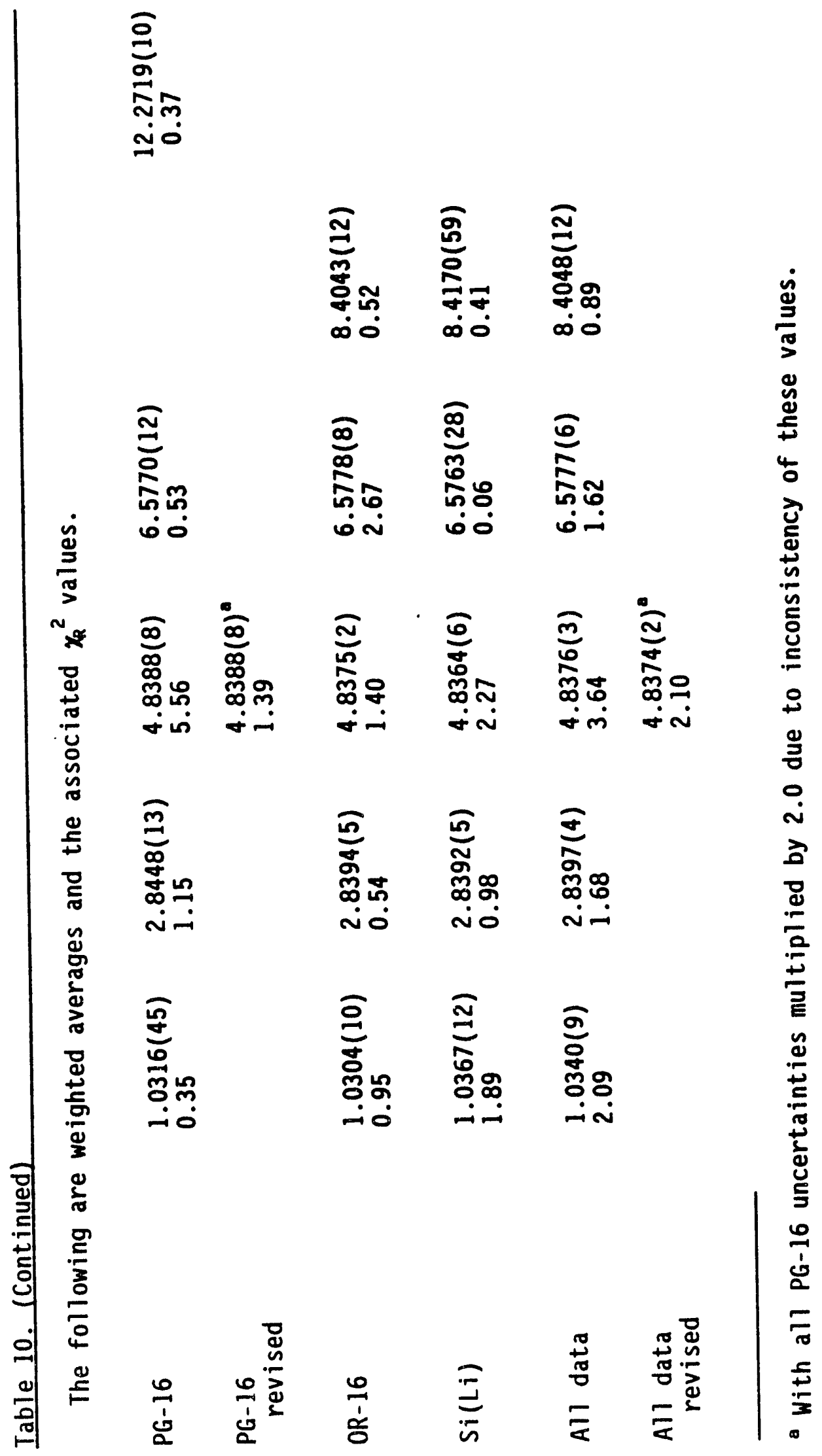




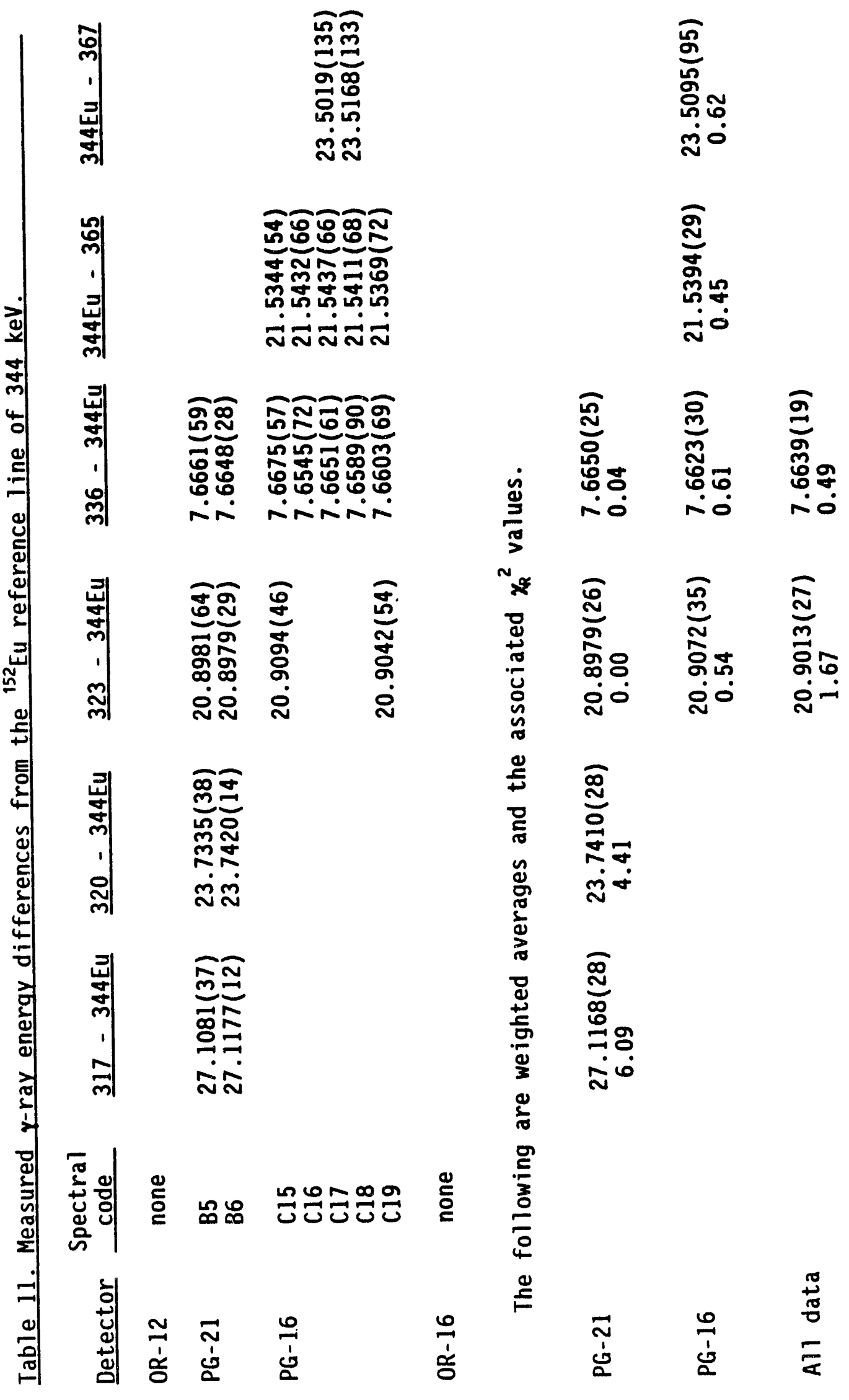




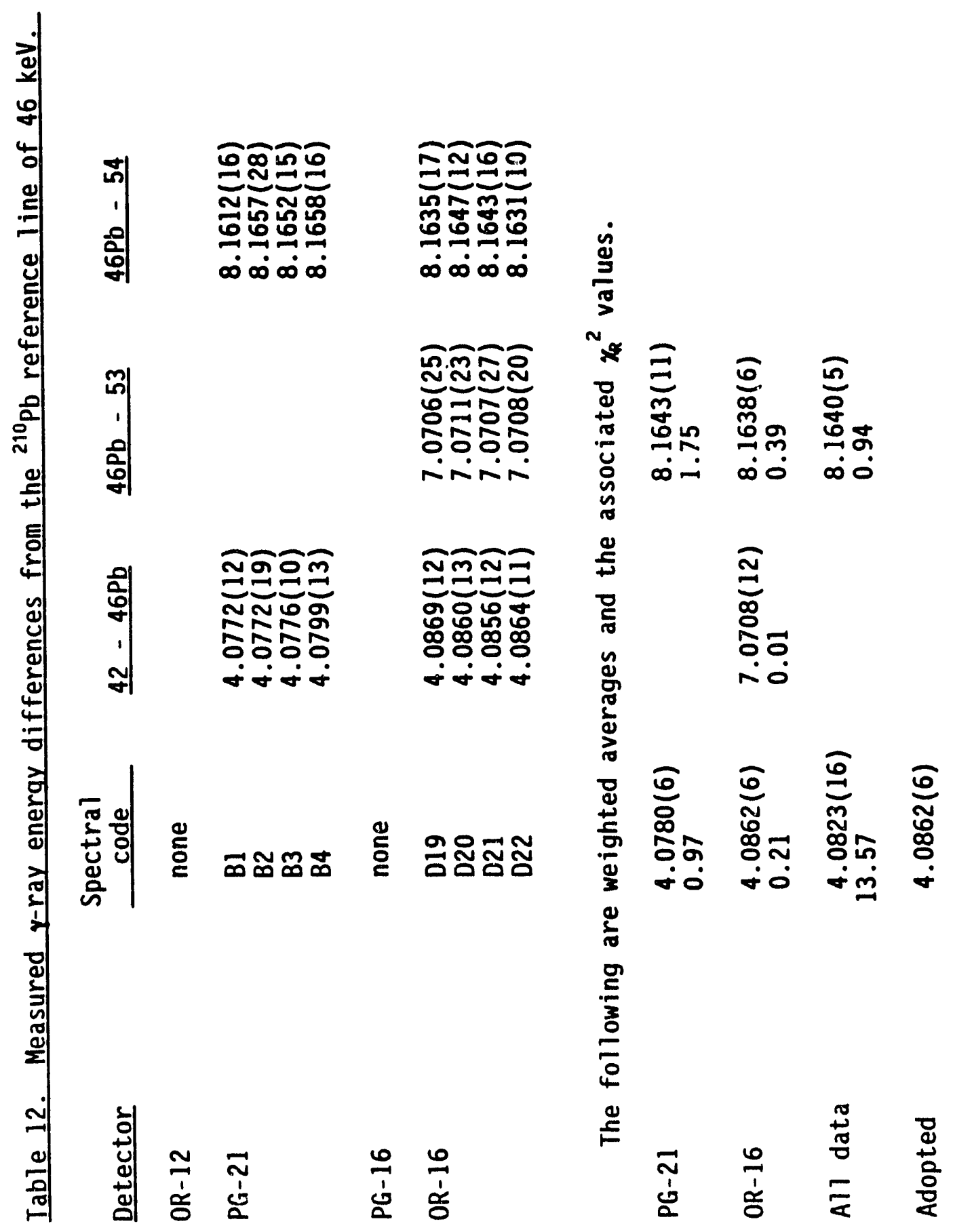




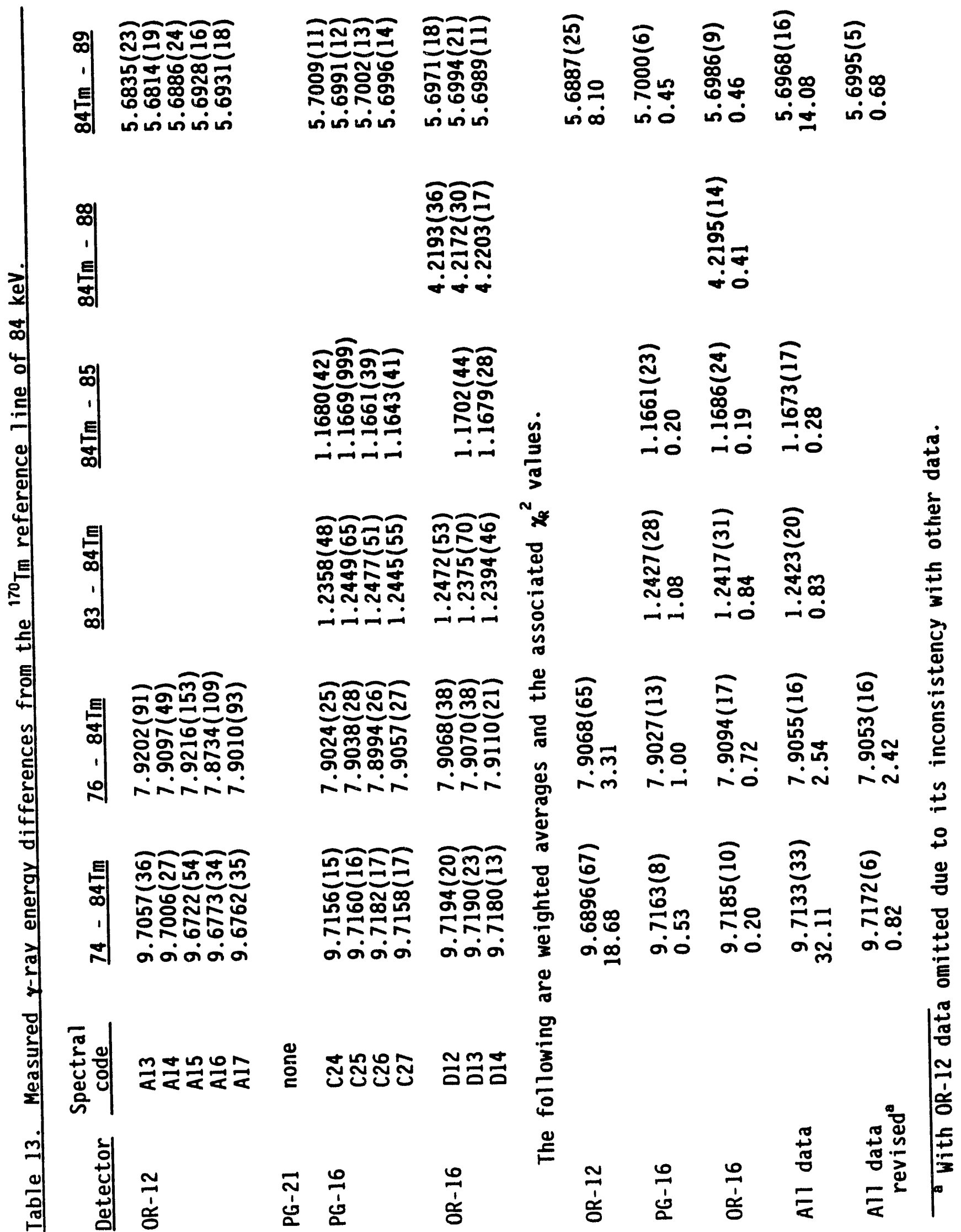




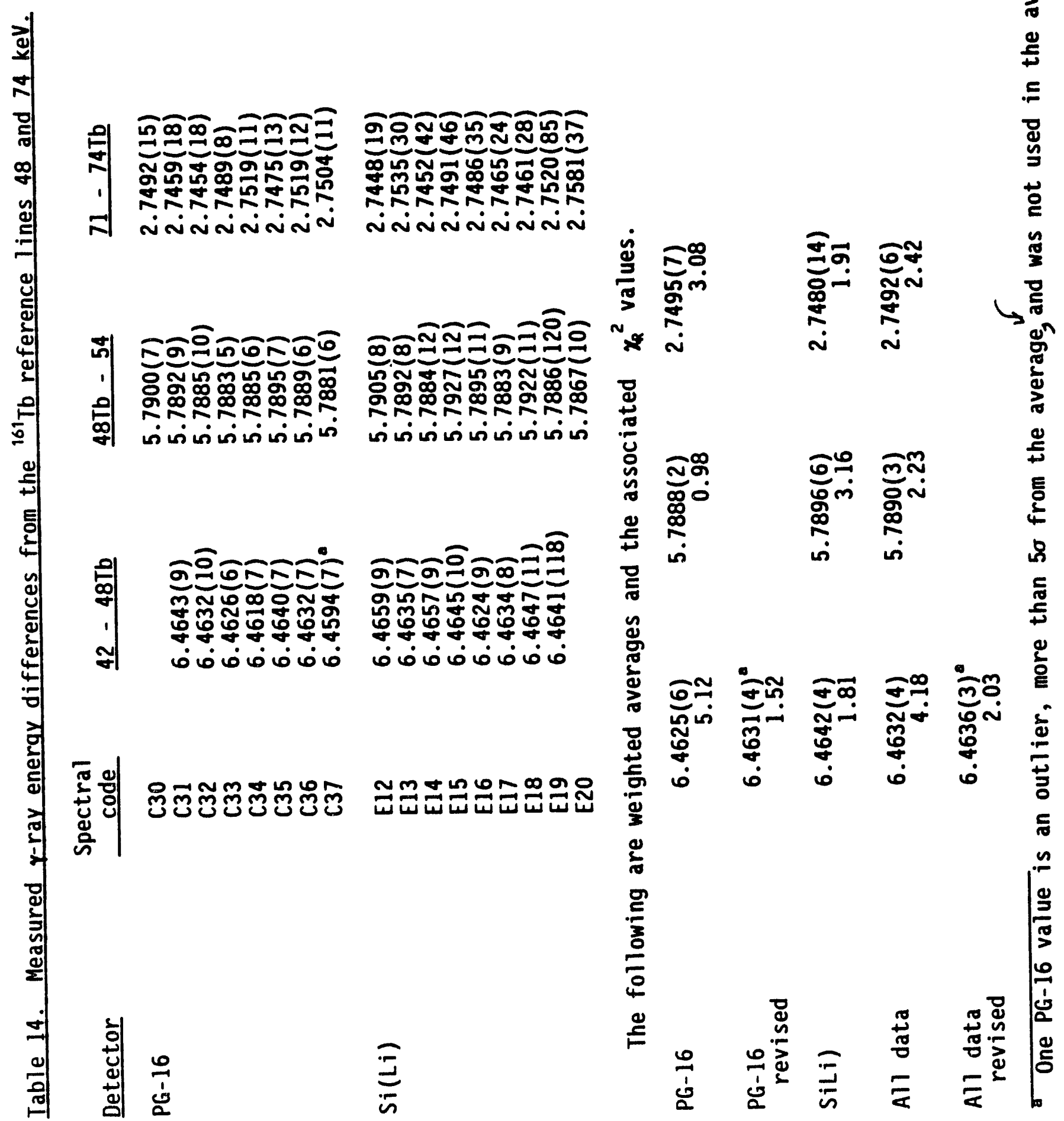




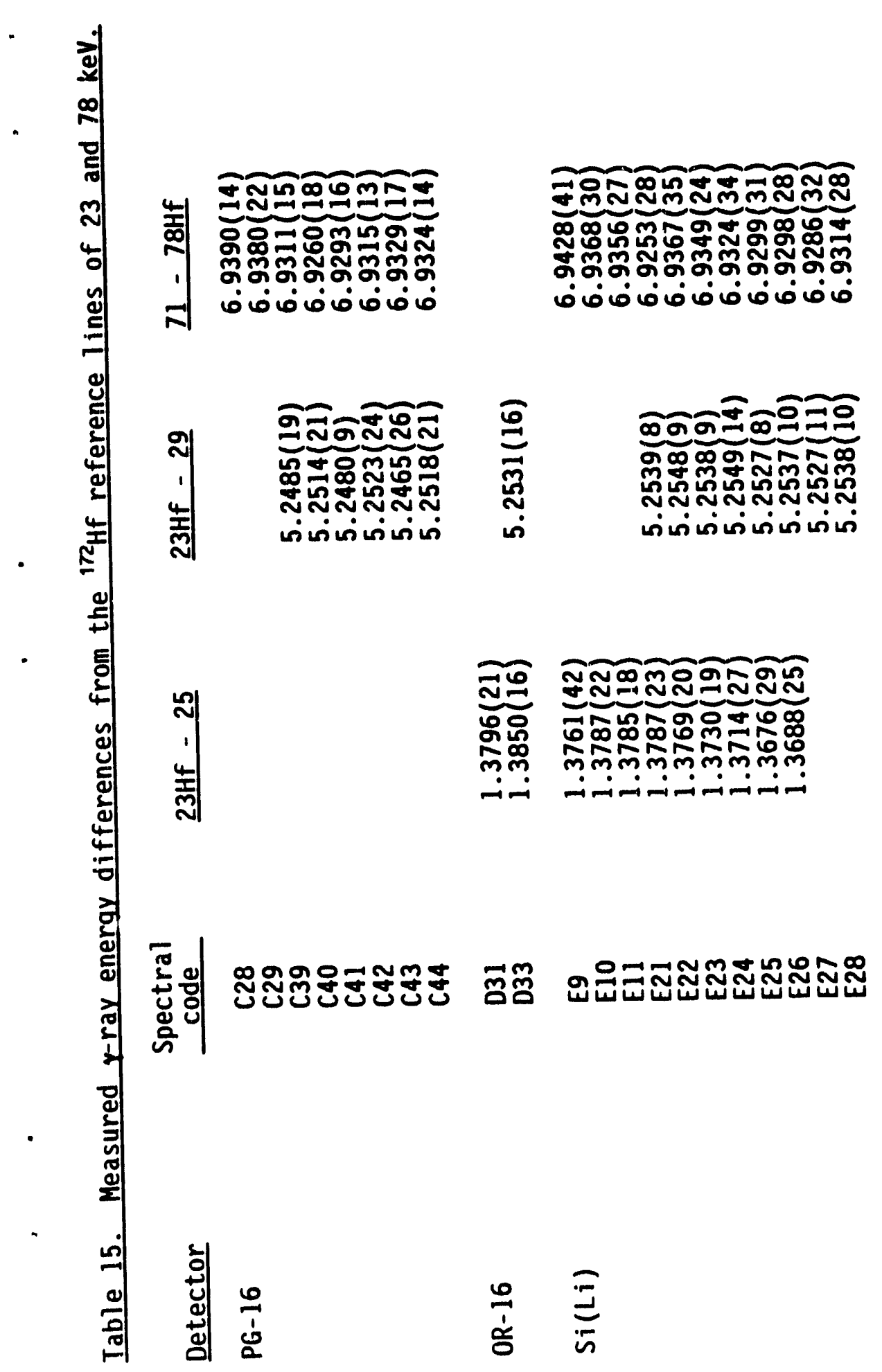




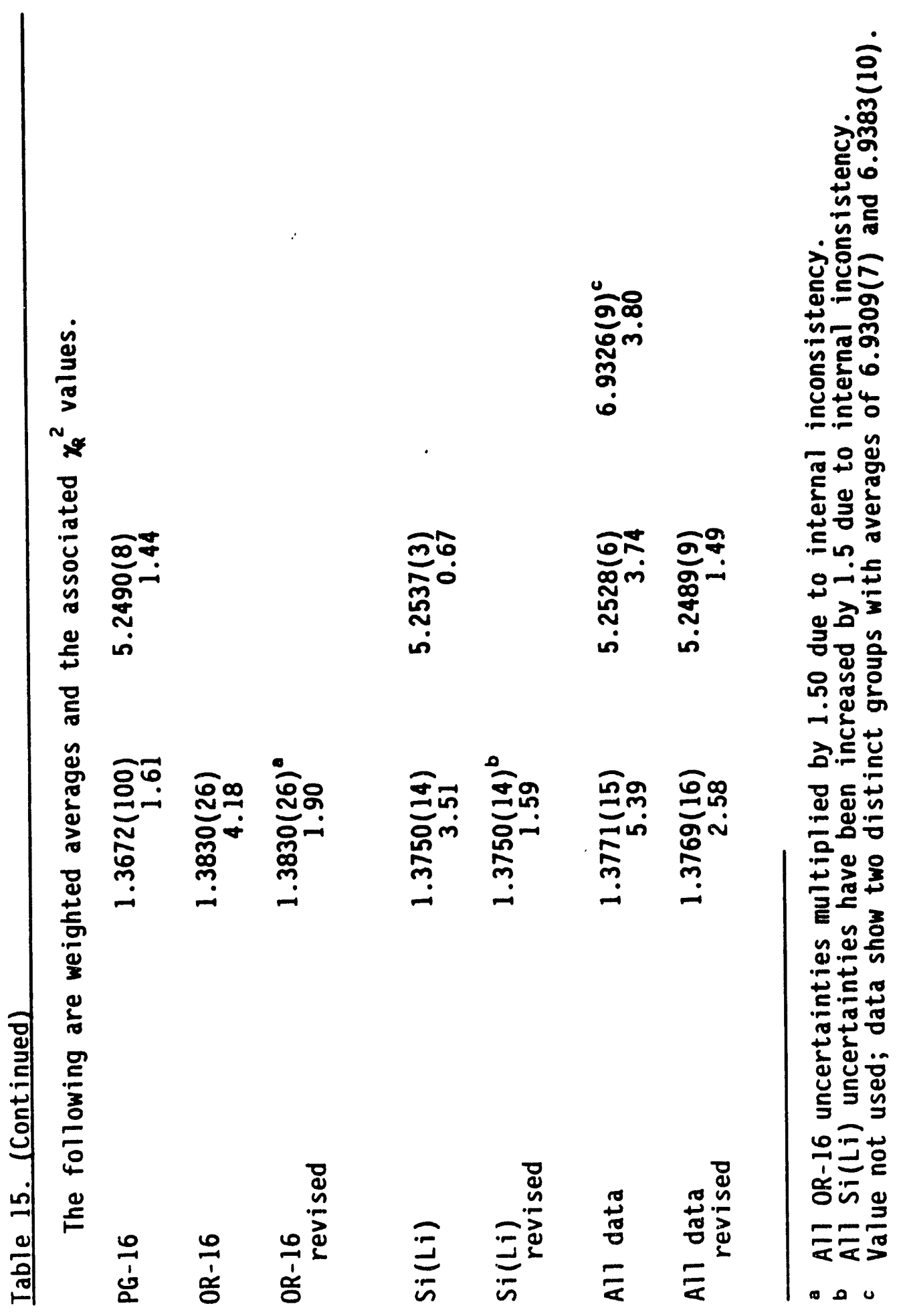




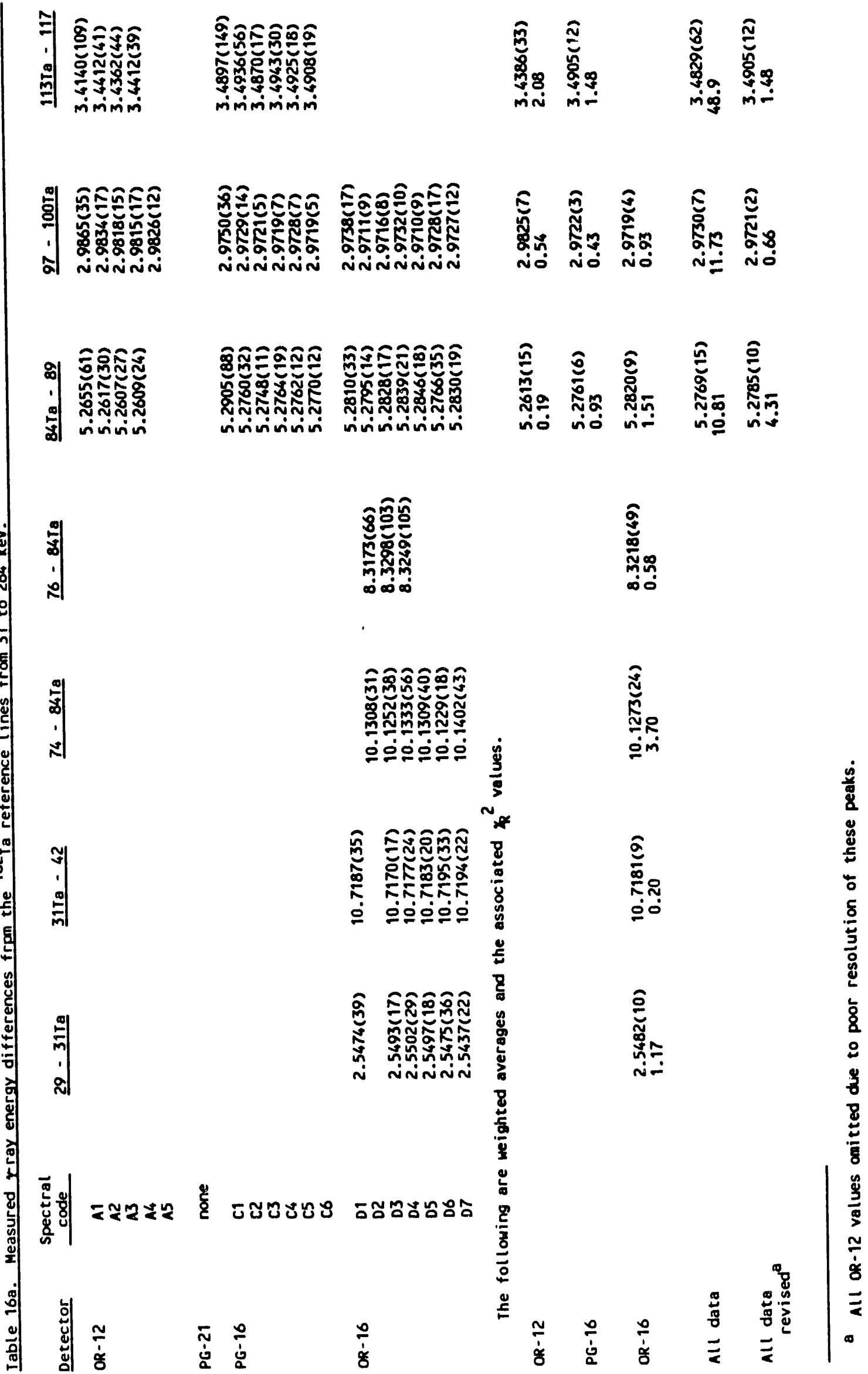




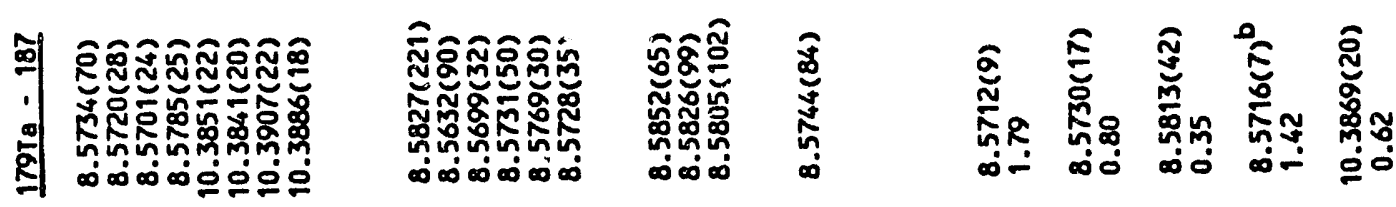

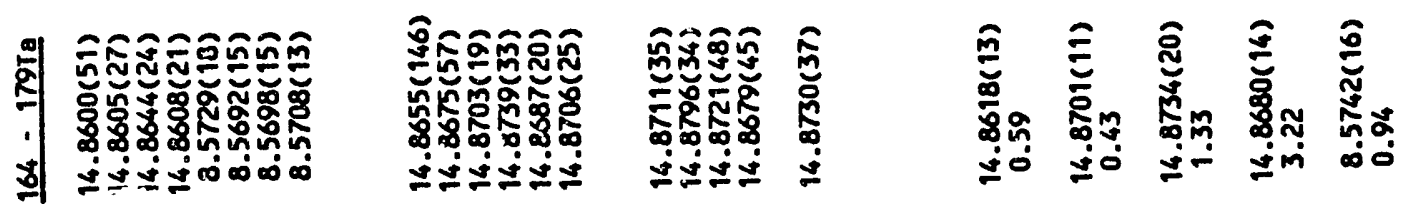

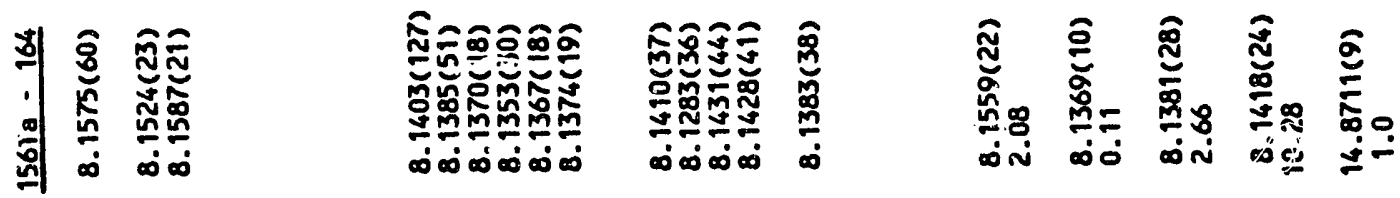

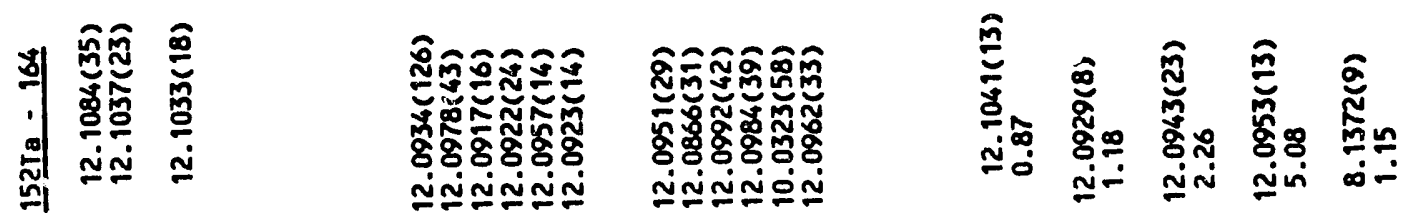

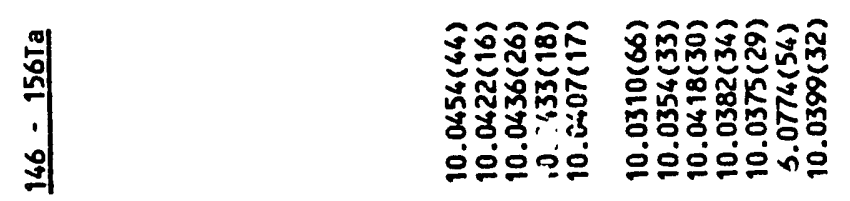

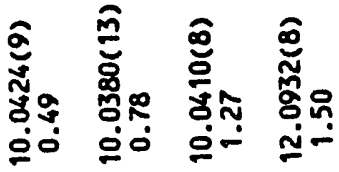

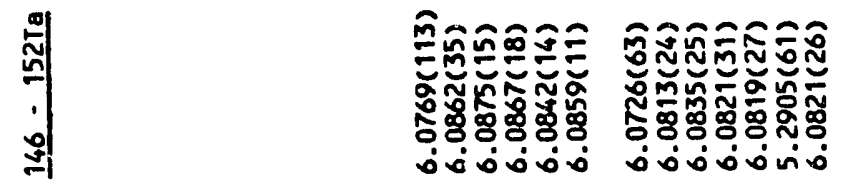

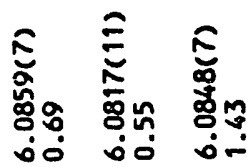

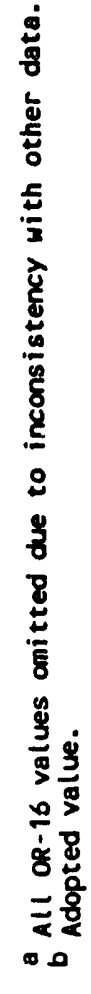

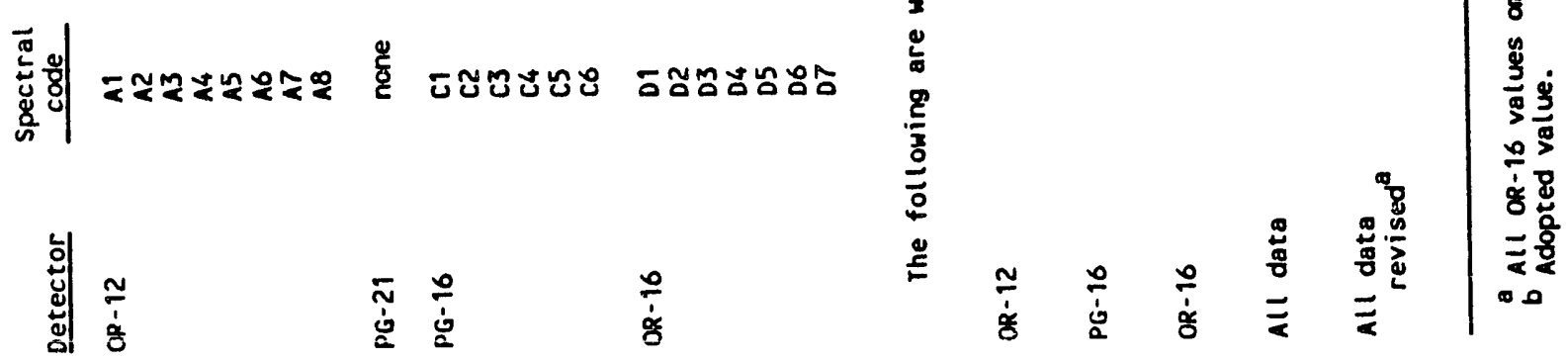



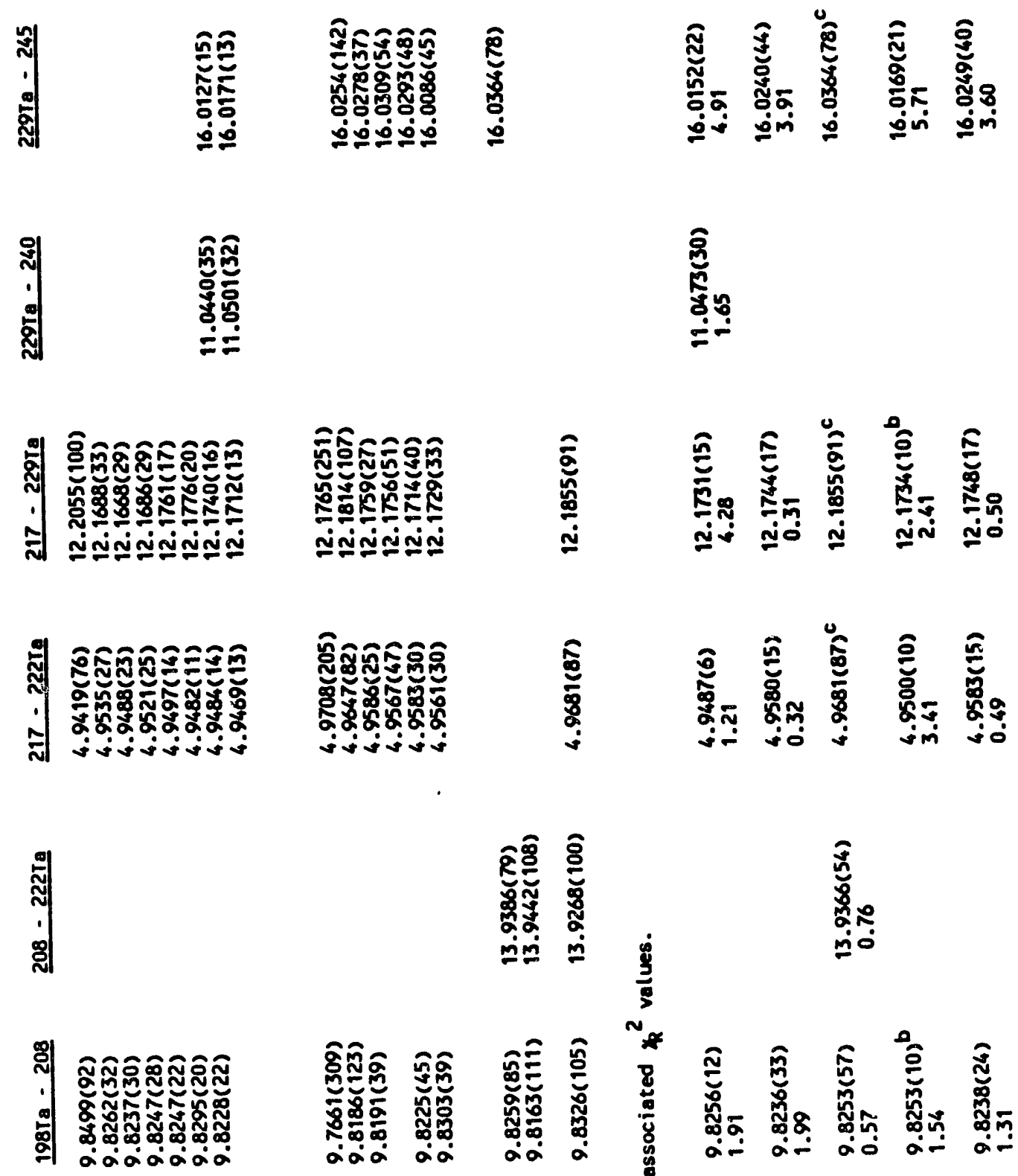

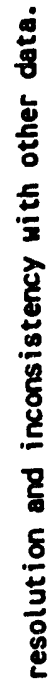

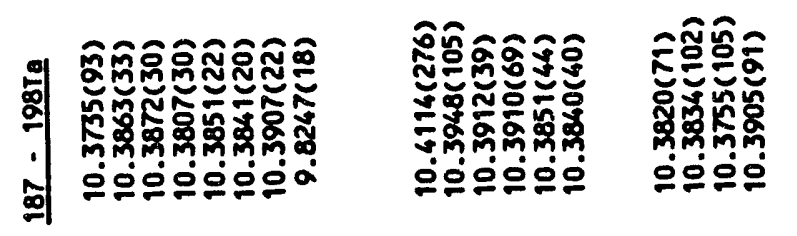

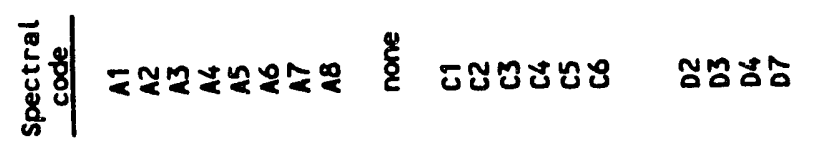

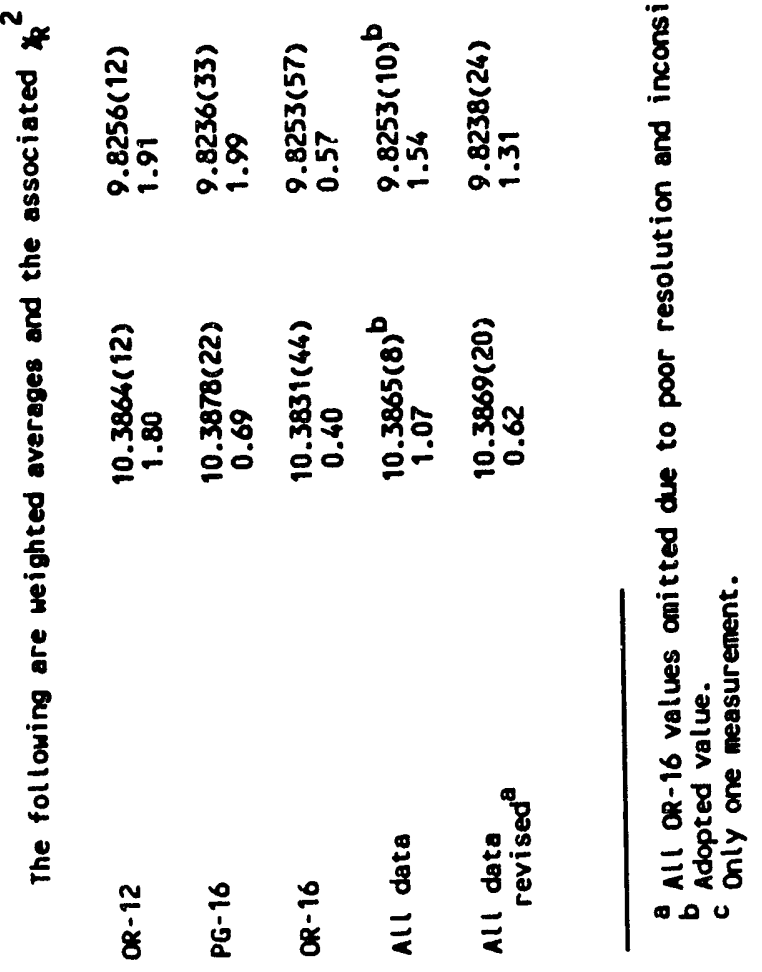




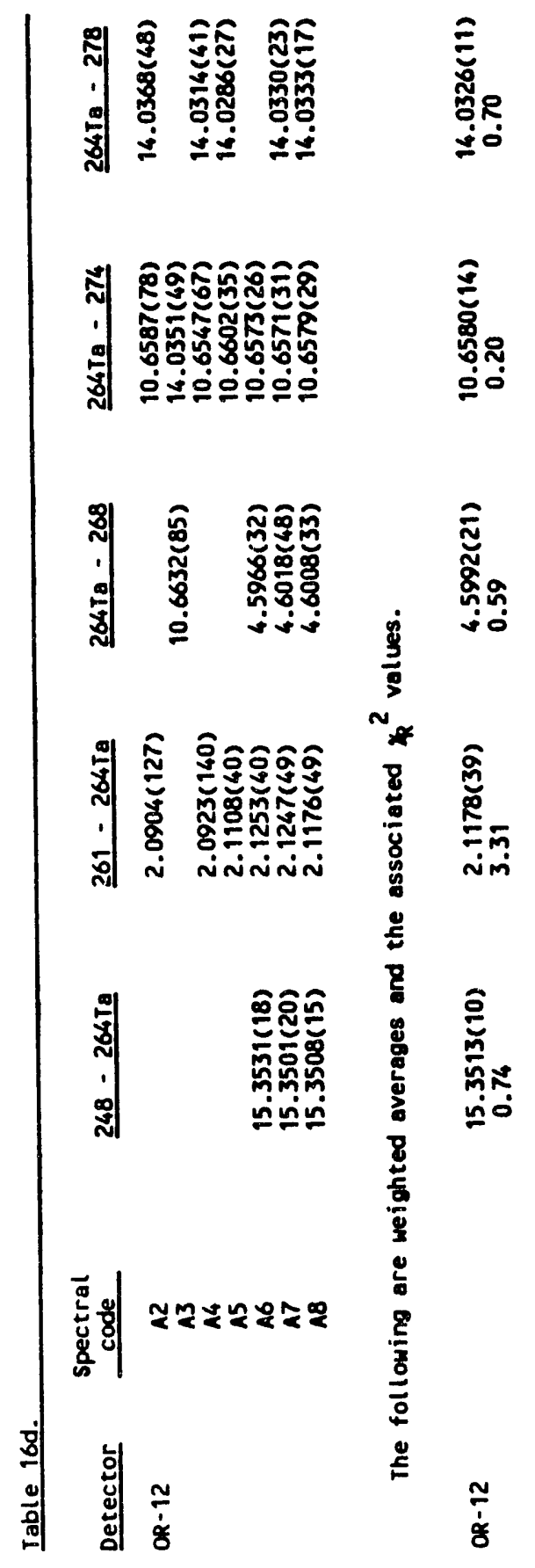



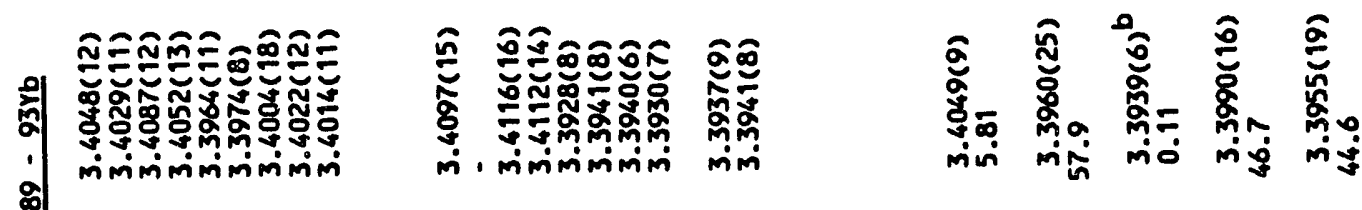

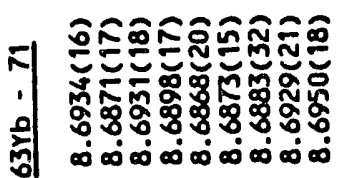
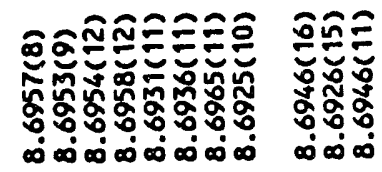

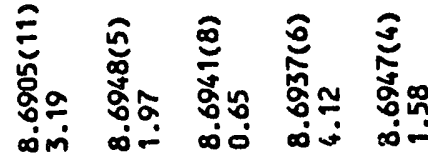
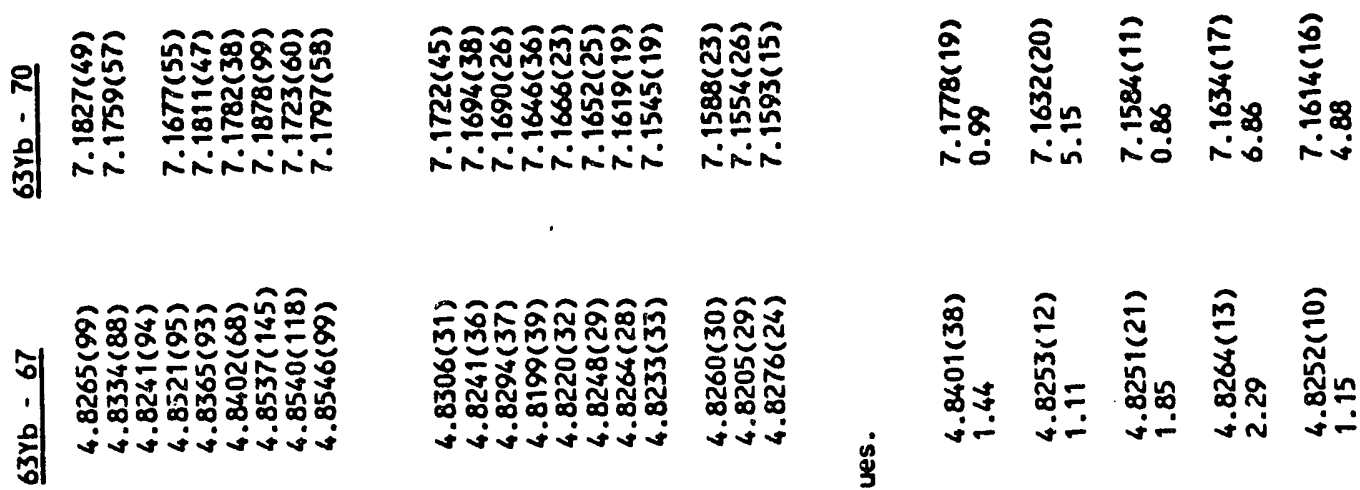

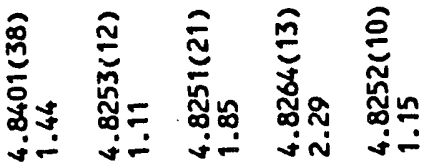


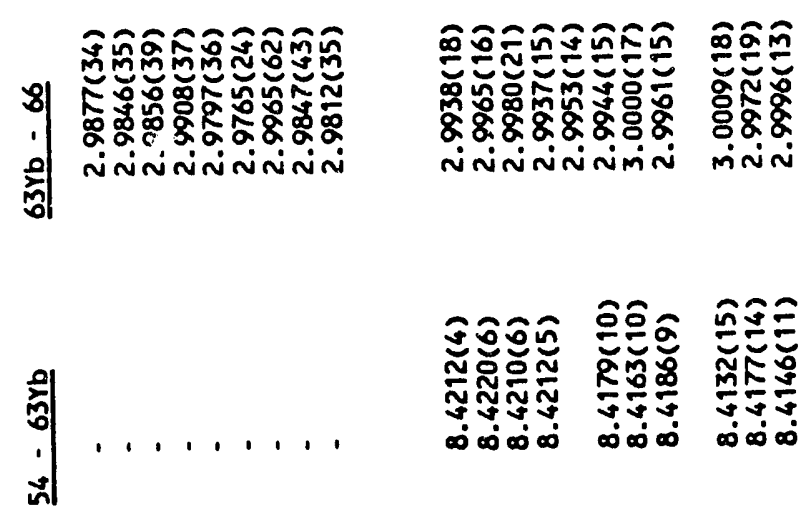

$\infty \infty_{\infty}^{\infty}$

$\infty \infty \omega \infty \omega$

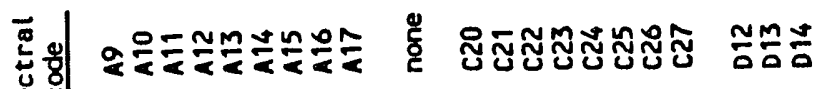

㔠 प्.

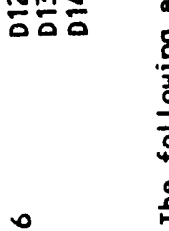

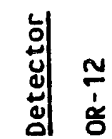

$\overline{\grave{j}} \frac{0}{\dot{\vdots}}$

$\frac{0}{\dot{\alpha}}$
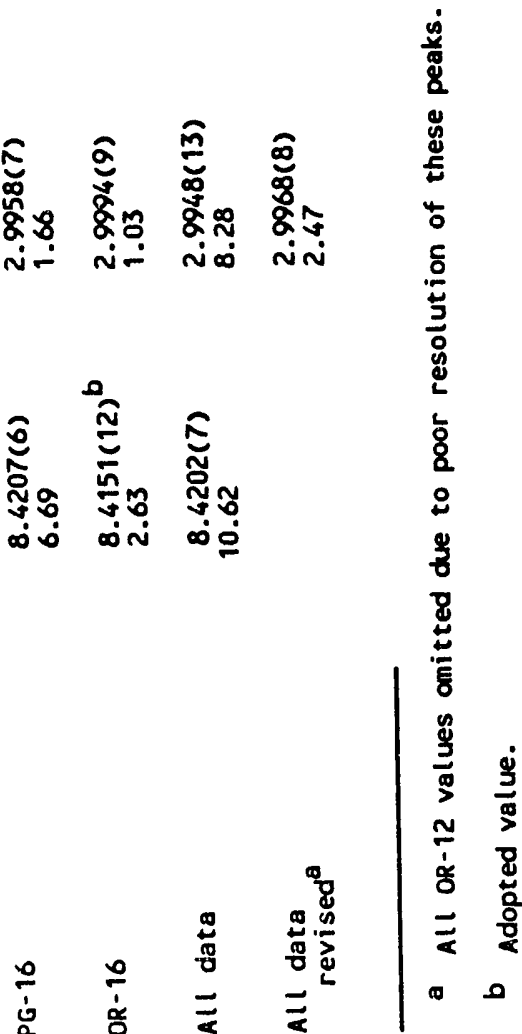
ํำ

ㅇำ

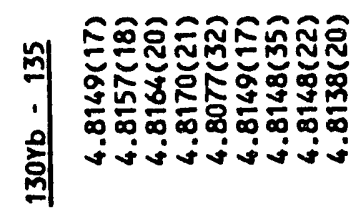

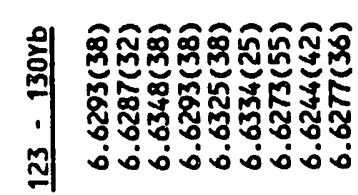

⿳亠े𠃌⿱口口-

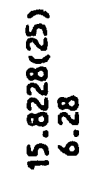

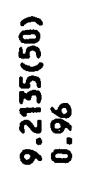

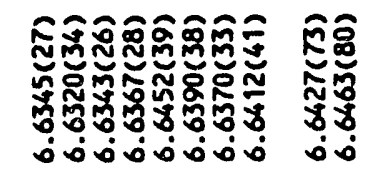

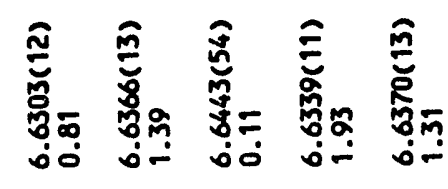

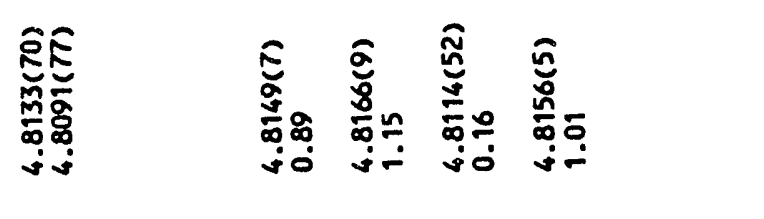

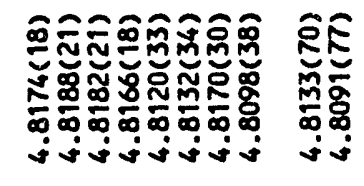

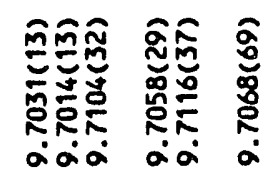

a)
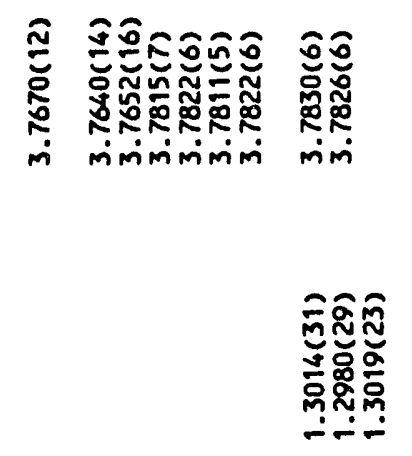

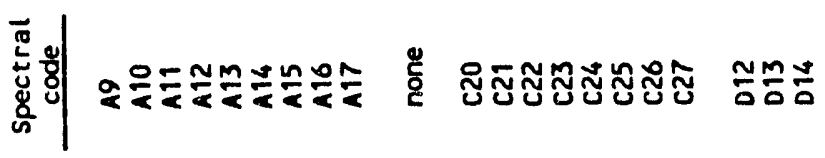

웜

:

$$
\text { | }
$$

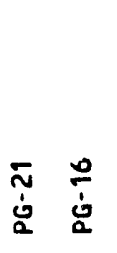

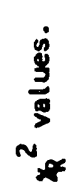

$\frac{0}{\dot{\alpha}}$

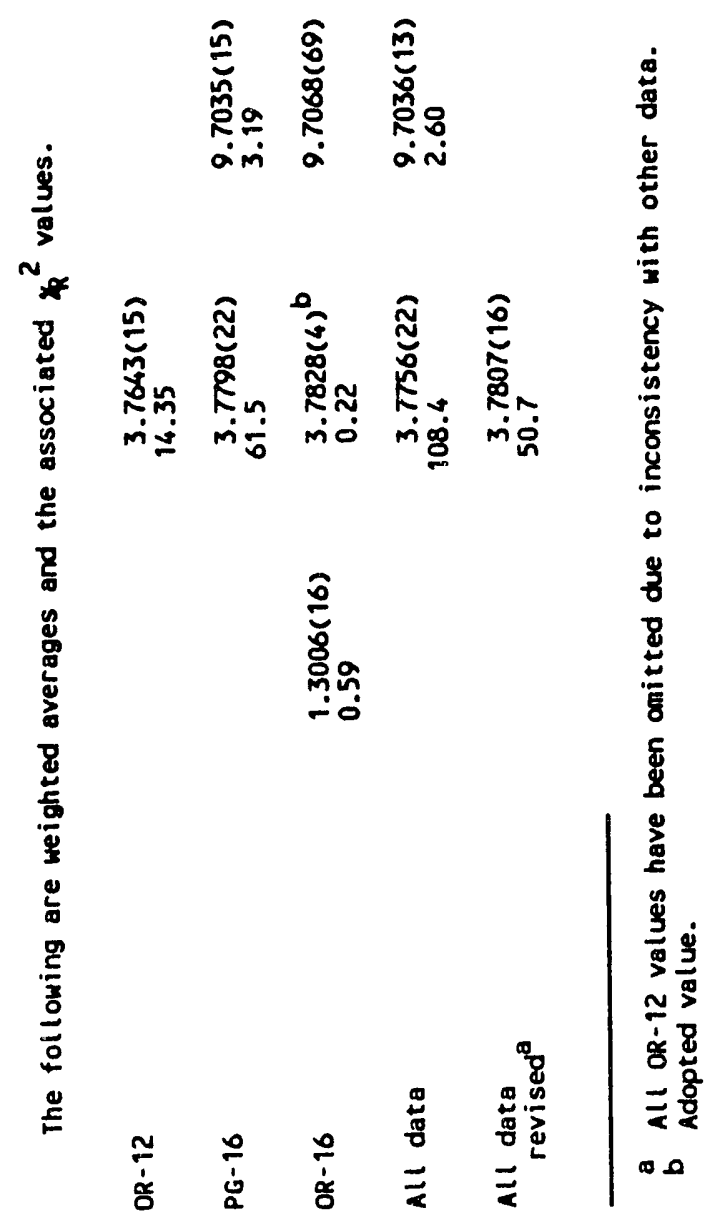


쵱

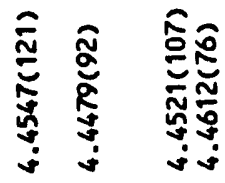

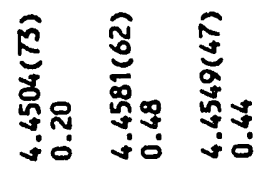
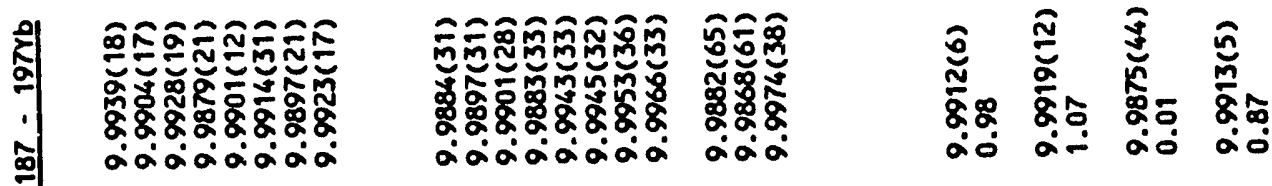

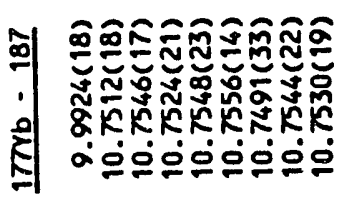

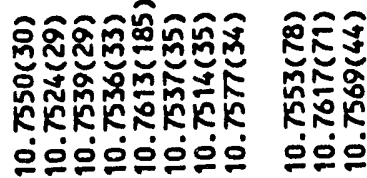

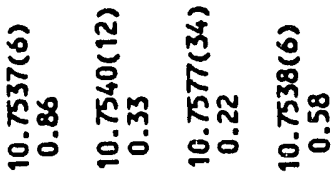
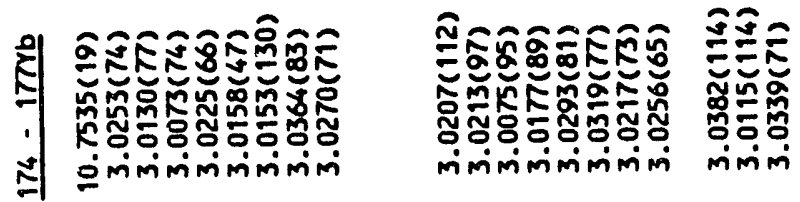

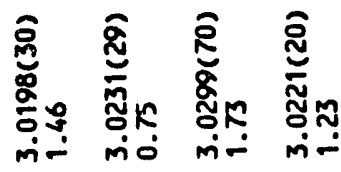
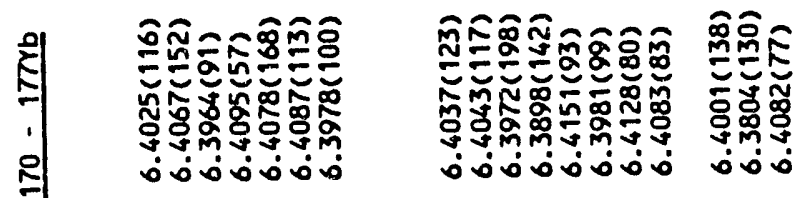

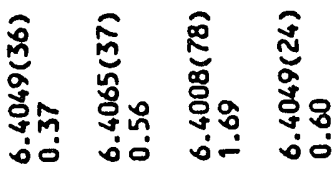

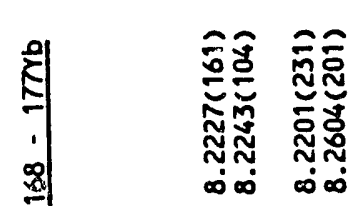

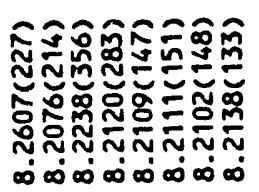

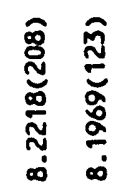

เัต

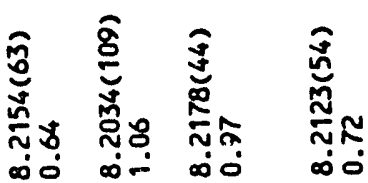

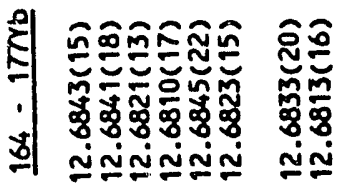

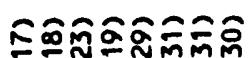

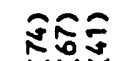

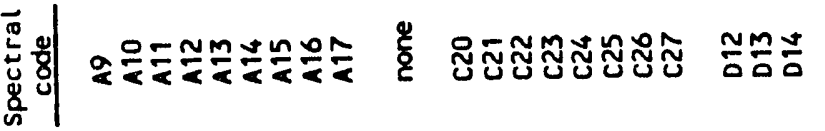

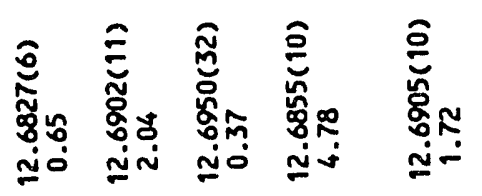

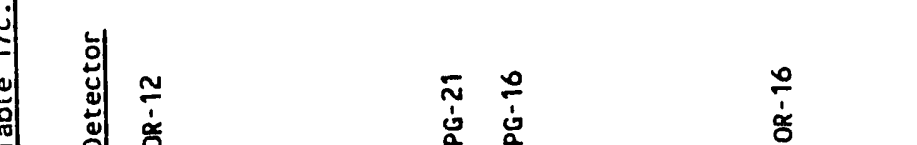




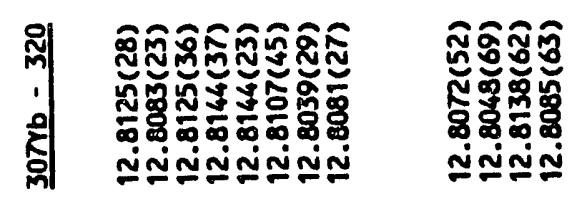

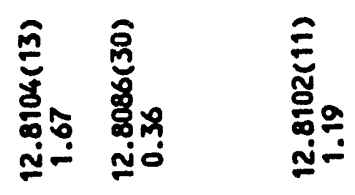

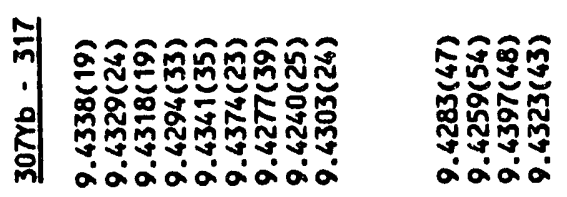

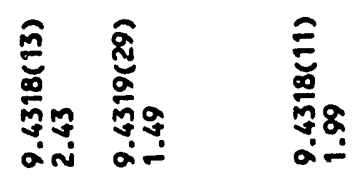
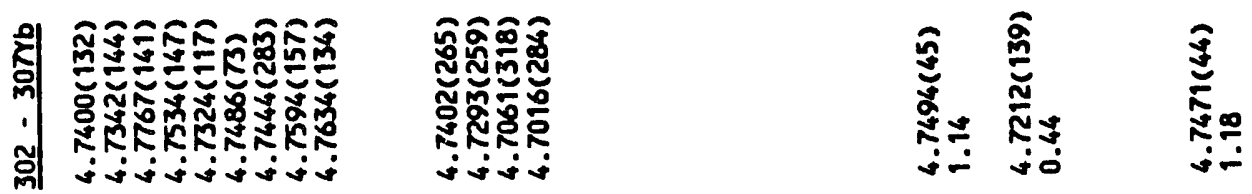

웜
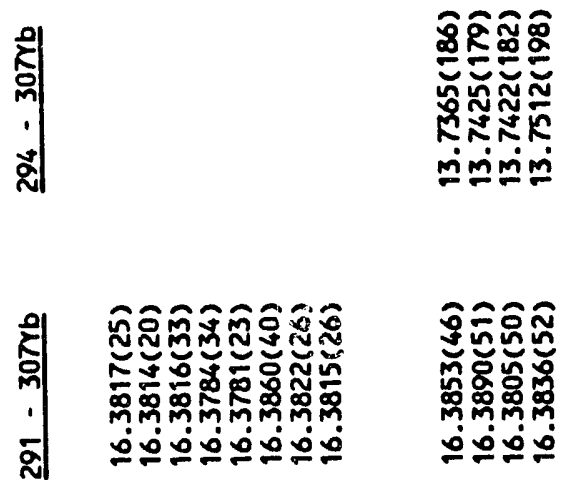

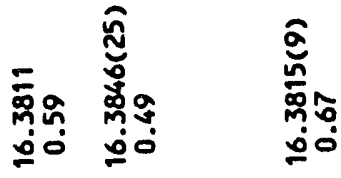

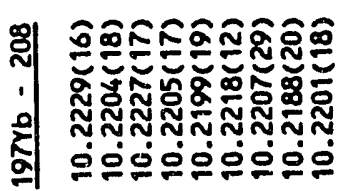

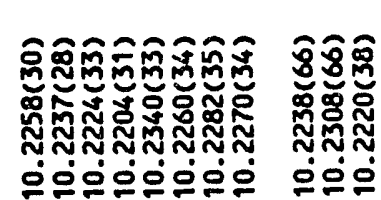

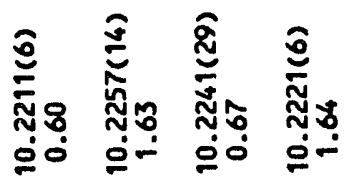

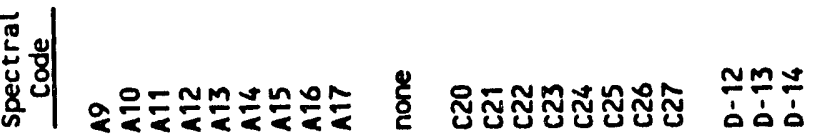

궁

矛

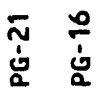

$\frac{0}{\dot{\alpha}}$

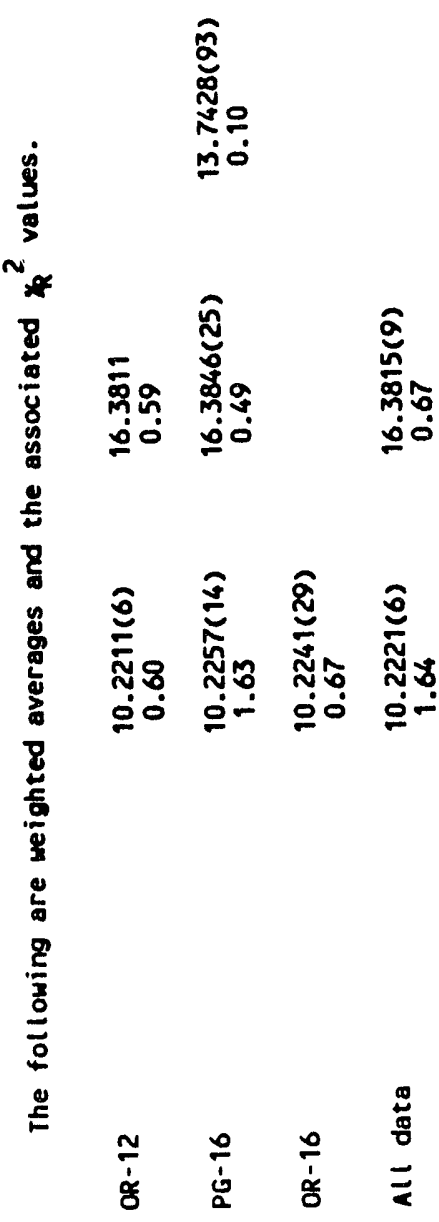




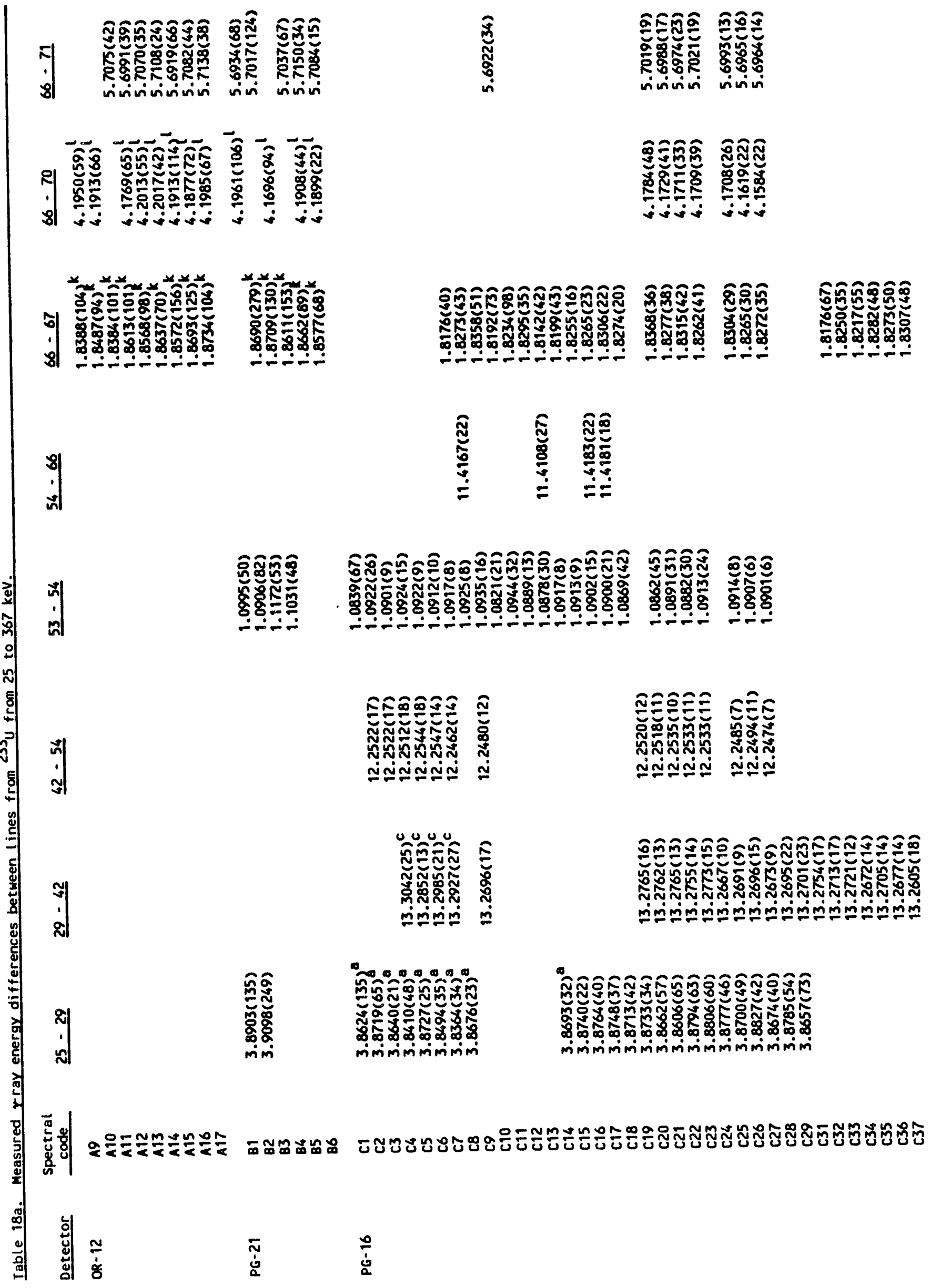


ำ

이

히

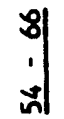

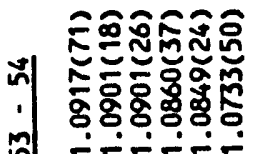

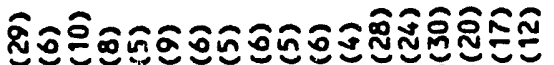

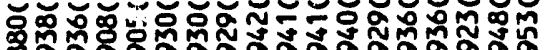

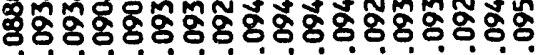
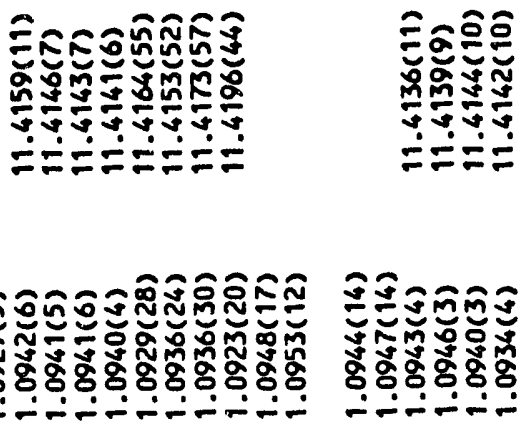

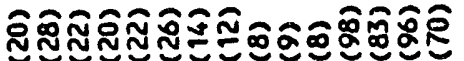

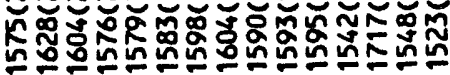
ivision
สิกิกิโอิ

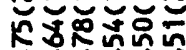

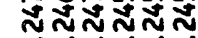
نِ
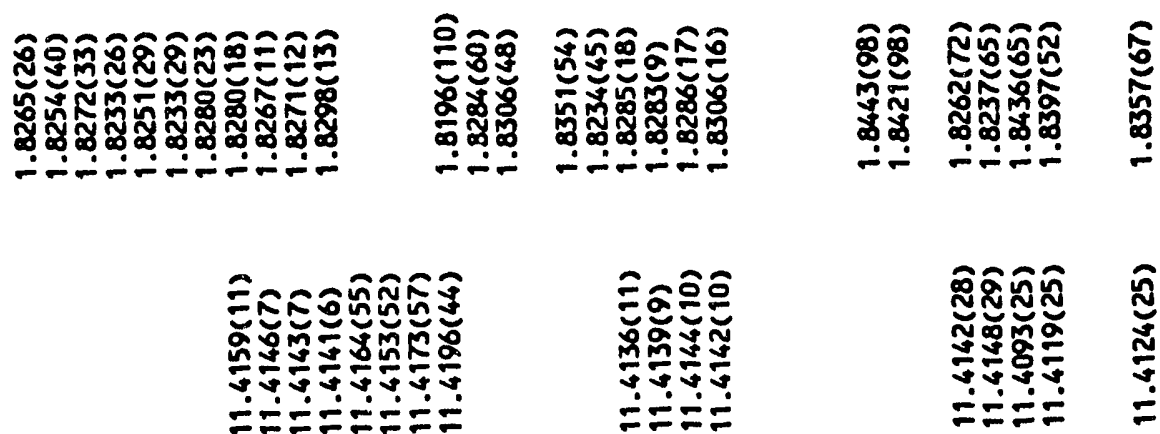

$\mathfrak{F}$

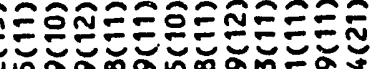

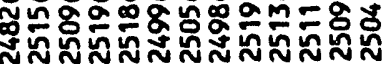

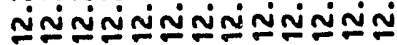

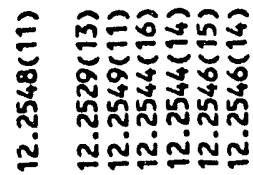

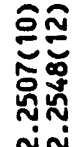

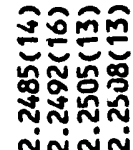

\section{(2)}

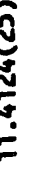

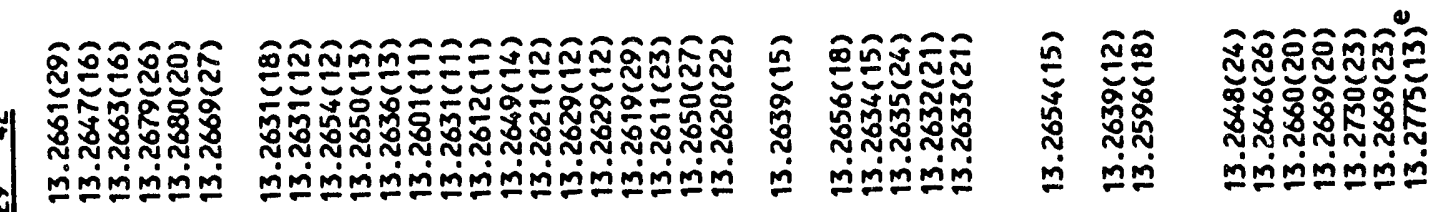

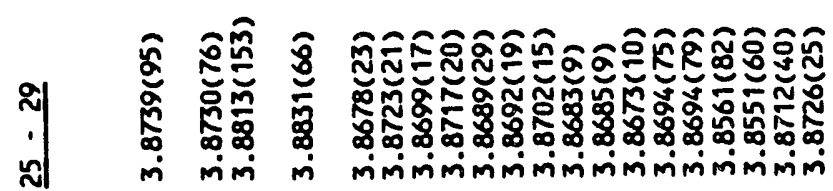

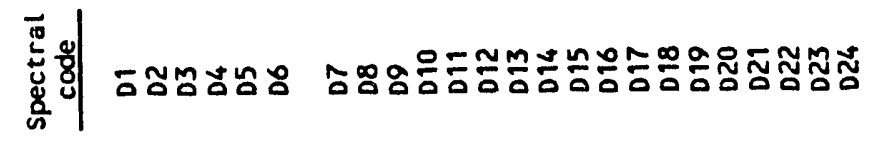

Nîñ

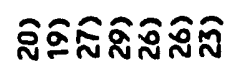
和 1. iminiminimin Th iniming

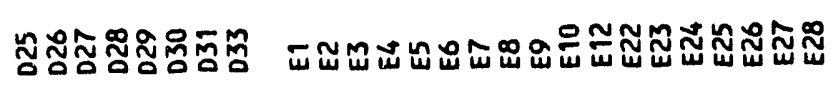

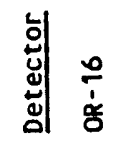

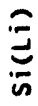




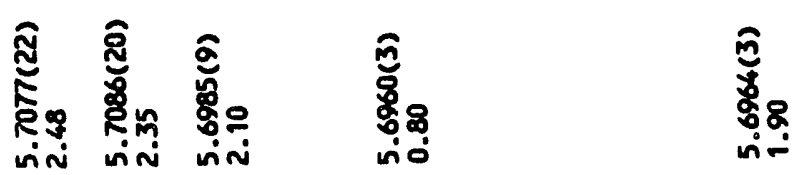

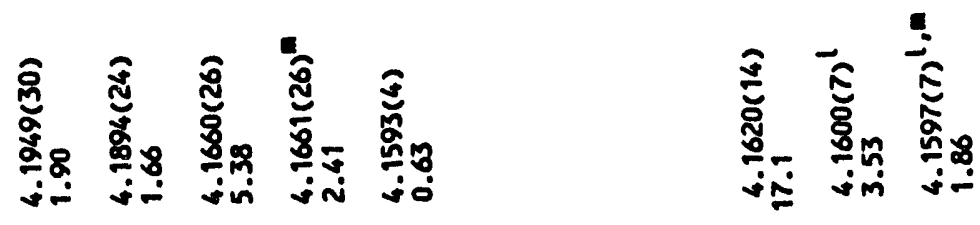

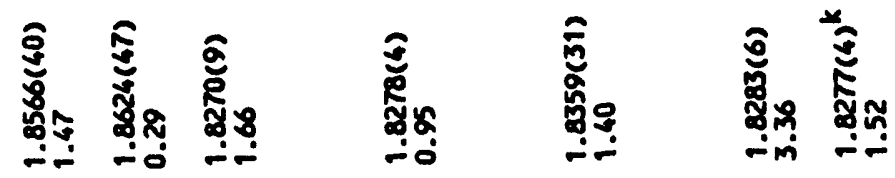

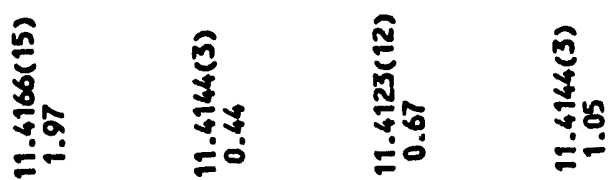

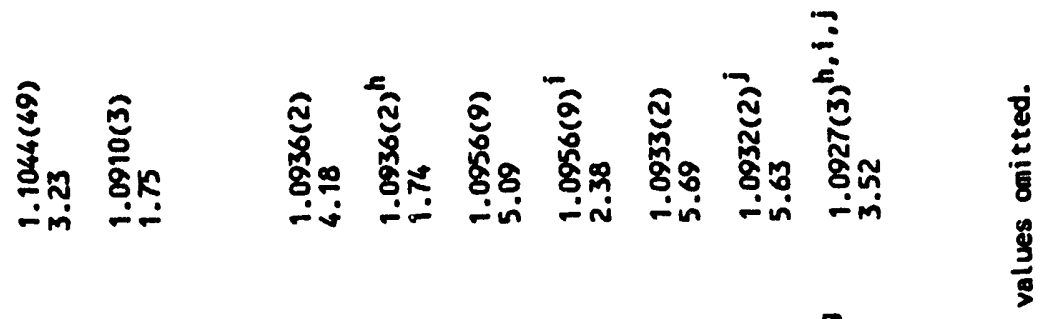

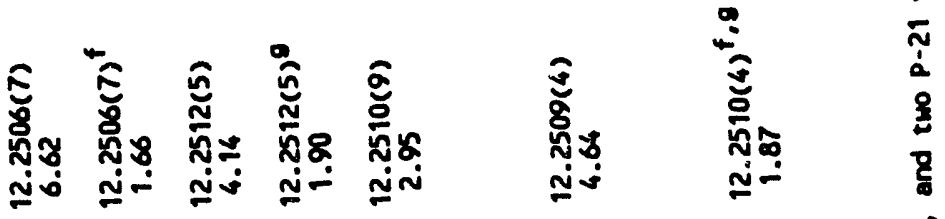

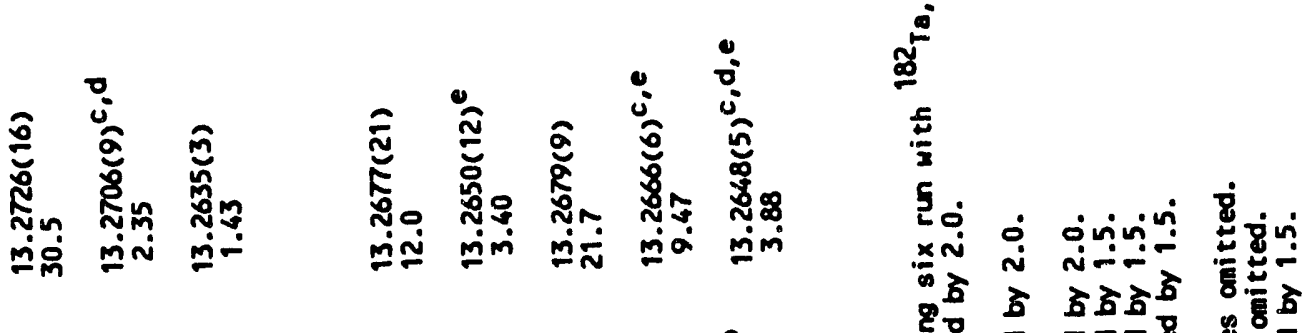

产

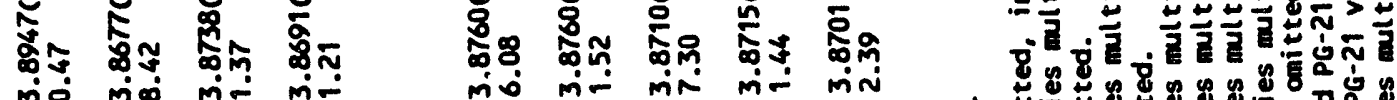

ठ্ّ

濖

究

$\frac{\dot{9}}{\mathbf{s}}$

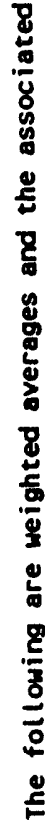

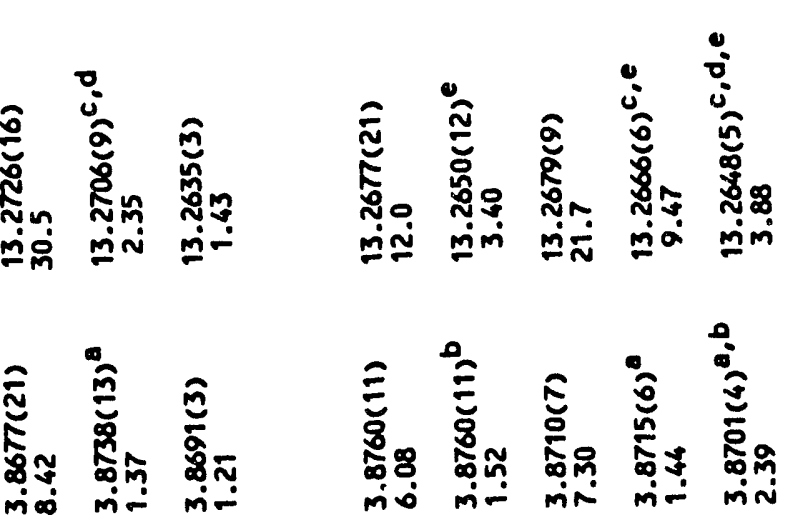

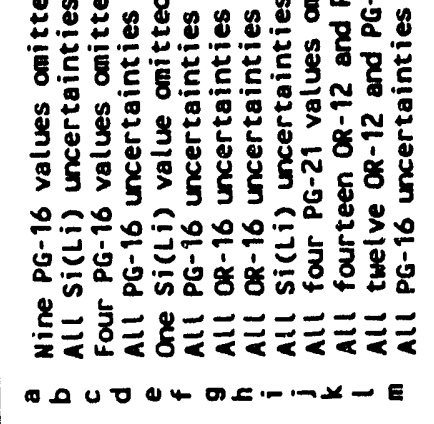




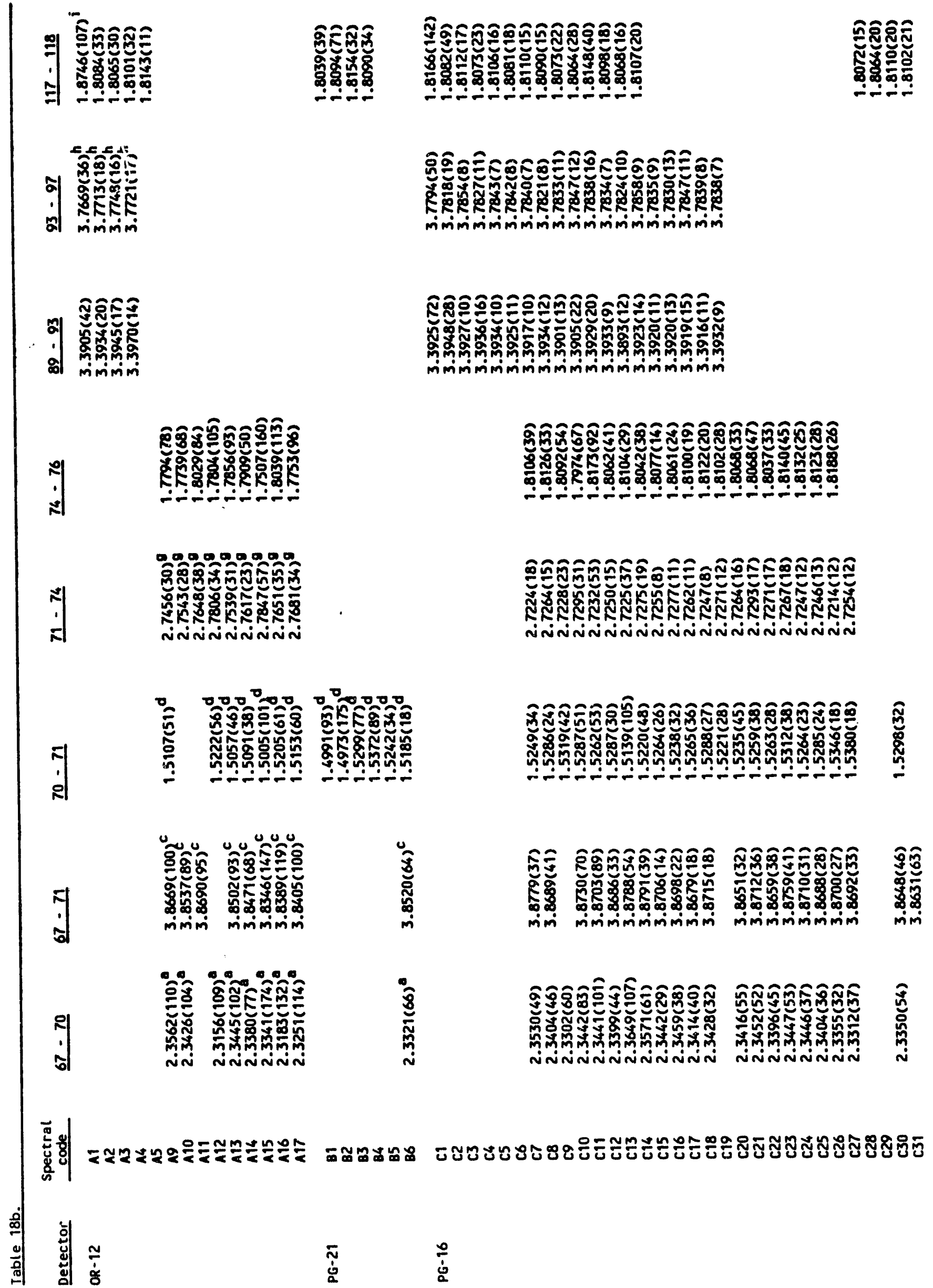


잉

잉

$*$
$N$

$N \mid$
$\vdots$

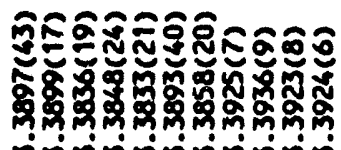

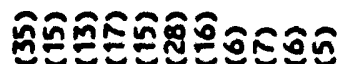

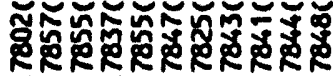

iniminiminiminiminim

miniminiminiminim

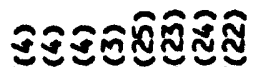

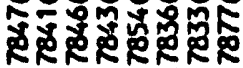

iniminimivivim
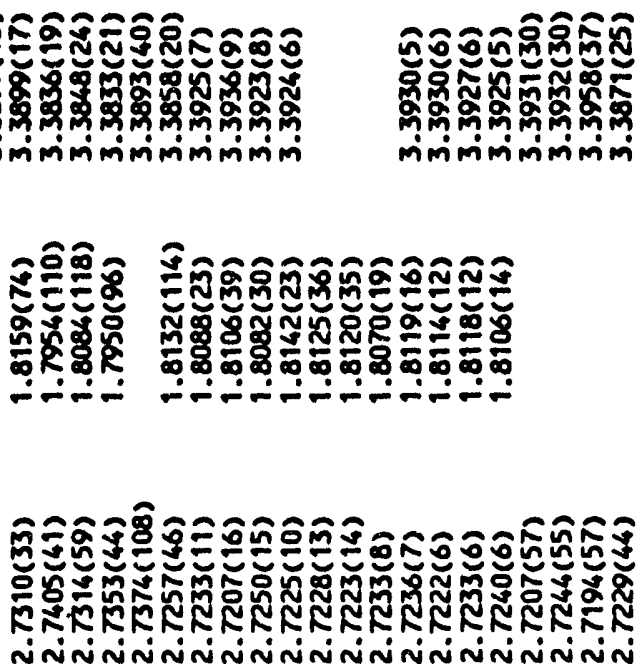

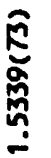
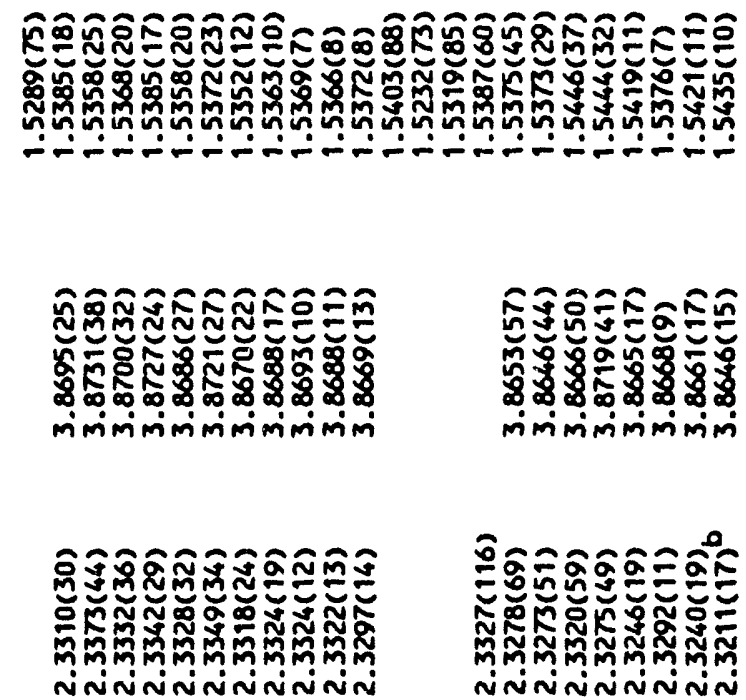

葆

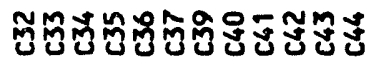

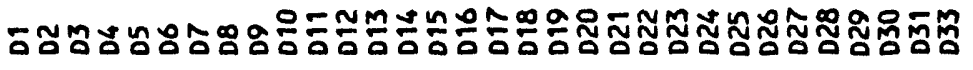

$\stackrel{\circ}{\dot{8}}$ 


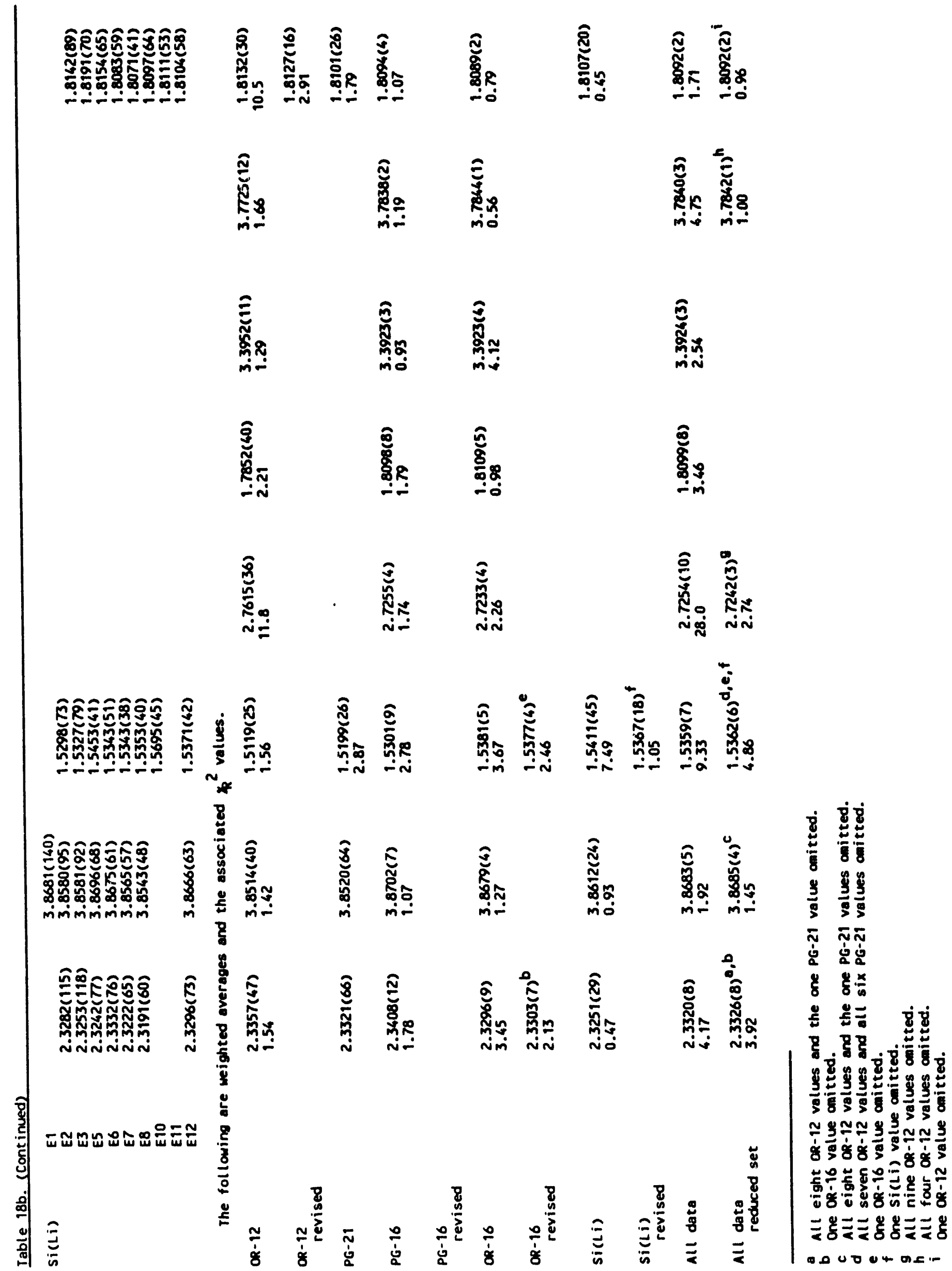


:

:ี้

ำ

羊

$\stackrel{0}{\cong}$

ำ

ิㅣำ

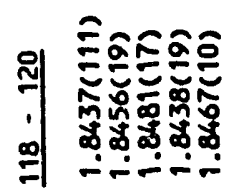

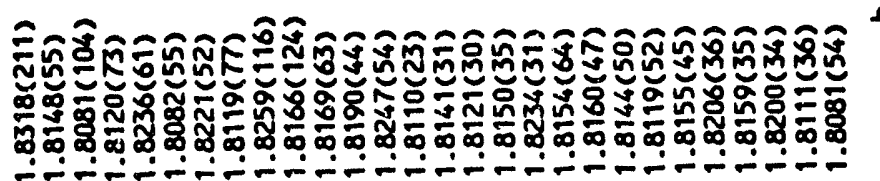

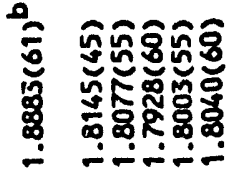

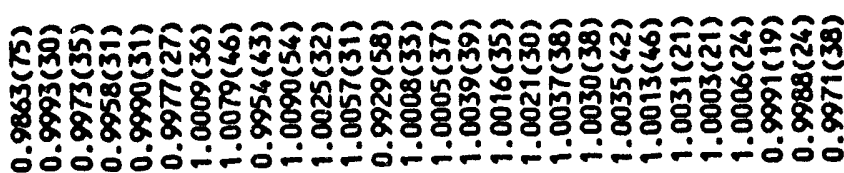

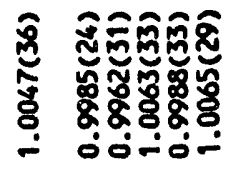

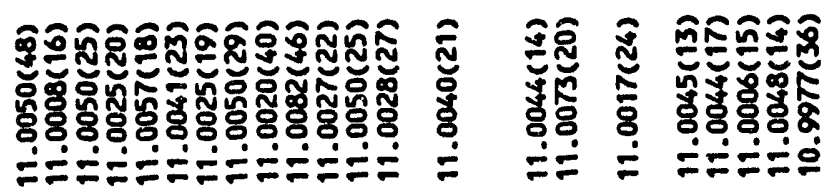

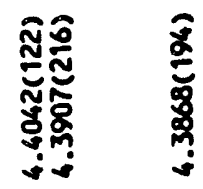

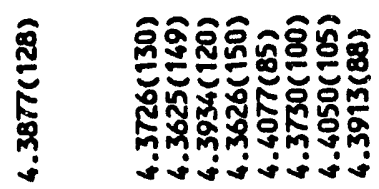

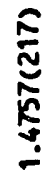

气્气

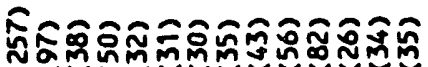

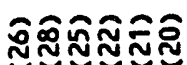

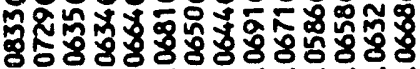

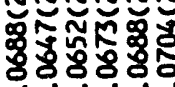

miniminiminiminiminimin

miniminimin

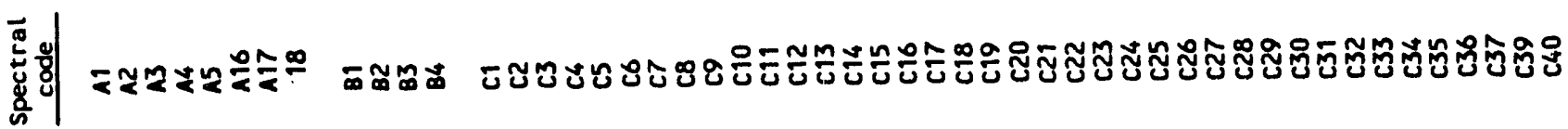

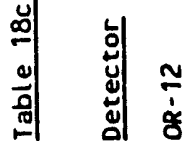

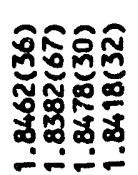

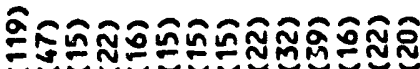

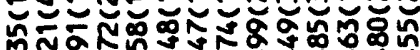

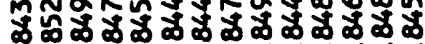

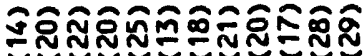

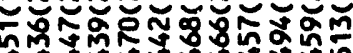

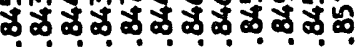

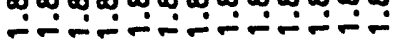
送 


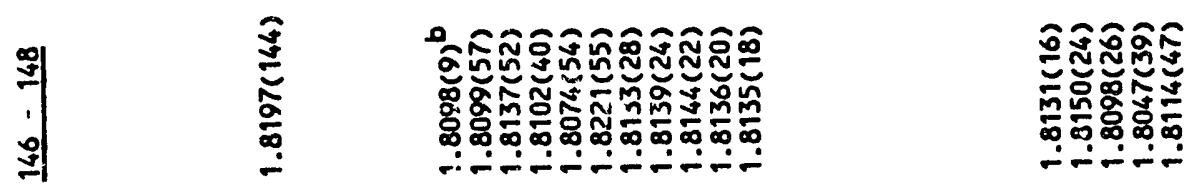

인

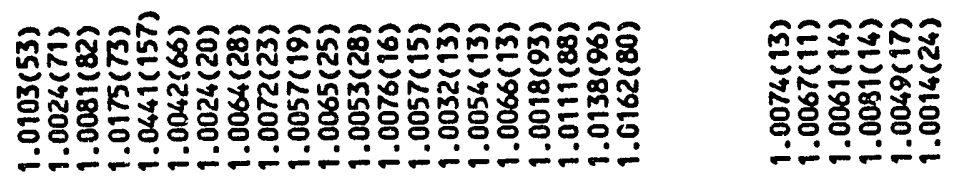

:

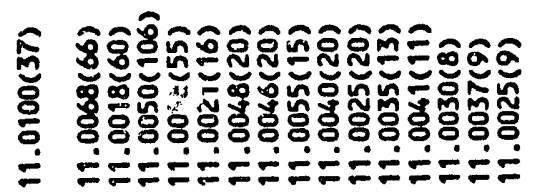

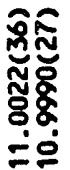

$\underset{1}{0}$

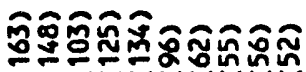

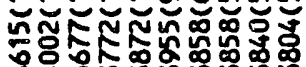

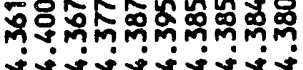

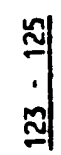

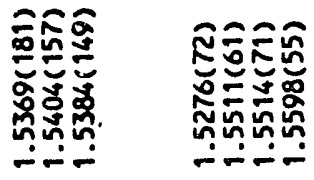

ํㅟㅁ

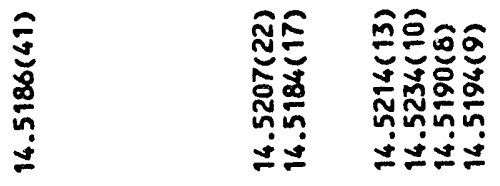

旅

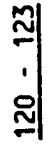

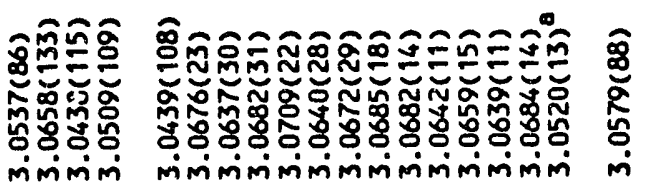

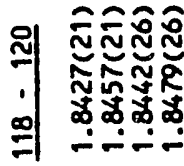

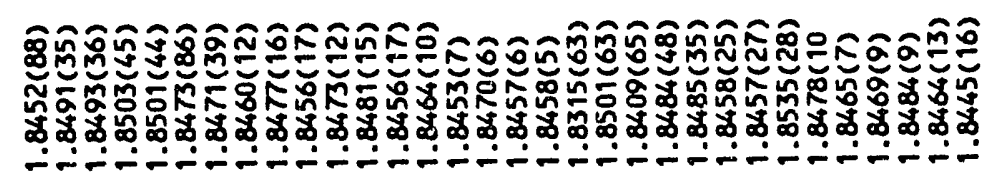

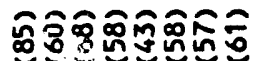
ㄴ. ळ பே-்ட்ட்

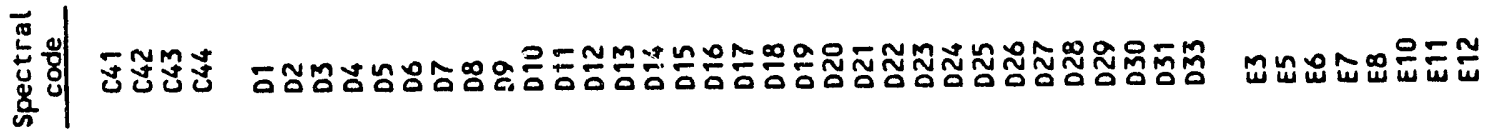

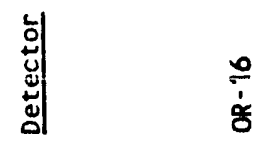

$\frac{1}{\mathrm{~s}}$ 


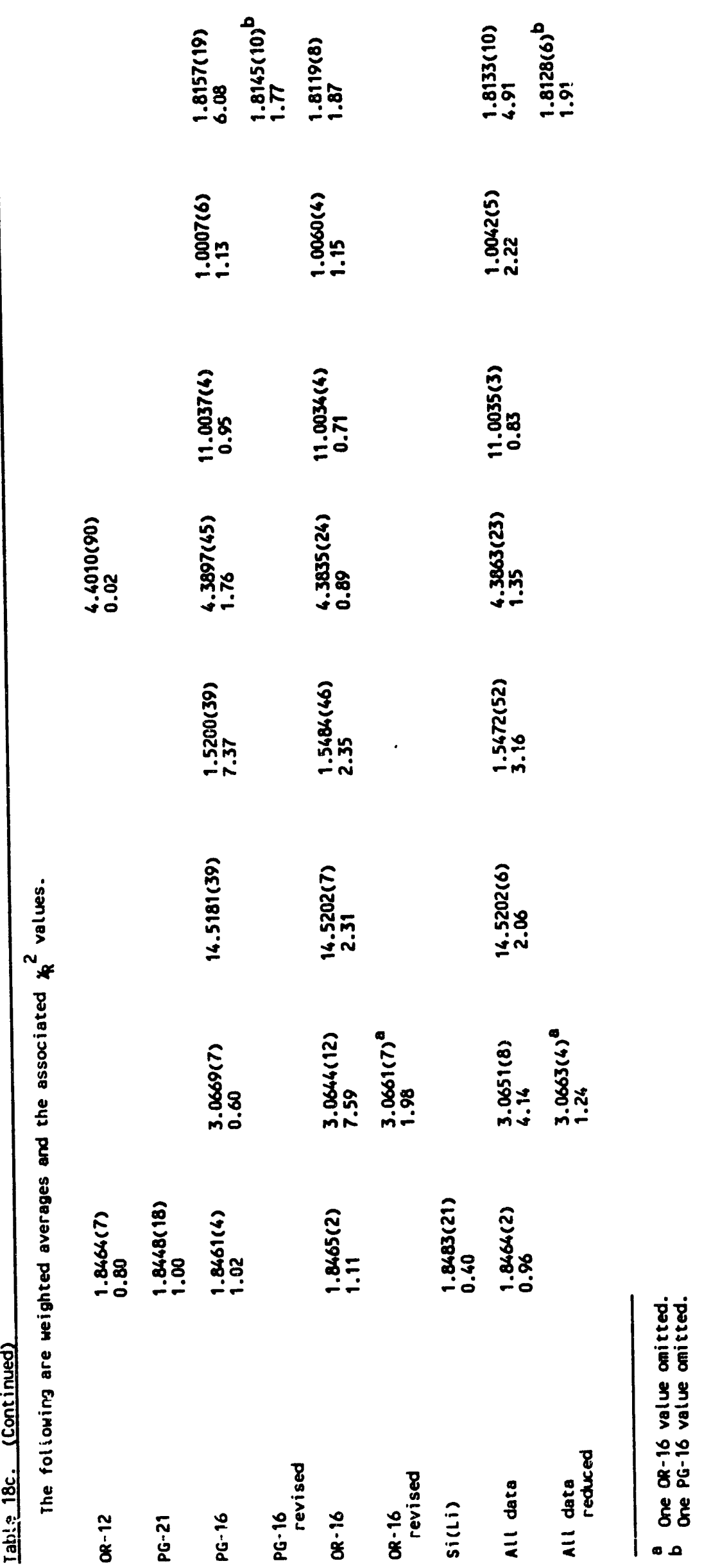




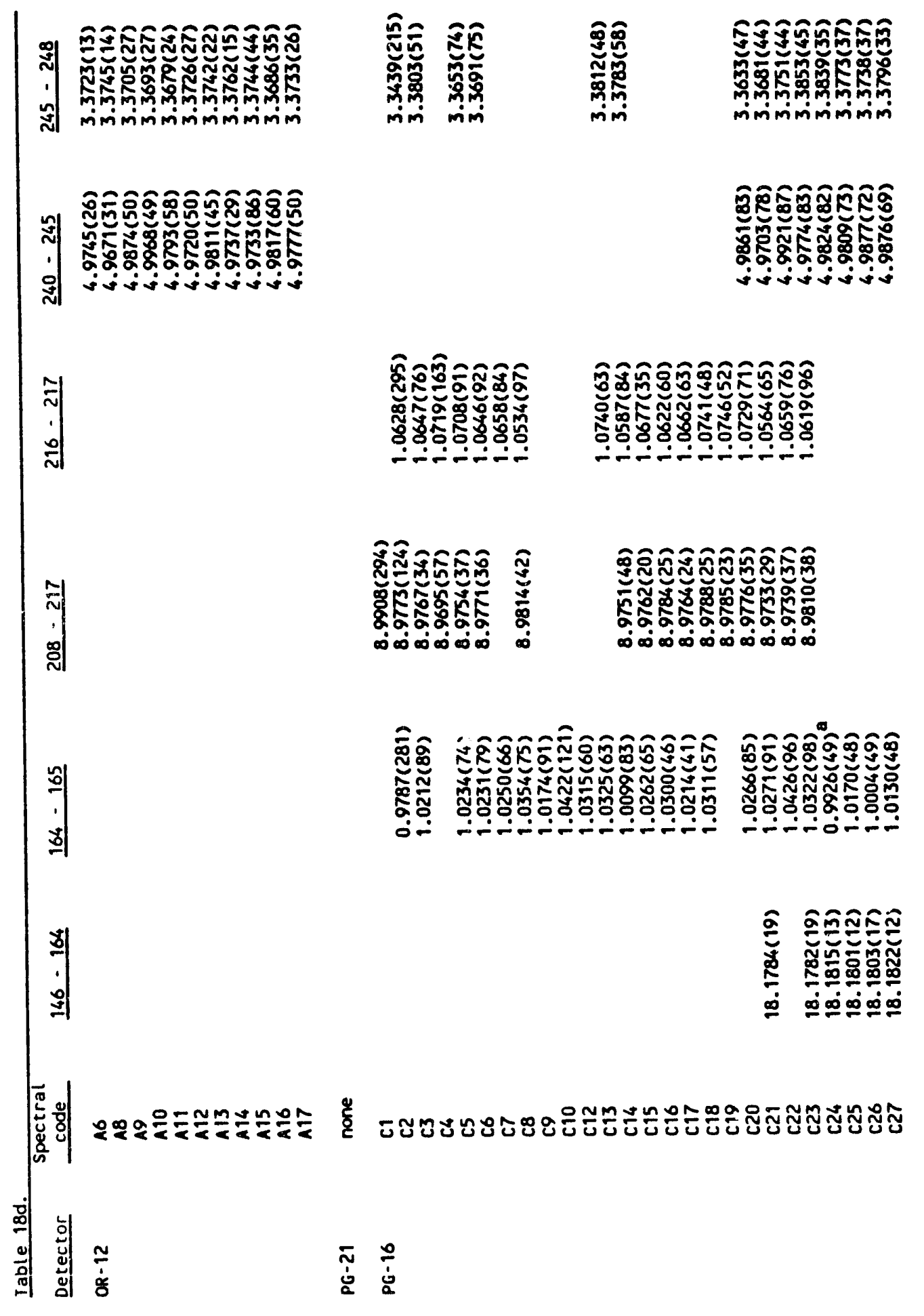



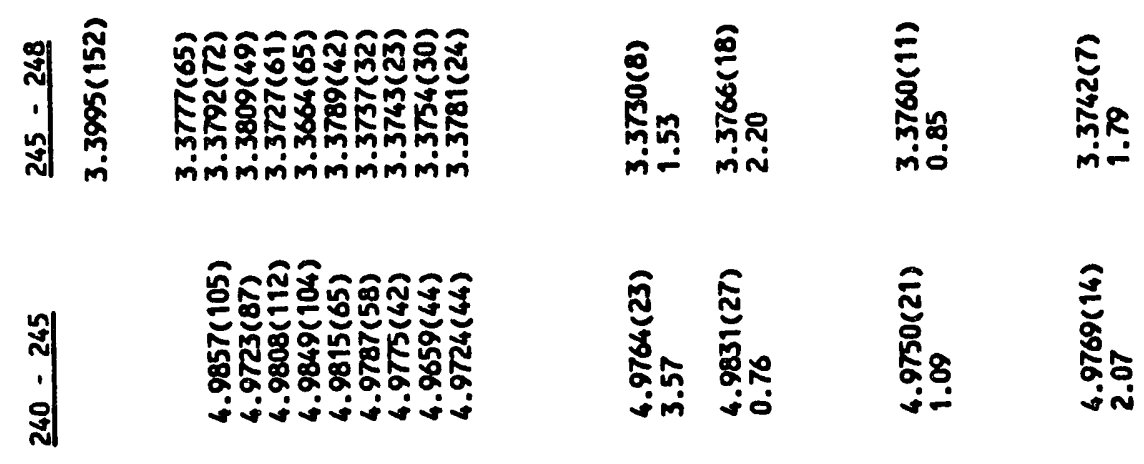

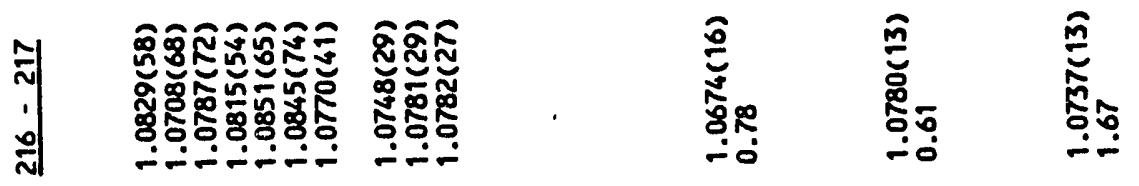

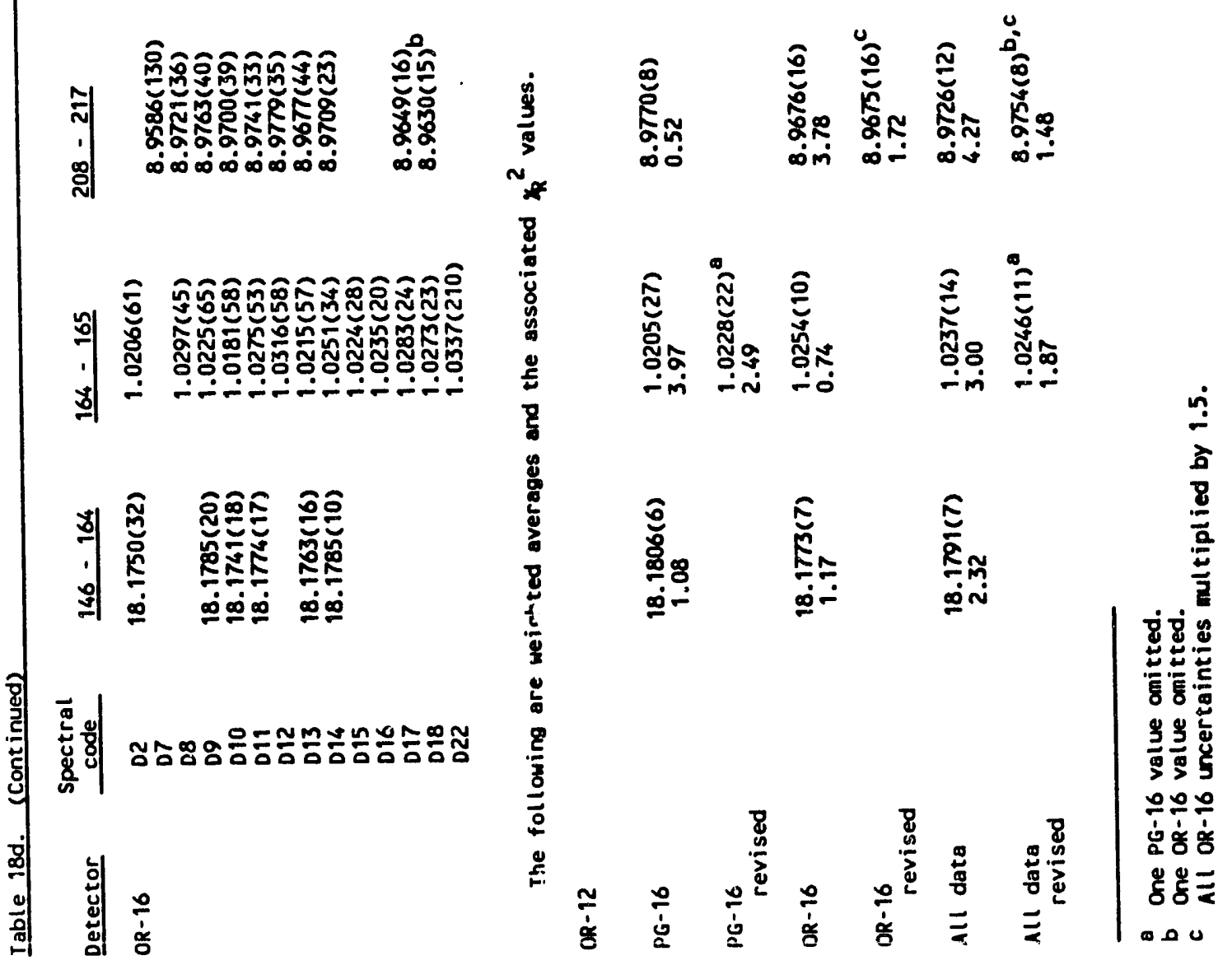




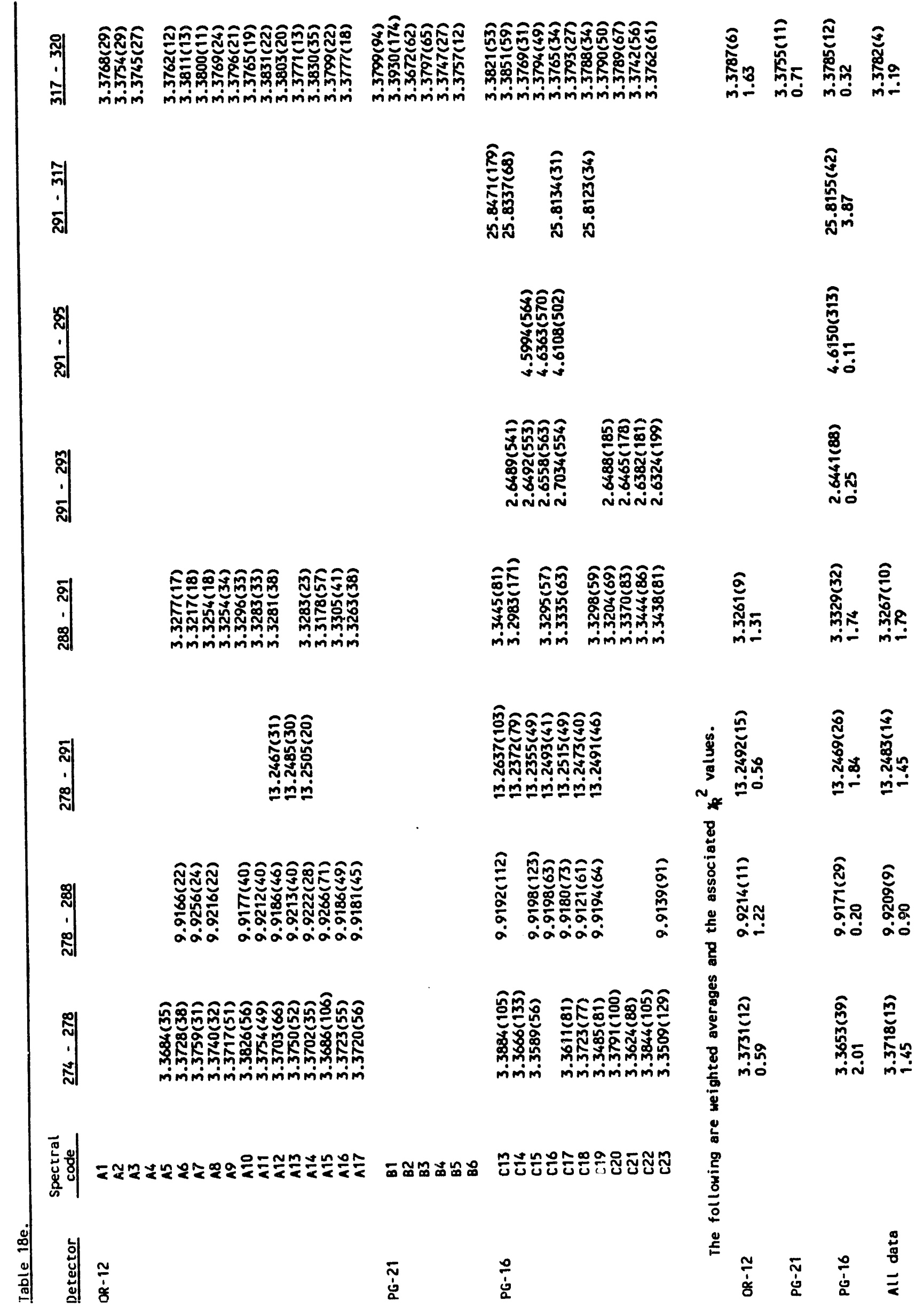




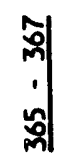
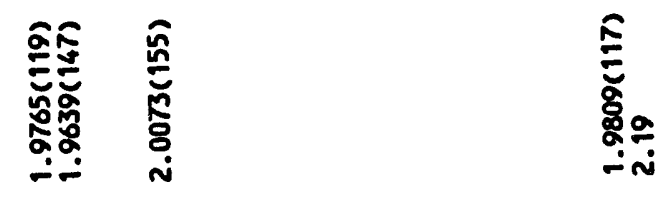

离
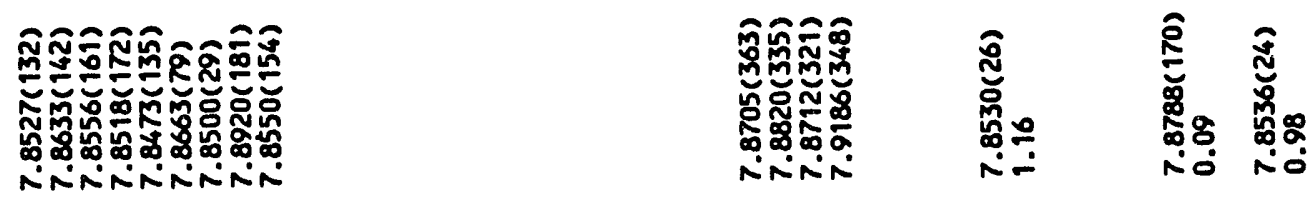

ले

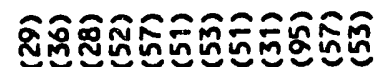

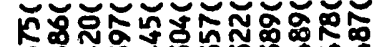

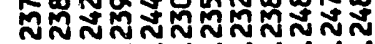

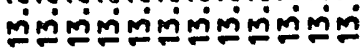

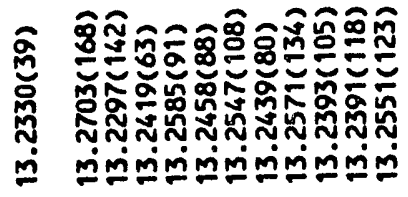

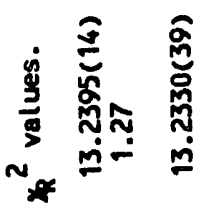

耪 产

ฆ్లి
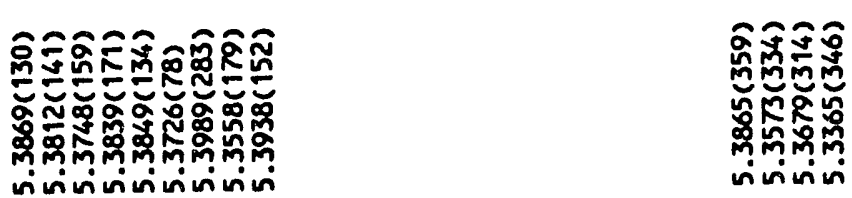

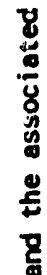

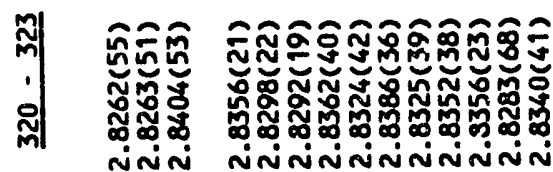

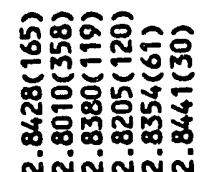

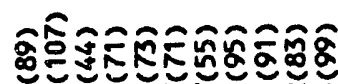
ก

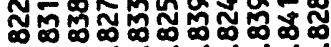
$\int_{\sim \sim \alpha \sim \sim \sim \sim \sim \sim \sim N}$

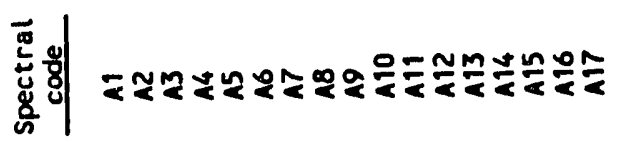

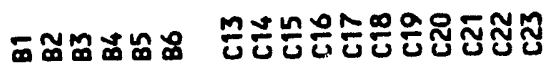

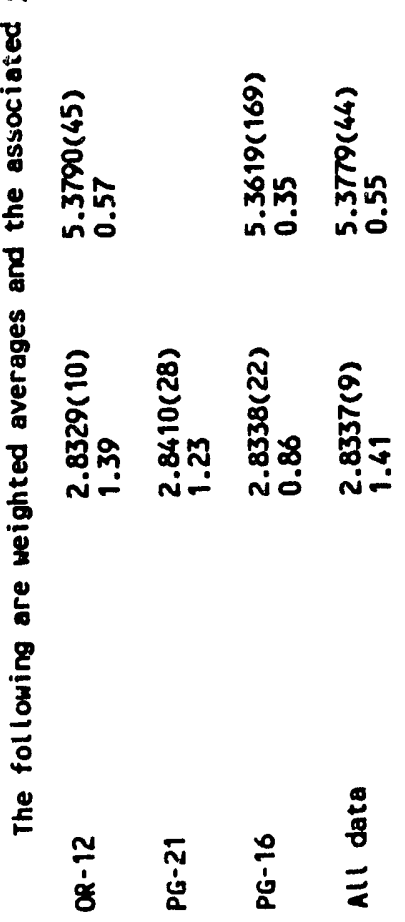



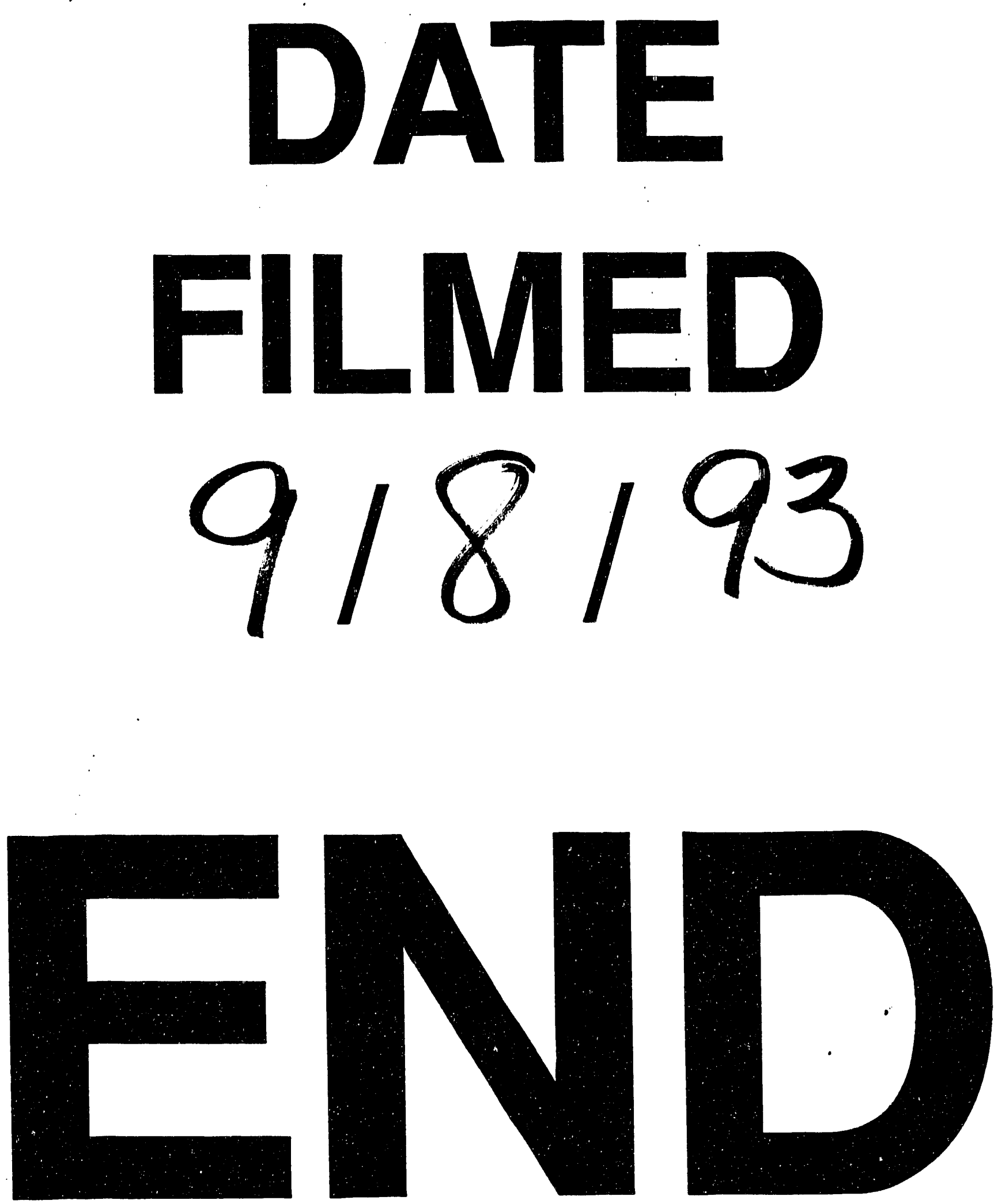
in is 